\title{
PATTERNS OF ACADEMIC SUCCESS OF SOUTHEAST ASIAN AMERICANS
}

\author{
A dissertation submitted to the faculty of \\ A5 San Francisco State University \\ 35 In partial fulfillment of \\ 2018 The Requirements for \\ EDD \\ The Degree \\ .083

\section{Doctor of Education} \\ In \\ Educational Leadership
}

\author{
by \\ Marlai Ouch \\ San Francisco, California
}

May 2018 
Copyright by Marlai Ouch 2018 


\section{CERTIFICATION OF APPROVAL}

I certify that I have read Patterns of Academic Success of Southeast Asian Americans by Marlai Ouch, and that in my opinion this work meets the criteria for approving a dissertation submitted in partial fulfillment of the requirements for the

degree: Doctor of Education in Educational Leadership at San Francisco State University.
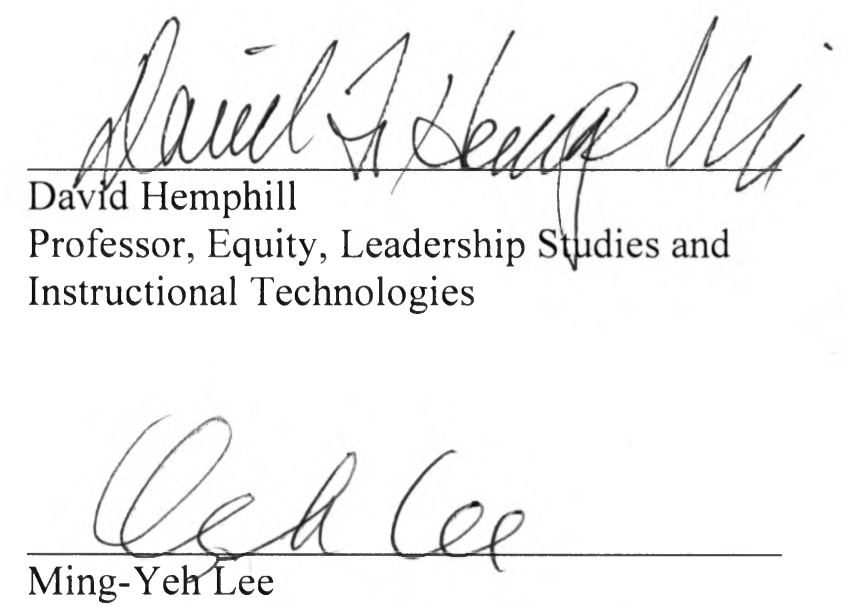

Professor, Equity, Leadership Studies and Instructional Technologies

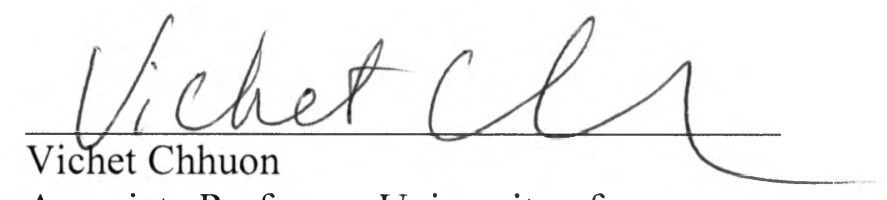
Associate Professor, University of Minnesota 


\title{
PATTERNS OF ACADEMIC SUCCESS OF SOUTEHAST ASIAN AMERICANS
}

\author{
Marlai Ouch \\ San Francisco State University \\ April 2018
}

The study examines the experiences of Southeast Asian (Cambodian, Hmong, Lao, and Mien) college graduates that have contributed to their academic success in higher education. These four specific communities were selected for the study because they exhibit the lowest college attainment rates among Asian Americans, and they are also far below the national average in college degree attainment. The four communities also share similar refugee status, struggles, and levels of economic and academic success. Five themes emerged from the study's qualitative and quantitative data: (1) schooling experiences; (2) refugee experiences; (3) cultural expectations; (4) liked-minded friends; and (5) identity in practice. In a concluding analysis, the study draws out equity issues and suggests leadership implications.

I certify that the Abstract is a correct representation of the content of this dissertation.

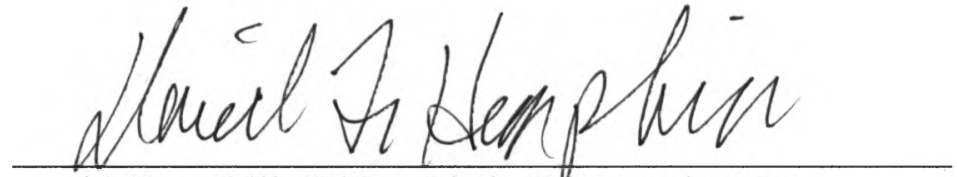

David Hemphill, Ed.D., Chair, Dissertation Committee

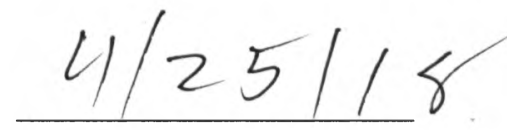

Date 


\section{PREFACE AND ACKNOWLEDGEMENTS}

My deepest gratitude to my mother, Sab Kann, who took over my household responsibilities with patience and understanding so that I could participate in this doctoral program. Thank you to my father, Savann Ouch, who encouraged me to explore my highest potential. My love for my two children, Jonathan Khuon and Amanda Khuon, for their support, patience, and understanding that their mother could not be with them all the times during the last three and a half years. I also want to thank my siblings (Lee, Sambo, La, and Davuth) and my sister-in-law, Saoly, for overseeing my two children when I was not available to do so.

My admiration and respect to my survey and interview participants for sharing their candid experiences. Your determination, strength, and motivation put me into tears. I want to thank my friends and colleagues for connecting me with the survey and interview participants. Without your help, this study would not be possible. I am also grateful to my boss for giving me a flexibility to work on this dissertation.

Finally, I am also greatly appreciative of my committee members, Dr. David Hemphill, Dr. Ming-Yeh Lee, and Dr. Vichet Chhuon, who agreed to guide me with this ambitious but needed study. 


\section{TABLE OF CONTENTS}

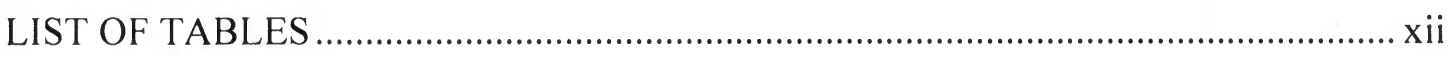

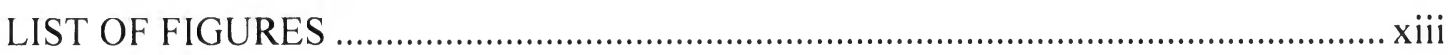

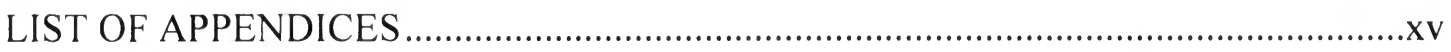

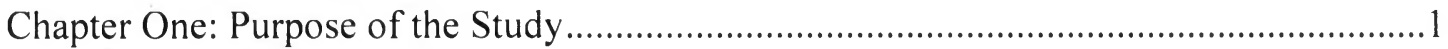

Introduction and Problem Statement .............................................................

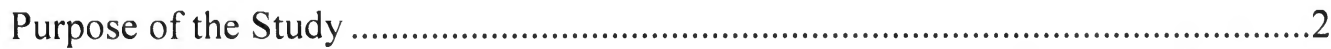

Research Questions or Initial Objectives ....................................................4

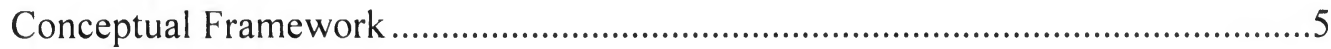

Operational Definitions of Key Terms .............................................................11

Statement of Delimitations and Scope of Study ............................................ 11

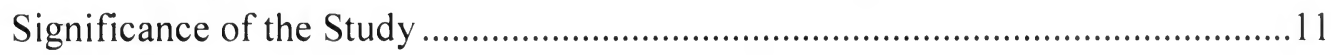

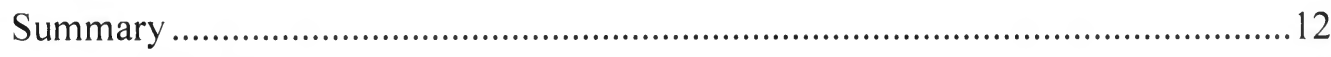

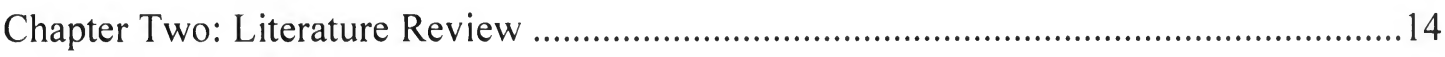

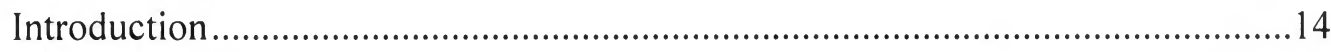

Part I: Methodology of the Literature Review Research ...................................14

Part II-Review of the Literature ................................................................. 15

Students of Color ............................................................................ 15

Immigrant Students and Immigrant Students of Color ........................... 16

Asian Immigrant Students............................................................ 17

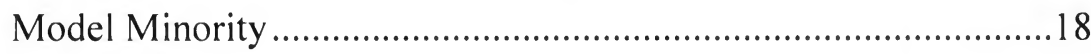

Southeast Asian Students .............................................................19

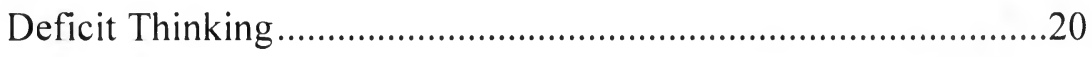

Academic Experiences of Southeast Asian American Students ....22

High School Experiences .................................................23

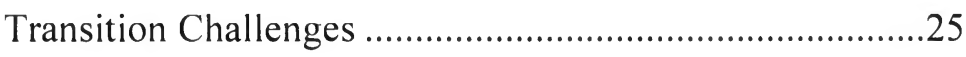


College Experiences..................................................26

Social Experiences of Southeast Asian Students ..........................28

Refugee Experiences..................................................28

Cultural Expectations .....................................................30

Like-Minded Friends ...............................................44

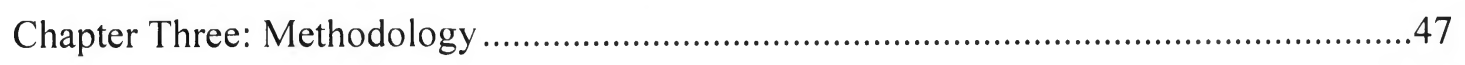

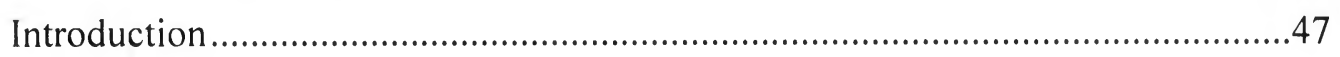

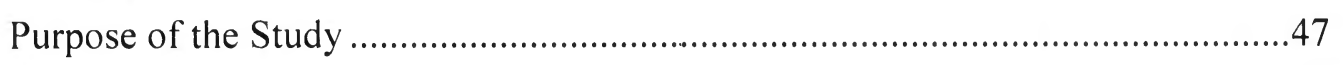

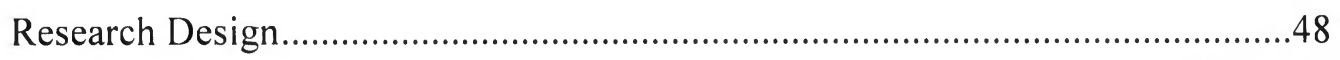

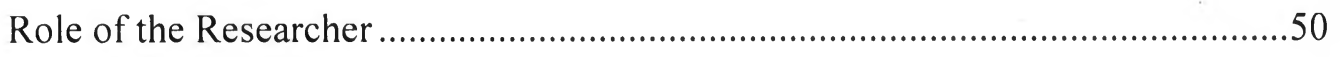

Research Questions and Sub-Questions.........................................................53

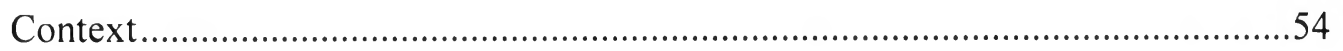

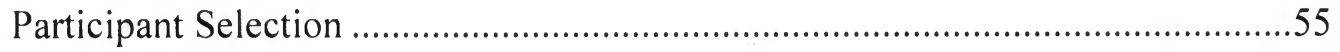

Ethics and Protection of Human Subjects .......................................................56

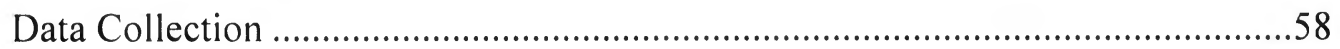

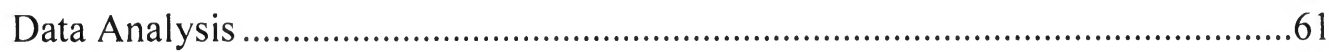

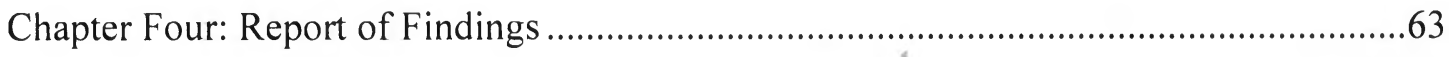

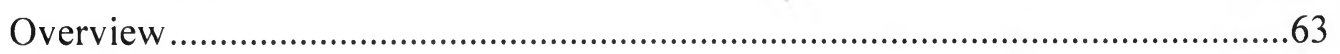

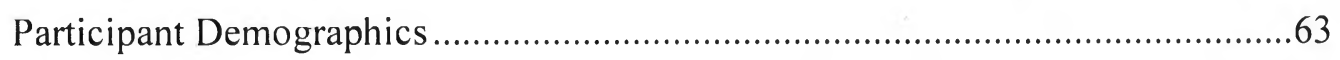

Survey Demographics and Participants' Characteristics .........................63

Interview Demographics and Participant Characteristics .........................68

Participant Narrative Portraits..........................................................................70

Chenda: A Chameleon ......................................................................... 70

Paj: An Assertive Mind...................................................................... 72

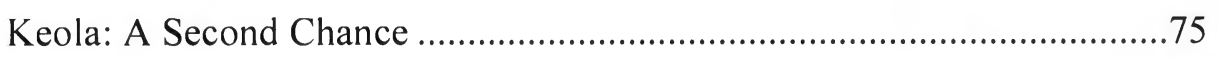

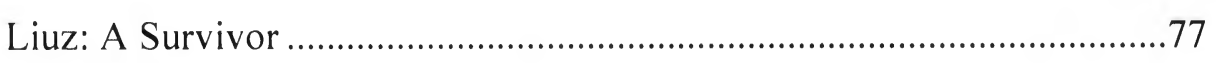

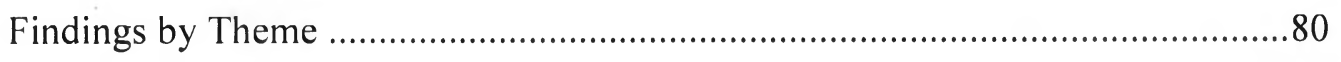

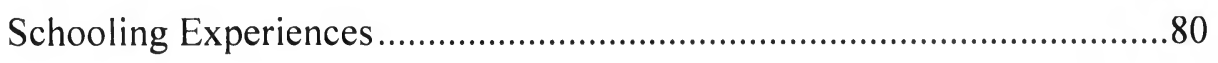


High School Experiences ......................................................... 80

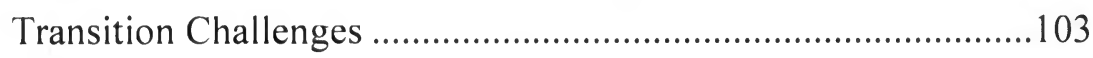

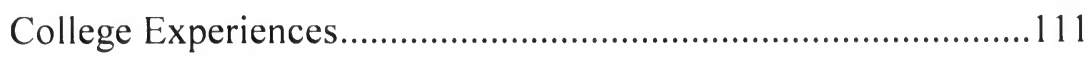

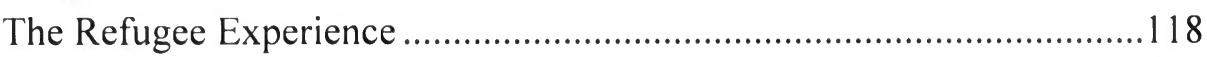

Refugee Resettlement and Migration.........................................118

Parents' Struggles ................................................................... 123

Parents' Progress ....................................................................... 129

Keys to Refugee Children's Academic Successes......................132

Cultural Expectations......................................................................139

Family Values ...................................................................... 140

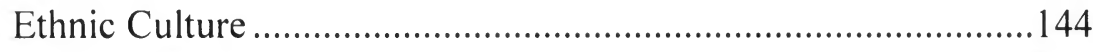

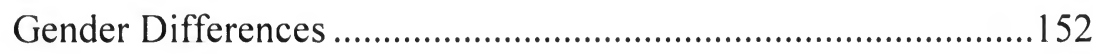

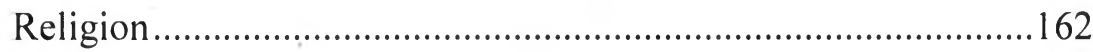

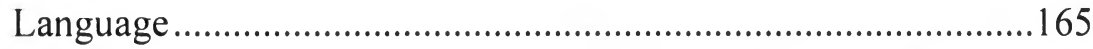

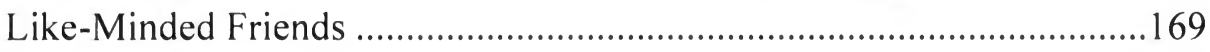

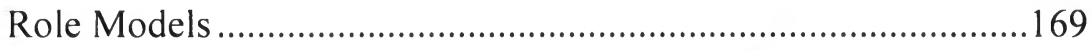

High Achievers …................................................................ 170

Friends in College prep Programs.............................................170

Friends in Outreach Programs ................................................171

Ethnic Community Friends ....................................................171

Friends in All Aspects of Life....................................................172

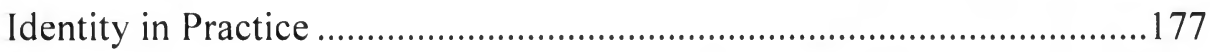

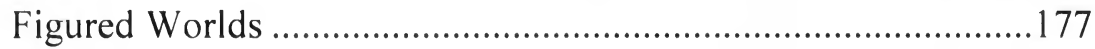

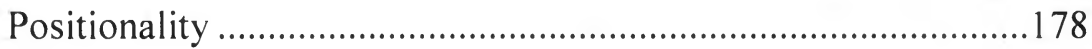

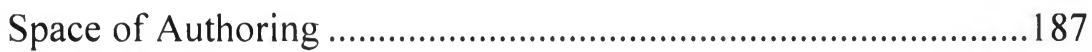

World Making .................................................................... 195

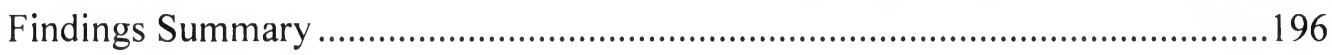

Chapter Five: Conclusions and Recommendations ...................................................199 


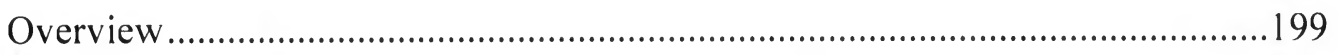

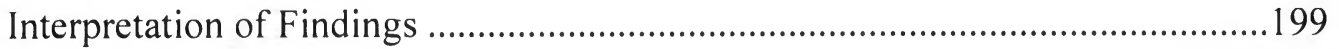

Schooling Experiences ......................................................................199

High School Experiences ........................................................200

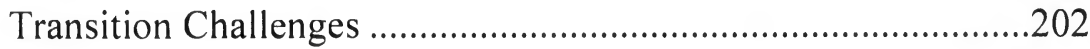

College Experiences.............................................................203

Social Experiences ....................................................................203

Refugee Experiences...........................................................204

Cultural Expectations...............................................................204

Like-Minded Friends ..............................................................205

Identity in Practice .........................................................................205

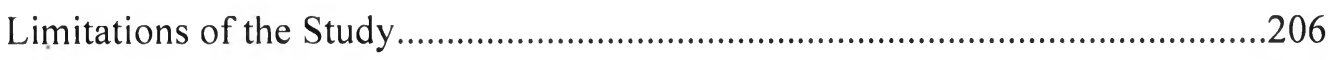

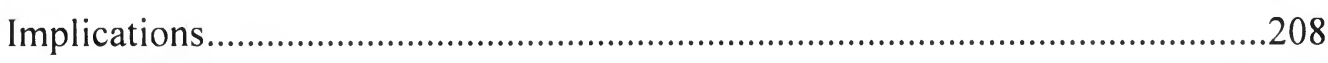

Educational Leadership................................................................208

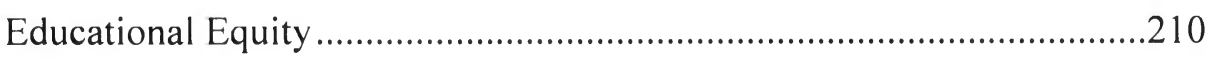

Improvements in Southeast Asian Communities ..................................211

Community-Based Ethnic Studies Programs ........................................215

Recognition of Culturally Relevant Programs ......................................216

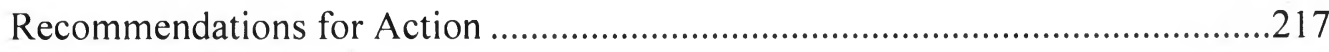

Provide College Prep Courses for All Students .....................................217

Bridge the Curriculum Gap between High Schools and Colleges ...........218

Provide Sufficient Financial Assistance ..............................................219

Support Student Organizations on Campus ….........................................219

Provide Mentorship ......................................................................220

Support Educational Opportunity Programs ..........................................221

Support Southeast Asian Community Centers.........................................221

Grant P-12 and College Credit for Community-Based Ethnic Studies

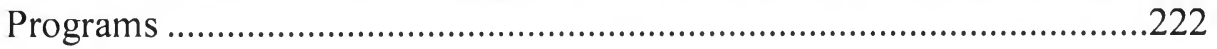

Recommendations for Further Study ......................................................223 
Reflections on the Research Process .............................................................224

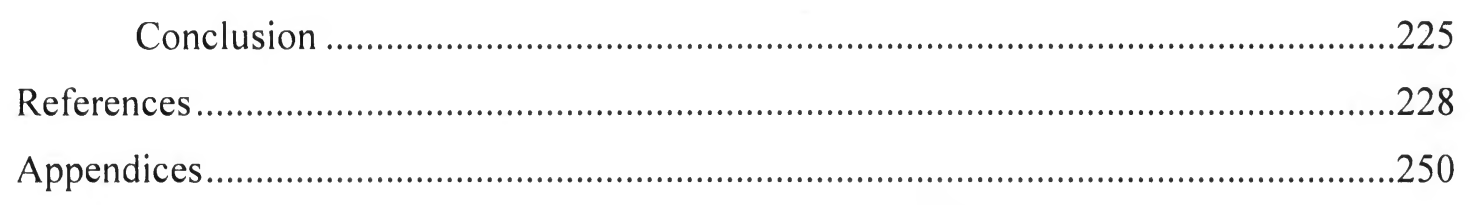




\section{LIST OF TABLES}

Table

1. Interview Participants and their Characteristics ....................................................69

2. Interview Participants' Family Refugee Resettlement and Migration..................... 121

3. Parents' Struggles for 19 Interview Participants Part 1 .......................................... 127

4. Parents' Struggles from 19 Interview Participants Part 2 ..................................... 128

5. Parents' Progress of 19 Interview Participants ........................................................ 132 


\section{LIST OF FIGURES}

Figure Page

1. Conceptual framework on identity and agency in cultural worlds ......................... 10

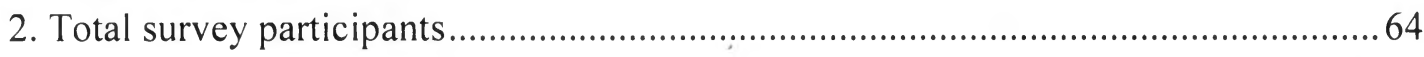

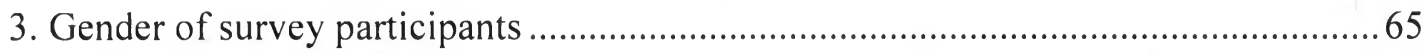

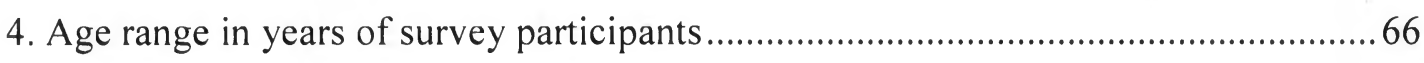

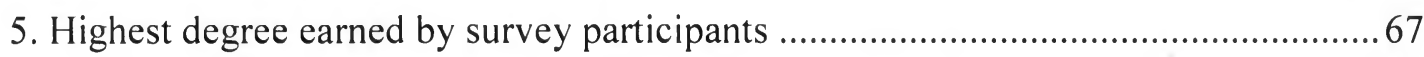

6. Parents' highest educational level of survey participants ......................................6 68

7. College prep courses by gender for survey participants ........................................ 84

8. Outreach programs by gender for survey participants ...................................... 87

9. Outreach programs and college prep courses for survey participants ..................... 88

10. Outreach programs and college prep courses by gender for survey participants .....89

11. Extracurricular activities for survey participants ............................................. 92

12. Extracurricular activities by gender for survey participants ............................... 93

13. Common assumptions from teachers (counselors) and students for survey

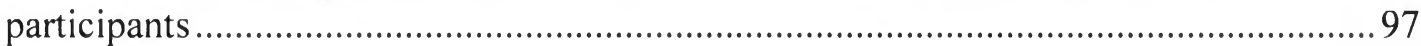

14. Common assumptions from teachers (counselors) and students by gender .............98

15. School resources and student needs for survey participants ............................... 100

16. School resources and student needs by gender for survey participants ................. 101

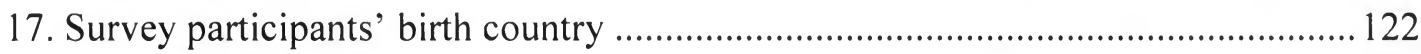

18. Family's U.S. entry of survey participants .................................................. 123

19. Family struggles of Survey Participants ............................................................. 129

20. Parents' educational expectations and obstacles for survey participants................ 141

21. Parents' influence on self-expectations for survey participants ............................. 144

22. Other cultural influences for Survey Participants ............................................... 145

23. Reward(s) expected to receive after achieving academic goals for survey participants

24. Parents' educational expectations and obstacles by gender for survey participants 
25. The highest frequency of interactions of survey participants ............................ 174

26. School activities for survey participants ....................................................... 175

27. School constraints from Survey Participants ....................................................... 176

28. Supports for Academic Success for Survey Participants .................................... 177 


\section{LIST OF APPENDICES}

Appendix Page

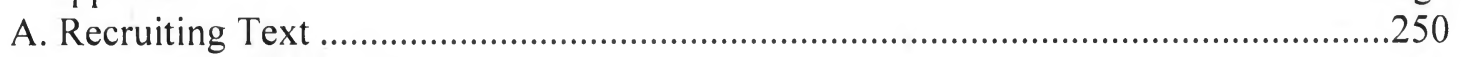

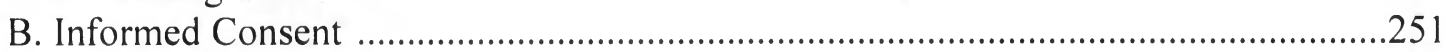

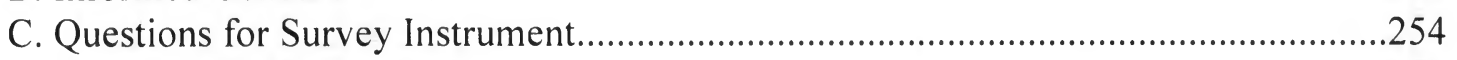

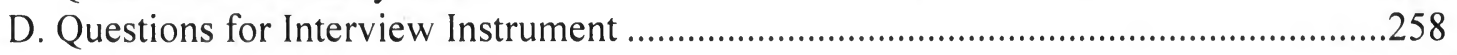




\section{Chapter One: Purpose of the Study \\ Introduction and Problem Statement}

The educational problem that this study addresses is the relatively low level of academic success in higher education of Southeast Asian Americans (whose ancestors are Cambodian, Hmong, and Laotian [Lao and Mien]). While the baccalaureate completion rate of Asian Americans as a group overall exceeds the national average (28\%), the educational attainment for Cambodian (14\%), Hmong (14\%), and Laotian Americans $(12 \%)$ is only half the national average (Asian Pacific American Legal Center [APALC] \& Asian American Justice Center [AAJC], 2011).

Educational attainment is generally believed to be a key pathway to prosperity. Higher education is said to increase opportunities in life and lead to higher incomes, which in turn generates increased tax revenues, greater productivity, and decreased reliance on government financial support (The Institute for Higher Education Policy [IHEP], 2013). Higher paying jobs, beyond salary, offer added benefits, including healthcare and retirement investments, which are associated with improved health and life expectancy as well as improved quality of life for families (IHEP, 1998). College completion is necessary for many high-skilled jobs in today's economy (Kirsch, Braun, Amamoto, \& Sum, 2007). At least $70 \%$ of the jobs in the United States now require specialized knowledge and skills, compared to only $5 \%$ at the beginning of the 20th century (Darling-Hammond, 2010). 


\section{Purpose of the Study}

The study examines the experiences of Southeast Asian (Cambodian, Hmong, Lao, and Mien) college graduates that have contributed to their academic success in higher education. The four specific communities were selected for this study because they exhibit the lowest college attainment rates among Asian Americans and are far below the national average (APALC \& AAJC, 2011). The four communities also share similar refugee status, struggles, and levels of success. It is anticipated that this study will identify patterns of success to generate recommendations for best practices in programming for this population. The study investigates educational issues confronted by Southeast Asian students by reviewing existing literature on challenges and academic successes, employing mixed methods to gather data, drawing out equity issues, and suggesting leadership implications.

Beyond educational attainment, Southeast Asian communities confront substantive socioeconomic issues. The per capita income for Cambodians $(\$ 15,940)$, Hmong $(\$ 10,949)$, and Laotians $(\$ 16,585)$ is far below that of Asian Americans as a group $(\$ 28,343$ ), and substantially below the national average of $\$ 27,100$ (APALC \& AAJC, 2011). Due to the demand for college completion in today's economy and the need to elevate the socioeconomic status of Southeast Asian Americans, investigating

patterns and predictors of academic success in higher education for this population should 
enable policy makers and educators with findings and recommendations to make more informed policy choices.

To explore the educational achievement of Southeast Asians in the United States, it is important to understand the historical context of their movement to this country. While the majority of immigrants come to the United States voluntarily to improve their lives, most Southeast Asian Americans came to the U.S. involuntarily as refugees to escape from political persecution after the Vietnam War ended (Akiba, 2010; Ngo \& Lee, 2007; Tang \& Kao, 2012). Many came with little or no formal education, limited English proficiency, and little understanding of the U.S. educational system. A large number also suffered from trauma-related ailments (Ngo \& Lee, 2007; Um, 2003; Yang, 2004).

Consequently, many refugee parents proved unable to relate to their children's problems or advocate for them with schools or other institutions, and often left their children to struggle on their own (Um, 2003; Yang, 2004).

Problems in P-12 schooling carry over to sparse college enrollment figures. For instance, as many as $67 \%$ of Southeast Asian adults over the age of 25 have not attended college of any sort due to multiple factors (Southeast Asian Resources Action Center, 2013). First, living in poverty discourages Southeast Asian students from going to college due to high costs. A disproportionately high percentage of Southeast Asian families (26\%) live below the poverty level, compared to the national average of $14 \%$ (APALC \& AAJC, 2011). Second, Southeast Asian students have problems acquiring the English 
language; at least $40 \%$ of them are English Language Learners (ELL), compared to only $9 \%$ for the entire population (APALC \& AAJC, 2011). ELL students often are made to repeat grades, placed in ELL classrooms separate from mainstream instruction, and isolated from the rich college prep core curriculum. This often prevents them from gaining the knowledge and skills needed for college attendance (Yang, 2004). Finally, cultural conflicts between parents, students, and teachers can create a communication gap and perceptions of Southeast Asian students as underachievers (Chhuon, 2013; Yang, 2004). Despite poverty and less access to opportunities and social capital from schools (Bankston \& Hidalgo, 2006), some Southeast Asian students still do manage to achieve academic success. It is their experience that is the focus of this study.

\section{Research Questions or Initial Objectives}

This study employed mixed methods. An explanatory sequential mixed methods design was used. It involved collecting quantitative data followed by qualitative datawith both data sets viewed as being in dialogue. In the initial quantitative phase of the study, survey data were collected from Cambodian, Hmong, Lao, and Mien adults who are refugees or come from a nuclear family of refugees and have completed high school and graduated from a four-year college. In the qualitative phase that follows, semistructured interviews were used to investigate the motivations, perceptions, and social and cultural interactions of the participants and their impacts on academic achievement. 
The researcher was interested in exploring the formation of the Southeast Asian college graduates' identities and how their identities shaped motivations, perceptions, and sociocultural interactions. The participants were recruited from Southeast Asian community organizations, Southeast Asian temples, and social networks of friends and colleagues. The data were analyzed using the results from the quantitative data to inform follow-up qualitative data analysis, thus generating patterns of activity and experience that are linked to academic success.

This study was guided by the following research questions: (a) What factors contribute to the academic success of Southeast Asian students in higher education? (b) How do Southeast Asian students interpret these factors and what significance do they have in their lives?

\section{Conceptual Framework}

The literature reviewed suggested that Southeast Asian American students often face barriers of poverty, limited social capital, and conflicts between home and school culture; yet, some individuals have surmounted these barriers to successfully navigate the transition to higher education and graduate. It is their experiences that are the focus of this study. To support this investigation, the work of Holland, Lachicotte, Skinner, and Cain (1998) on identity and agency in cultural worlds is employed as a theoretical framework to explore how academically successful Southeast Asian students navigate across the different worlds of family, community, school, and peers. The major categories 
of identity and agency described include: (a) identity in practice, (b) figured worlds, (c) positionality, (d) space of authoring, and (e) world making.

Identity in practice. Holland et al. (1998) explored the formation of identity as a process rather than a product, and how individuals exercise their own agency over the social and cultural construction of their identities. Identity is defined as how individuals understand and view themselves, and are viewed by others. It is a process that is changing over personal lifetimes and in the histories of the social practice. Southeast Asian identity continues to form and be reshaped after high school into adulthood. These self-understandings are connections to the "figured worlds" of social life.

Figured worlds. Figured worlds represent one of four contexts that are thought to produce personal and social identities. They are places where individuals encounter stories derived from historical accounts, which either oppress or liberate them via power distribution, rank, and prestige. Individuals learn to accept, reject, or negotiate these relationships. The other three contexts that are said to produce personal and social identities are positionality, space of authoring, and world making.

Positionality. Positionality describes the social locations that individuals occupy in different figured worlds. Similar to figured worlds, when people are positioned, they may be limited in their capacity to accept, reject, or negotiate the identities that are available to them in the figured worlds. 
Space of authoring. Space of authoring refers to the capacity of individuals to make sense of their identities or positions through internal dialogue. When individuals are required to accept, reject, or negotiate offered positions, they must make choices and respond. A non-response is also a type of response. There are two main conceptual tools that are used to explain choices and responses: improvisations and self-directed symbolizations.

Improvisations. Improvisations are a significant form of human agency because even the most powerful institutions or individuals cannot prevent students from improvising. These are the moments of resourcefulness that connect existing cultural resources opportunistically to confront present conditions and problems.

Self-directed symbolizations. Self-directed symbolizations are also a form of agency. Holland et al. (1998) argued that people use whatever is at hand to opportunistically adjust their position in the cultural arena to form sets of characters. For example, recalled stories of parents' refugee experiences of escaping a war, sacrifices to give children a better opportunity in this country, and hard work to support families can support persistence in school. To enhance understanding of self-directed symbolizations, this study also employed Bandura's (2001) human agency concept, which consists of four core features: intentionality (making choices), forethought (action plans), selfreactiveness (motivating and regulating execution), and self-reflectiveness (personal agency). 
Intentionality implies is a proactive commitment to act on future performances. It is a force that motivates an action to take place for a given purpose. Forethought describes the expected consequences of actions after individuals have made their choices. Courses of action are selected to produce desired outcomes and avoid unfavorable ones. A perspective of forethought can give direction, coherence, and meaning to one's life (Bandura, 2001). Self-reactiveness describes appropriate courses of action individuals take to inspire and monitor execution after they make choices. It is the motivation and regulation behind the execution of the action.

Self-reflectiveness refers to the agentic people (those with personal agency) who exercise control over the nature and quality of their lives. These individuals are selfexaminers of their own functioning, with the capacity to reflect upon themselves and their thoughts. Agentic people can assess their motivation, values, and meaning of life pursuits.

The preceding four core concepts of human agency are expected to enable analysis of the steps that Southeast Asian students have taken to self-direct themselves to succeed academically. The four concepts may also help to distinguish agency derived from self-directed symbolization versus improvisation. The Southeast Asian students in this study may need to improvise resistance against their obstacles to succeed academically. They may also direct themselves to persist and succeed in college. 
World making. World making, the final context proposed by Holland et al. (1998), emerges through social interaction at the margins of newly imagined worlds. Humans can imagine new worlds, play in them, act them out, and then make them socially, culturally, and materially consequential. This provides the possibility for generating new ways, artifacts, discourses, acts, and potentially more liberated worlds. Thus, world making connects personal and social identities back to the first context of figured worlds.

To summarize, this study examined how Southeast Asian students used improvisations and self-directed symbolizations, along with existing cultural tools, to opportunistically address conditions and challenges in their pursuit of academic success in higher education. It also examined how these students challenge specific figured worlds reflected in dominant ideology, such as the model minority myth and deficit thinking, and how they negotiate to overcome challenges. The study explored how Southeast Asian students create spaces of authoring to make choices and respond to the dominant ideology in order to create new figured worlds that result in academic success in higher education. To achieve these purposes, the study employed Holland et al.'s (1998) work on identity and agency in cultural worlds as a conceptual framework. This framework is visually represented below. 


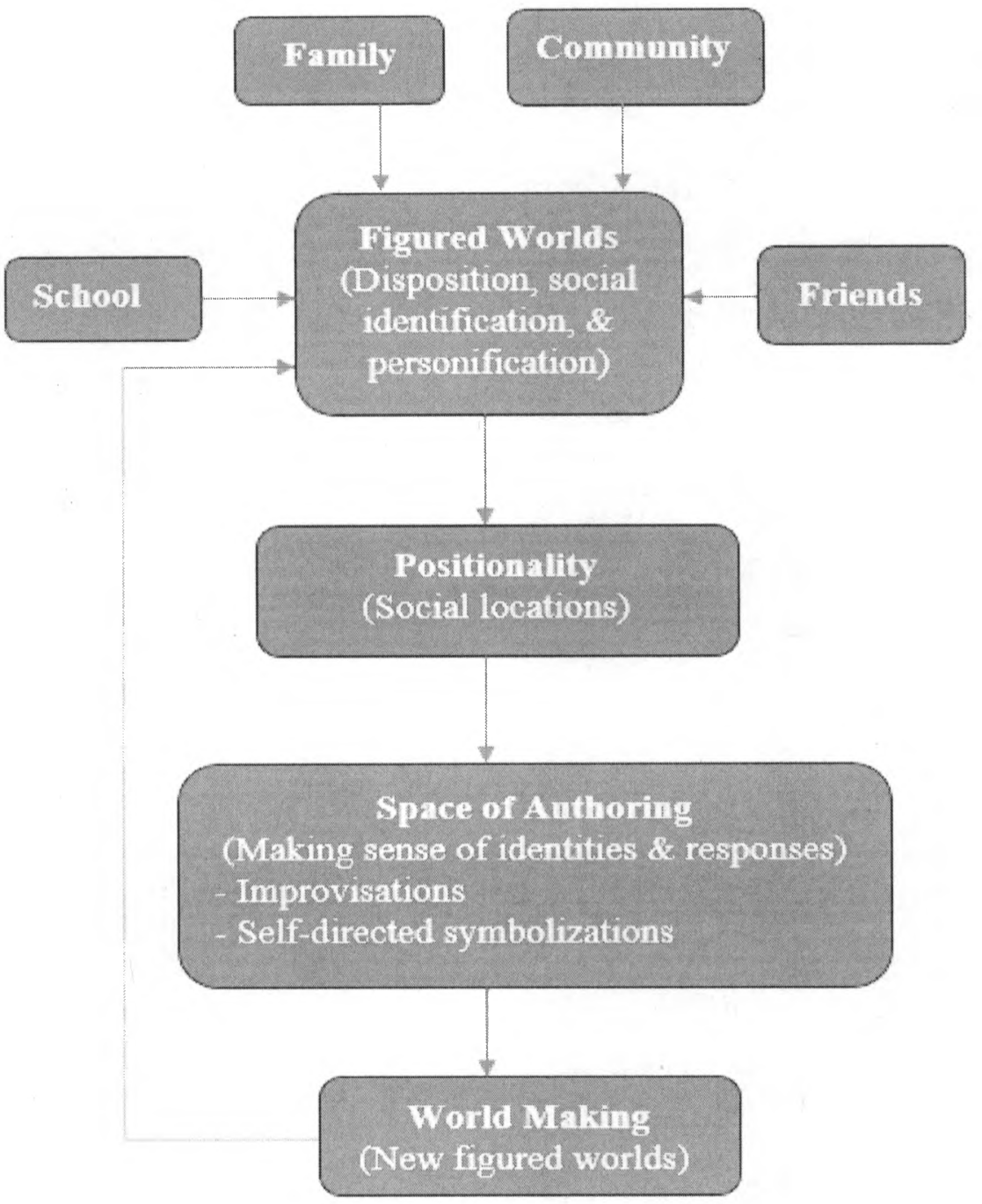

Figure 1. Conceptual framework on identity and agency in cultural worlds. 


\section{Operational Definitions of Key Terms}

The terms used in this study can be grouped around: (a) academic success, (b) Southeast Asian students, (c) contributing factors or patterns, and (d) higher education. Academic success. Completion of a four-year college degree.

Southeast Asian students. The students from four communities (Cambodian, Hmong, Lao, and Mien American) included in this study.

Contributing factors or patterns. The characteristics that enabled Southeast Asian students to complete a four-year degree.

Higher education. Four-year baccalaureate and graduate-level academic institutions.

\section{Statement of Delimitations and Scope of Study}

This study included the Southeast Asian American college graduates who selfidentified as Cambodian, Hmong, Lao, and Mien and are either refugees or from a nuclear family of refugees. They were all over 21 years old.

\section{Significance of the Study}

The aim of this study was to support allocating resources equitably, challenge deficit perspectives and behaviors, establish strong support and high expectations, and enable Southeast Asian Americans, low-income students, and other students of color to commit to themselves and their learning. 
By documenting and disseminating factors that lead to academic success in higher education for Southeast Asian American students, the study has the potential to contribute a new body of knowledge that addresses a long underserved population in U.S. education. The findings of the study shall enable educators to gain insights into obstacles faced by these students by acquiring an understanding of how successful students have overcome obstacles and gone on to achieve academic success in higher education.

Educators, policymakers, and other stakeholders should be able to make use of the findings of the study to learn about potential best practices to support the development of educational equity initiatives for Southeast Asian students. Educational leaders should be able to manage resources more effectively to enhance educational outcomes for Southeast Asian Americans and other marginalized groups. If the issues raised by the study remain unaddressed, educational inequality is likely to continue as a challenging issue for Southeast Asian Americans in California and throughout the country.

\section{Summary}

As educators, policymakers, and other stakeholders ponder the low college completion rates of students of color, particularly Southeast Asian refugee students, this study highlights the experiences of these students in successfully obtaining a four-year college degree. The study employed mixed methods to answer two research questions, one with a qualitative focus and the other with a quantitative focus. The qualitative phase captured information on general background, family struggles, goals and expectations, 
social interactions, and keys to academic success. In semi-structured interviews, 19 Southeast Asian college graduates subsequently shared details of their journeys from high school to college. The quantitative phase provided outcomes and comparisons among the four ethnic groups, which were integrated with findings from the qualitative phase. Through this triangulation, the study offered an integrated view of the experiences of Southeast Asian students in higher education. 


\section{Chapter Two: Literature Review}

\section{Introduction}

This chapter examines research literature related to the issue of academic success of Southeast Asian students in higher education. The review has two elements. Part I describes the methodology of the literature review research. Part II reports on the literature review. The review moves from general to specific as follows: (a) students of color, (b) immigrant students of color, (c) Asian immigrant students, and (d) Southeast Asian immigrant students.

\section{Part I: Methodology of the Literature Review Research}

The review initially involved a search of electronic databases, such as OneSearch, which determined the content available from over 200 databases and library catalogs. OneSearch was developed by the California State University System-wide Digital Library Services group. I searched under the following keywords: Cambodian (Khmer), Hmong, Laotian (Lao), Mien, Southeast Asian, refugee, college, experience, and higher education. I narrowed the scope of the literature that I reviewed to: (a) the experiences of Southeast Asian college graduates in the United States, (b) the education of Southeast Asian Americans, and (c) the education of the specific Southeast Asian ethnic groups (Cambodian, Hmong, Laotian, and Mien). 


\section{Part II-Review of the Literature}

This section reviews literature on: (a) students of color, (b) immigrant students of color, (c) Asian immigrant students, and (d) Southeast Asian immigrant students. This is followed by an exploration of the academic and social experiences of Southeast Asian Americans.

\section{Students of Color}

Academic success is the norm and the expectation for White middle-class students, and it is embraced by school cultures. These students generally take advanced honors classes and represent the students from the "good" families with "strong" values . High-achieving students of color, who may come from less privileged communities but also take these classes, are expected to reflect the same values, although their experiences may diverge (Chambers \& Huggins, 2014). These dominant norms may pressure students of color to shift their values and identities to pursue their goal of academic achievement. There is sometimes the implication that the school culture of White middle-class norms and expectations may be more desirable than preexisting values and expectations. Due to the lack of consideration of their values and a sense of community, students of color may thus feel isolated on a college campus (Chambers \& Huggins, 2014; Phommasa, Duran, Brenner, \& Hudley, 2016).

Researchers have investigated successful academic experiences of a range of underrepresented racial minority college students and found that support systems, campus 
culture, and successful school engagement are associated with academic success (Chhuon, Hudley, Brenner, \& Macias, 2010; Hurtado, Milem, Clayton-Pedersen, \& Allen,1998; Museus, 2012; Museus \& Liverman, 2010; Segedin, 2012; Tkatchov \& Pillnow, 2008). It is likely that some of these findings may be applied to immigrant students and immigrant students of color.

\section{Immigrant Students and Immigrant Students of Color}

Immigrant students are said to adapt processes and achieve educational outcomes via three connected factors: (a) parental levels of human capital, (b) family structure, and (c) the larger social context of the immigrant experiences in the host country (Kim, 2012). Parental levels of human capital translate into a competitive view of the host country's labor market and the desire to achieve positions in terms of American dreams of status and wealth. This may depend on three factors. First, their receptive context is significant in terms of socioeconomic outcomes and shapes how immigrants may become involved in the host country's cultural, social, and economic practices. Second, racial stereotypes affect the assimilation paths of certain groups of immigrants more than

others. For example, immigrants of color may be less likely to be assimilated than White immigrants because of racial stereotypes. Third, the existence of receptive communal members of an ethnic group can impact the quality of co-ethnic communities and how these communities rise to support new members as they arrive in the host country. Finally, geographic proximity to a similar ethnic community helps immigrants to have 
access to the social and economic resources that allow them to build a life in a new host country and to protect them from prejudices of the host country's society (Kim, 2012).

Kao and Tienda (1995, as cited in Uy, 2011) assert that immigrant parents tend to have high expectations for their children and want their children to take advantage of the educational opportunities available in the U.S. (Uy, 2011). These expectations can play a major role in immigrant children's educational experiences (Kibria, 1993; Lew, 2006; Louie, 2001; Portes \& Rumbaut, 1996; Suarez-Orozco \& Suarez-Orozco, 2001; Uy, 2011; Zhou \& Bankston, 2001). Immigrant parents appear to exercise stricter control over their daughters' activities outside of the house and have higher expectations for their daughters to follow traditional values than for their sons (Suarez-Orozco \& Qin, 2006). Asian immigrant parents are said to have particularly high expectations for their children's academic achievement (Goyette \& Xie, 1999; Uy, 2011).

\section{Asian Immigrant Students}

In addition to having high expectations for their children's academic achievement, Asian immigrant parents are said to maintain a strong sense of community due to their tendency to preserve ethnic values and maintain social cohesion. Chinese and Korean communities, for instance, are described as places where communal cultures are used to convey the importance of educational values and college access. Religious activities in churches or temples may also influence student access to ethnic social networks and information about college regardless of socioeconomic background (Kim, 2012). 
Asian immigrants are also said to use ethnic business networks and organizations to share information and resources (Kim, 2012). Asian parents see education as a vehicle for upward mobility (Chen \& Stevenson, 1995; Uy, 2011). Thus, the high expectations of Asian parents for their children can cause Asian American students to experience high familial pressure to perform well in school (Cimmarusti, 1996; Gomez, 2005). Academically successful Asian American students are sometimes described as obedient, industrious, and intelligent, which brings honor to their families (Cimmarusti,1996; Gomez, 2005). Other scholars, however, critique this view of Asian Americans as a "model minority" myth (Ngo \& Lee, 2007).

\section{Model Minority}

The term model minority describes a stereotype that depicts Asian Americans as a group that has achieved uniformly high levels of educational success, while facing marginality and discrimination (Covarrubias \& Liou, 2014; Wallitt, 2008). At the aggregated level, the achievement data of Asian Americans has been similar to or more accomplished than White Americans. This flawed aggregation reinforces the model minority myth while minimizing the complexities of the Southeast Asian American experience by conflating them together with "all Asians" (Covarrubias \& Liou, 2014; Teranishi, 2002). As a homogenized group, Asian Americans have achieved above all other groups in higher education by a large margin. Furthermore, Asian American men 
have performed better than all other groups, including their female counterparts, in attaining higher number of degrees in all levels.

However, essentializing Asian Americans as a homogenous group overlooks the educational achievement gap and income gap of Southeast Asian Americans, which leaves them invisible in the dominant, hegemonic discourse (Covarrubias \& Liou, 2014). Due to this perception, Southeast Asian Americans continue to be excluded from racial discourses on educational issues because the issues they face are not always evident. This is despite the fact that Southeast Asian Americans continue to manifest need of structural resources, educational opportunities, and civil rights protections (Covarrubias \& Liou, 2014; Teranishi, 2002).

\section{Southeast Asian Students}

Kao and Tienda (1995) assert that Southeast Asian parents share the "immigrant optimism" of having higher expectations for their children (as cited in Uy, 2011) and play a major role in their children's educational experience (Uy, 2011). However, Kim, Atkinson et al. (2001) counter that many Southeast Asian Americans as recent firstgeneration immigrants may tend to adhere more to their traditional values more than do those who have been in the U.S. longer, such as Chinese, Koreans, and Japanese (as cited in Her \& Gloria, 2016). In addition, the academic achievement of more recent immigrant American students, including Southeast Asian students, is likely to be influenced by length of stay in the U.S. and family income (Youn, 1993). The per capita income of 
Southeast Asian Americans (less than \$17,000) is also far below that of Asian Americans as a group $(\$ 28,343)$, and substantially below the national average of $\$ 27,100$ (APALC \& AAJC, 2011). Furthermore, unlike the Chinese and Korean communities, Southeast Asian cultural, religious, and community-based organizations often lack the human capital and economic resources necessary to promote the importance of educational values and college access (Uy, 2011). Furthermore, in contrast to the model minority view of Asian Americans in general, Southeast Asian Americans are sometimes perceived from a deficit perspective, particularly in schools, as gang members or "at risk" (Chhuon, 2013).

\section{Deficit Thinking}

Southeast Asian students and parents may be viewed from a deficit perspective and be portrayed as inferior underachievers. This view is based on the assumption the White middle-class values should serve as a standard (Teranishi, 2002). Southeast Asian students are at times stigmatized as a traumatized community consisting of welfare dependents, high school dropouts, and delinquents (Ngo \& Lee, 2007; Um, 2003). A deficit thinking view may result in blaming Southeast Asian students and parents for low academic performance, presuming that parents do not care about or support their children's education (Yosso, 2005).

Because of these assumptions, teachers and counselors may form negative stereotypes, have low expectations, and label Southeast Asian students as gangsters, 
being at risk, or possessing limited capability, deeming them not worthwhile to invest time or resources (Chhuon, 2013; Um, 2003). As a result, Southeast Asian students may be tracked in remedial and vocational preparation programs where teachers offer limited college advice and instead direct them toward community colleges or the military (Teranishi, 2002; Um, 2003; Anyon, 1980). Furthermore, Southeast Asian students' cultures are generally excluded from school curriculum at their schools, which can disengage them from learning (Anyon, 1980). Therefore, Southeast Asian students are at times left to feel neglected and even disrespected by their teachers, feeling excluded from their school's curriculum and culture (Wallitt, 2008; Teranishi, 2002). Thus, they are often poorly prepared to enter college.

Some research, however, refutes the deficit view of Southeast Asian parents, suggesting that Southeast Asian parents may become highly involved in their children's education, although it is in non-Western, traditionally Southeast Asian ways. For instance, teachers in Southeast Asia are traditionally absolute authority figures over parents for academic and moral development of children. Also, Southeast Asian parents value the importance of teachers highly and influence their children to view their teachers as "second mothers or fathers" (Akiba, 2010; Canniff, 1999; Norasing, Mack, \& Collins, 1999; Uy, 2011; Xiong \& Obiakor, 2013). Therefore, given this high degree of respect for teachers, some Southeast Asian parents may not consider it appropriate to play a role in their children's education. However, U.S. educators are generally not well acquainted 
with these values of Southeast Asian parents, and they may misinterpret the parents' respect for teachers as a lack of caring or engagement.

This brief review suggests that the values of communities of color are not often considered form the perspective of dominant U.S. cultural norms where academic success is the expectation, even though immigrant parents tend to have higher expectations for their children and want their children to take advantage of the educational opportunities available in this country. In addition, Asian immigrant parents are reported to have particularly high expectations for their children's academic achievement. These parents have a strong sense of community due to their tendency to preserve ethnic values and maintain social cohesion. They may see education as a vehicle for upward mobility. Similarly, Southeast Asian parents share the "immigrant optimism" of having higher expectations for their children. Yet many Southeast Asian Americans are recent immigrants, and their per capita income is also far below that of Asian Americans as a whole. Unlike Chinese and Koreans, Southeast Asian cultural, religious, and communitybased organizations may therefore lack the human capital and economic resources needed to promote and support college access.

\section{Academic Experiences of Southeast Asian American Students}

The academic experiences of Southeast Asian American students addressed in this section include high school experiences, transition challenges, and college experiences. 


\section{High School Experiences}

Local high schools are responsible for preparing high school students academically for the transition from high school to college, and positive high school experiences can lead to a smooth transition into college (Clark, 1998). Understanding high school academic success factors can help educational administrators build a college pipeline for Southeast Asian students and improve their chances of graduating from college (Astin, 1993). High school experiences addressed here that are particularly relevent to college access include (a) college prep courses, (b) extracurricular activities, (c) outreach programs, and (d) teachers and counselors' interactions.

College preparatory courses. College preparatory ("prep") courses offered at local high schools are designed to prepare students for college work (Clark, 1998; Strayhorn, 2011; Uy, 2011). Reid and Moore's (2008) study on the college readiness of 13 first-generation students found that certain classes, including English, AP classes, and college-level math, appeared to prepare high school for college (Strayhorn, 2011). Parents and students today see AP classes as an opportunity to gain credits for related college courses prior to entering the university (Clark, 1998). However, despite AP enrollment, some students do not feel sufficiently prepared for college level work (Clark, 1998). Hallett and Venegas's (2011) study similarly reports that the students who took AP courses did not feel adequately prepared for college. 
Extracurricular activities. Extracurricular activities play a substantive role in the college application process and the awarding of scholarships for high school students (Sharpe, 1999). Students are frequently advised to participate in extracurricular activities in high school to make an impression on college admission officers (Proefriedt, 2010).

Outreach programs. Participation in outreach programs can increase the number of college-related resources available students, especially for the students from singleparent households (Fester \& Perna, 2010). Early academic outreach programs were created beginning in the late 20 th century to reach out to students of color and to inspire and motivate them to prepare for college (Roberto, 1997; Strayhorn, 2011). Many outreach programs have subsequently developed into curriculum-based programs to address the specific needs or academic interests of students (Roberto, 1997). Outreach programs by discipline, such as math, engineering, or science, have proven to be successful (Roberto, 1997). As a caveat, Fester and Perna's (2010) study on participation precollege outreach programs found a limited positive effect on a four-year college enrollment, especially for students from single-parent households.

Teacher and counselor interactions with students. Allen, Gregory, Mikami, Lun, Hamre, and Pianta's (2013) study on effective teacher-student interactions among secondary students found that qualities of teacher interactions with students predicted student performance on year-end standardized tests. Higher levels of student achievement were associated with teachers facilitating a positive emotional climate, being sensitive to 
adolescent needs and perspectives, using diverse and engaging learning formats, and focusing on analysis and problem solving. Furthermore, teacher perceptions of students have been found to be related to student academic outcomes (Blanchard \& Muller, 2015). In addition, Linnehan, Weer, and Stonely's (2011) research on the relationship between student characteristics and counselor recommendations found that counselors were more likely to recommend community colleges to students from the less privileged socioeconomic status (SES) backgrounds and four-year colleges to students from the higher SES.

Based upon the literature reviewed, it appears likely that students who take college prep courses become involved in extracurricular activities, participate in outreach programs, and have positive interactions with teachers and counselors are more likely to be better prepared to apply and be accepted to a four-year college. Alternatively, those students who have attended community college and successfully transferred to four-year institutions seem to share the following characteristics: (a) clear goals, (b) strong motivation and a drive to succeed, (c) ability to manage external demands, and (d) selfempowerment (Martin, Galentino, \& Townsend, 2014).

\section{Transition Challenges}

Trivett (1976) cited that the transition challenges remain the issues for many students in the U.S. due to a mutual lack of respect for both school and college in terms of curriculum and expectation of student preparation (as cited in Clark, 1998). There 
appeared to be a lack of knowledge in each other's programs and courses (Clark, 1998). Students are confronted with challenges in trying to bridge the gap between high school and college courses (Clark, 1998). Some students who enroll in college prep courses in high school may need to take remedial classes in college (Clark, 1998). High school graduates may not be prepared for college; even though, they passed the mathematics courses and the exit test for graduation (Hull \& Seeley, 2010). Feeling unprepared causes students to leave college and return home (Clark, 1998). Predominantly White institutions have responded and developed transition programs for underrepresented groups that focus on academic preparedness and general social adjustment (Lee, Barnes, Kenkel, \& Monteith, 2015). In addition, Her's (2014) study reported that a high percentage of Southeast Asian students are not college ready by 11 th grade. Despite their transition challenges, some Southeast Asian students overcome these challenges to experience their college life and graduated.

\section{College Experiences}

Prior research noted various factors contributing to academic experiences during college. Lor's (2008) study of 18 Hmong college graduates from different universities found that both academic and social experiences were contributing factors to academic success. Academic experiences that contributed to success included student-faculty interaction, support systems, and financial assistance. In addition, Chhuon and Hudley (2008), who conducted a study of 10 Cambodian students from a four-year college 
campus in Southern California, found that educational opportunity programs, positive faculty interactions, and student organizations were academic success factors. They also reported that social and emotional support from home communities was important to academic success (Chhuon \& Hudley, 2008). Even though study subjects were still in college during the study, they were reported as being more likely to graduate within a sixyear time frame due to their supportive campus environment (Chhuon \& Hudley, 2008).

Furthermore, Xiong and Lee (2011) studied 55 Hmong students from a California public university and found that academic advising and financial services were most helpful. These findings may be relevant for other Southeast Asian students, particularly Cambodian, Lao, and Mien students, because they often share similar backgrounds (Bempechat \& Omori, 1990; Norasing et al., 1999). Although this study was conducted in a single university context, its conclusions reflect Lor's (2008) findings across multiple universities.

The limited available literature on academic success among Southeast Asian American students in higher education reviewed in this section suggests that there may be similar academic experiences across the four Southeast Asian ethnic groups targeted in this study. Successful academic experiences appear to be critical to increasing persistence and graduation rates. Like other successful students, it appears that when Southeast Asian students are given encouragement to do well, expected to do well by their teachers, given access to adequate support systems on campus, and provided with financial assistance; 
then, they are more likely to succeed academically. The literature review in the next section describes the social experiences of Southeast Asian Americans.

\section{Social Experiences of Southeast Asian Students}

Social experiences of Southeast Asian students play an important role in their academic success. They consist of refugee experiences, cultural expectations, and likeminded friends.

\section{Refugee Experiences}

When refugee families arrive, a resettlement representative meets them and is responsible for providing them with the initial reception and placement services for the first 30 to 90 days after their arrival (Department of State, 2017). Once 90 days have expired, refugee families are eligible to participate in programs funded by the Department of Health and Human Services' Office of Refugee Resettlement (ORR) for up to five years (Department of State, 2017). Gordon's (1987) study found that Southeast Asian refugee families were placed away from their relatives and from their ethnic communities, which caused them to migrate once they were resettled.

The refugee journey and its hardship became a source of motivation for refugee children (Truong, 2014; Uy, 2011). These experiences originated from the refugee children's understandings of their parents' history and struggles, and they used this knowledge as an inspiration to make a difference in their families by persisting in school (Lor, 2008; Truong, 2014; Uy, 2011). Parents told stories about their hardships in 
Southeast Asia or when they first arrived in the U.S. as a motivator to their children (Uy, 2011). When they saw their parents' sacrifices and hard work in a new world with an unknown language and culture, they wanted to help their parents and families overcome their hardships by persisting in school (Lor, 2008; Truong, 2014; Uy, 2011). In addition, some students saw their family's financial struggle and wanted to do better than their families as a motivator to do well in school (Uy, 2011).

Refugee children used a dual frame of reference to compare their own situations to that of their parents (Lopez, 2002; Ogbu \& Simons, 1998; Suarez-Orozco, 1987; Uy, 2011). These children took ownership of their families' responsibilities by realizing that they must succeed no matter what, because everyone in their family was counting on them. Thus, failure to succeed in school was not an option for them because they viewed dropping out and quitting as a bad reflection of their families and a source of embarrassment (Lor, 2008; Uy, 2011). Many refugee students are first-generation students and are motivated to serve as role models for their younger siblings by persisting in and graduating from college (Chhuon et al., 2010).

Supportive parents were key to the refugee experience, although most parents did not know how to help their children with their homework or guide them through the educational system $(U y, 2011)$. Yet, they helped their children with everything that they could so that their children could succeed in school. This included finding tutors and relieving them from house chores or from working to provide family income support. 
These parents also demonstrated what the lack of educational opportunity had done to them, which resulted in unstable, low-skilled, and low-paying jobs. In contrast, they told their children that their lives could be different and easier if they took advantage of the educational opportunities in this country (Uy, 2011).

\section{Cultural Expectations}

Many Southeast Asian parents seek to maintain their culture, to keep their heritage language alive, and to ensure their children know about and participate in religious ceremonies and traditions (Canniff, 1999; Gomez, 2005; Millhollen, 1994; Norasing et al., 1999; Vue, 2013) as their children are socialized and become more educated in the U.S. Cultural expectations become the tools that they use to support their sons and daughters (Her \& Gloria, 2016; Yang, 2008). In this study, cultural expectations consist of the following four sub-themes: family values, family expectations, gender differences, and religion and language.

Family values. Southeast Asian parents value education and teach their children to respect their elders (Bempechat \& Omori, 1990; Canniff, 1999), which are aligned with American values. They have limited human and cultural capital to offer to their children and lack educational experiences to guide them, but they provide moral support as a motivation for their children to succeed (Uy, 2011). Southeast Asian parents are a primary source of support (Bankston \& Hidalgo, 2006); they provide encouragement, set high expectations, and expect their children to go to college and graduate (Akiba, 2010; 
Ngo \& Lee, 2007; Tang et al., 2013). Thus, their children have a strong sense of obligation to their parents and graduating from college becomes a way of paying back to their parents (Ngo \& Lee, 2007; Supple, McCoy, \& Wang, 2010).

Family expectations. Parents' expectations have a great influence on their children's ambitions. Southeast Asian parents have high expectations that their children would finish high school and would able to contribute to the family's income (Uy, 2011). Doing well in high school, going to college, and getting a job are a family enterprise with collective implications (Uy, 2011). Parental and familial expectations are also reported to motivate success in students' academic lives (Uy, 2011). Some of the parents inspired their children to get scholarships to go to college since they could not afford the high costs of higher education (Uy, 2011). Family expectations include ethnic culture and traditions for this study.

Ethnic culture. The cultural preservation goal of maintaining culture, heritage language, and religious traditions is similar across all the four ethnic groups . Parents and elders are responsible for instilling their cultural norms to their children (Canniff, 1999; Gomez, 2005; Her \& Gloria, 2016; Lor, 2008; Millhollen, 1994; Norasing et al., 1999; Peng \& Solheim, 2015; Tran, 2014; Truong, 2014; Vue, 2013; Xiong \& Lam, 2013; Yang, 2012). Southeast Asian Americans also learn about their culture and traditions by being involved in their communities. However, each ethnicity is unique. 
Cambodian culture. Cambodian cultural norms and values are centered on being a good child to the family (Canniff, 1999). One must respect the family and follow advice conscientiously so that the family will not lose face among community members (Canniff, 1999; Willitt, 2008). A good child follows Cambodian cultural norms, has good character, succeeds in school, is loved by friends and teachers, and is generous with resources (Canniff, 1999).

In addition, the oldest Cambodian children have responsibilities for their siblings and parents, which make them accountable to succeed to help the family (Canniff, 1999; Chhuon et al., 2010). They provide resources to help their siblings succeed in college (Ngo \& Lee, 2007; Palmer \& Maramba, 2015).

Furthermore, the goal in life for a Cambodian person is to maintain a balance between the emotional fulfillment in life and the pressure to get ahead, which is a belief that success is possible when one lives a balanced life between the two cultures (Canniff, 1999). Similarly, Cambodian parents take the middle path for raising their children, not too strict and not too loose (Canniff, 1999).

However, a Cambodian family is autonomous and has its own dwelling unit (Canniff, 1999). The mother and even the grandmother have the greatest responsibilities for the family (Canniff, 1999). They must be mentally, physically, and financially strong (Canniff, 1999). Their job is to prepare their child to be self-reliant and to have good 
character in school and with his or her friends so that the child does not shame her in the community (Canniff, 1999).

Traditionally, Cambodian parents consider teachers as the second parents for their children and expect the teachers to teach them the moral behavior and good attitude to provide opportunities for their children to succeed (Canniff, 1999; Uy, 2011).

Hmong culture. Hmong values are a collectivistic culture where higher values are placed on the interest of the group as opposed to individual's needs (Rothstein-Fish \& Trumbull, 2008; Xiong, \& Obiakor, 2013) and are based on clanships that serves as a biological and social structure of networks (Her, \& Gloria, 2016; Xiong, \& Obiakor, 2013). Hmong families place the importance of ethnic community and family ties and expect their children to carry family responsibilities (Moua \& Lamborn, 2010; Tatman, 2004; Peng \& Solheim, 2015). Like the Cambodian tradition, Hmong parents also see the school as the sole authority for their child's education (Xiong \& Obiakor, 2013).

Lao culture. Lao parents want their children to maintain their language, Buddhist traditions, and culture, which they believe are interconnected (Norasing et al., 1999). Lao values include working deligently, concern about personal honor, and honesty, which are shared with the American mainstream values (Norasing et al., 1999). Traditionally, Lao values are based on a strong family-oriented society, tradition of arranged marriage, nonassertiveness, strong group identity, belief in education for some but not for all male in the family, need to display material possessions of extreme value and prestige, 
embarrassment in receiving praise, social structure designed to avoid "loss of face," a belief held by extremely limited women in favor of marriage, and a resolute Buddhist religious tradition (Norasing et al., 1999, p.6).

Like Cambodian and Hmong parents, Lao parents expect a teacher to fulfill a unique role in the education of their children (Norasing et al., 1999; Uy, 2011). They grant the teacher full authority to accomplish his or her mission using whatever methods, discipline, or nurturing required (Norasing et al., 1999; Uy, 2011).

Mien culture. Mien family roles are fixed and patriarchal. Grandparents or elders take care of and teach their children to work (Gomez, 2005). Life lessons are learned through oral storytelling and modeling based on what is needed to survive in the highlands of Laos (Gomez, 2005). They learn farming and other agriculture practices; beliefs, customs, and religion; Iu-Mien language skills; and local community development and administration (Gomez, 2005). The Mien are self-sufficient and have little need from outsider's products or service that allowed them to live independently from non-Miens until the civil war happened in the 1960s (Gomez, 2005).

Formal education was traditionally only available to Mien males in Laos, and cooking and cleaning were the primary tasks for Mien females in Laos (Gomez, 2005). Although public education in the U.S. is available regardless of gender (Gomez, 2005), some Mien parents still reinforced traditional gendered beliefs with their children in the 
U.S. As a result, some Mien Americans have started to transition away from their traditional culture (Millhollen, 1994).

Cultures and traditions were established to protect and preserve the survival of their people. For the most part, these cultural values were dynamic and could be transferred and seen across other cultures. For example, being a good child, being responsible for the family, living a balanced life, valuing the importance of community and family ties, working hard, taking personal honor, and being honest are not only seen in these four ethnic groups but are also seen in American culture. However, certain traditions limit women to fewer opportunities and restrict them to their gender roles.

Gender differences. Gender is constructed socially and serves as a process to shape our actions and thinking and to negotiate relationships (Tran, 2014). SuarezOrozco and Qin (2006) suggested that immigrant parents have stricter control over their daughters' activities outside of the house and have higher expectations for their daughters to follow their traditional values than for their sons. Similarly, studies on Southeast Asian Americans have shown socialization at home may be a gendered process where parents monitor girls more closely than boys (Tran, 2014). This practice of favoring a son over a daughter is rooted in Southeast Asian family practices, standards, and expectations because a son is believed to bring luck and prestige to the family (Truong, 2014) and is responsible for parents in old age (Millhollen, 1994). Gender differences vary across the four ethnic groups. 
Cambodian gender differences. Historically and before the Indian influence, Cambodian women had a higher status and were more powerful than Cambodian men. After a Cambodian female ruler met and married a Hindu prince, Cambodian women's status became weaker (Canniff, 1999).

Thereafter, Cambodian parents expected their daughters to be more responsible for maintaining proper behavior than boys (Tran, 2014). They were concerned about their daughters' chastity because they strongly believed the Cambodian identity and culture were based on the purity and the proper behavior of Cambodian women; yet, they recognized the necessity of education and wanted their daughters to be successful in school (Tran, 2014). Traditionally, a Cambodian girl's reputation is the most important thing. However, Cambodians believe both boys and girls have equal access to education, but the Cambodian culture is very protective of a girl's reputation in the community (Canniff, 1999).

Although Cambodian women had more power and higher status than Cambodian men historically, outside influences caused Cambodian women's status to be weaker and inferior to Cambodian men until today. Cambodian women nowadays are expected to uphold purity, while Cambodian men do not have the same expectation.

Hmong gender differences. Traditionally, many Hmong families have clear gender roles and are patrilineal. Hmong men are the providers, decision-makers, and protectors; are responsible for the families; and hold higher status than Hmong women. 
Hmong women are responsible for the familial household work and have few privileges (Her, \& Gloria, 2016; Peng \& Solheim, 2015).

In addition, Hmong parents have different expectations for their sons and their daughters. They reserved higher education for their sons more than for their daughters; although, they encourage their children to go to school to help advance their family. They expect their daughters to be good housewives and daughter-in-law and their sons to be good providers and promoters for their community. Additionally, they encourage their daughters to remain strict on their values and to show what it means to be Hmong females while encouraging them to advance their education (Her \& Gloria, 2016; Tran, 2014). However, they are less strict and hold their sons less accountable for their roles (Her \& Gloria, 2016).

Peng and Solheim's (2015) study on 14 Hmong college women's experiences of being a daughter found that these women became psychologically close to their parents and were more independent when they were in college. They also learned to negotiate and balance the two cultures (Hmong and American). Although they clashed with the "good daughter-in-law" image and felt marginalized of the son-favoritism, they felt privileged to have the opportunity to become educated women and to negotiate their role expectations. For these women, a good daughter meant to be successful in achieving a college education that would lead to a good career while preserving their Hmong cultural traditions (Peng \& Solheim, 2015). They expanded what it meant to be a good daughter 
to include being an honorable successful, educated women, which they incorporate into their goals and dreams of becoming a successfully professional woman while honoring their parents' expectations (Peng \& Solheim, 2015).

Lao gender differences. Lao females are given limited educational opportunities but are in favor of getting married instead (Norasing et al., 1999; Uy, 2011). They are encouraged to get married as soon as possible, raise children, and work at home. They also have limited rights to challenge male authority or to develop self-esteem (Norasing et al., 1999).

Mien gender differences. Traditionally, Mien parents and community emphasize and transfer Mien gender roles and expectations to their children. Traditionally, Mien mothers were responsible for the household. Mien fathers or grandfathers made all the decisions, performed all ceremonial customs, and carried out the farm work. While Mien men were expected to perform ritual ceremonies, Mien women's self-worth was judged by how well they cleaned and cooked for their own families and for their husband's families after they got married (Gomez, 2005).

In addition, traditional Mien gender roles are valued, reaffirmed, and passed onto the children by their parents and community. Mien males are expected to hold an acceptable manner for the Mien gender roles. Mien American males are not expected to cook but to know and perform religious ceremonies that have been entrusted to them. Mien American females are expected to continue to be responsible for the household 
activities, such as cooking and cleaning. Mien women are also expected to serve others before themselves. Maintaining these gender roles through each generation is key to sustaining the Mien identity, culture, traditions, and beliefs (Gomez, 2005).

Unlike Cambodian, Hmong, and Lao traditions, formal education was only available to Mien males in Laos (Gomez, 2005). However, the gender roles have changed due to the socio-economic shift from Mien agrarian to the U.S. post-industrial. In the U.S. where public education is available to anyone regardless of gender, Mien women have benefitted more than Mien men (Gomez, 2005).

Gender differences were found across the four ethnic groups where women were expected to perform household chores, restricted to certain standards and were given fewer privileges, while men were expected to be the decision makers and had more privileges. With an educational opportunity in this country regardless to gender, Asian American girls, including Southeast Asian women, are more motivated to achieve academic success than boys, because they have less educational status in their country of origin and thus may acculturate more easily than males into American culture (Tran, 2014).

Religion and academic success in communities of color. Spirituality and religion have been used as coping strategies for different communities of color. For instance, African male and female students have found support in religion to help them succeed in college (Brooks \& Allen, 2016; English, 2015; Patton \& McClure, 2012; 
Placenti, 2012). For Southeast Asian students, their spirituality and religion are often manifested in the form of Buddhism, particularly Theravada Buddhism (Ark, 2014; Canda \& Phaobtong,1992; Canniff, 1999; Tran, 2014). Buddhism is regarded as a moral philosophy, a form of practical human psychology, and one of the world's major religions (Ark, 2014). Buddhism today has many forms but shares its core beliefs across the different Buddhist traditions.

Theravada Buddhism is traditionally practiced in five Southeast Asian countries: Myanmar (formerly Burma), Cambodia, Laos, Thailand, and Sri Lanka (Canda \& Phaobtong, 1992; Canniff, 1999). It has approximately 100 million followers worldwide (Ark, 2014, Canniff, 1999). Buddhism expanded to Southeast Asian mainland in the third century (Canda \& Phaobtong, 1992).

Cambodian Buddhism. Cambodian Buddhist monks have substantial power in society because they are involved in almost every aspect of family and community life from performing ritual blessings, to offering spiritual counsel; monks lead chanting, teach meditation, teach children, raise orphans, set moral and social standards, and give instructive talks on the Buddha's teachings (Canda \& Phaobtong, 1992; Canniff, 1999). Buddhist monks are understood to be responsible for protecting traditional values and culture, and they command great respect for their good character and personality (Ark, 2014; Canda \& Phaobtong, 1992; Canniff, 1999). Cambodian Theravada Buddhist monks may also serve as surrogate parents and role models for troubled youth (Canniff, 1999). 
Lao Buddhism. In Laos, before the expansion of the state school system in the 1950s and 1960s, Phimmasone (1973, p. 126) reported that monastic education was highly regarded and considered as the center for religious, professional, social, and moral education (as cited in Ladwig, 2011). Buddhist monks taught children and novices reading, writing, arts, and sciences together in the temple (Ladwig, 2011). Monks' positions were compared to those of intellectuals because they were recognized as more insightful than laypeople (Ladwig, 2011). In addition, Tambiah (1968) and Taillard (1974) cited that monks were largely responsible for public education until World War II (as cited in Ladwig, 2011). Pottier (2007, 123f) also asserted that monks provided traditional healthcare and trained traditional healers at their monasteries (as cited in Ladwig, 2011). Moreover, Koret (1996, p. 12) reported that they served a critical role in conflict resolutions and local village law (as cited in Ladwig, 2011). Crabowsky (2007) further noted that they were even involved in important political positions in earlier periods (as cited in Ladwig, 2011). The temple also held different roles, was the center of the social space, and was a focal point for various social relations in Lao peasant society (Ladwig, 2011).

Subsequent educational politics has marginalized monks' role in public education and changed toward a state school system (Ladwig, 2011). Consequentially, monks lost one of their principal tasks in their communities and now only teach other monks and have a more restricted responsibility (Ladwig, 2011). Today, monastic education 
primarily serves the rural poor and has little value in comparison to a certificate from a business school (Ladwig, 2011).

Religion in U.S. refugee communities. In the U.S., Theravada Buddhism is found in the Southeast Asian immigrant communities (Ark, 2014). Canda and Phaobtong's (1992) study of human services at three Lao and Khmer temples for refugees living in the U.S. found that the capacity of Southeast Asian refugees to overcome the war trauma can be linked to maintenance of a traditional life-style and support efforts from Buddhist centers. The authors also found that Buddhist services were a combination of traditionally expected activities of the temple and ad hoc requirements of the refugee community, such as material, psychological, social, and spiritual support. The leaders of the Buddhist association who were bilingual caseworkers at the refugee assistance agencies worked as brokers, advocates, and liaisons between refugees and conventional Euro-American delivery service support systems (Canda and Phaobtong, 1992). Similarly, Canniff (1999) studied cultural sources of adaption success in three Cambodian families in relationship to Theravada Buddhism. The three families successfully navigated through life in the host country, while being guided by Buddhist teachings (Canniff, 1999). Theravada Buddhism is more likely practiced by Cambodian and Lao Americans than that of Hmong and Mien Americans because Hmong and Mien Americans originally came from China. 
Hmong religious beliefs traditionally focus on the existence of the soul in the human body and the force of spirits in objects in nature. Hmong people are said to practice a form of Shamanism, which is a system of curing illness and suffering through a Shaman's ability to transcend into the other world to reveal the causes of the illness and misfortune. Besides Shamanism, the Hmong may also worship their ancestors in an approach called "propitiating the spirits," which connects the value of their kinship to their everyday life. In addition, some Hmong families may have been converted to Christianity when they were in China Moreover, some Hmong families have partially adopted some Buddhist beliefs and practices while still maintaining traditional beliefs (Lee, Tapp, \& Gale Group, 2010).

Mien religious traditions and rituals center around ancestor and spirit worship and recognition of the "owners" of land or earth. Mien beliefs reflect a Taoist system, which has enabled them historically to resist Buddhism. The interaction with ancestral spirits and leader spirits is fundamental for many Mien decisions (Millhollen, 1994').

Home language. Maintaining the home language reduces the cultural disharmony between parents and children, strengthening parental authority and thus improving children's behavioral problems (Gandara, 2015; Yang, 2008, 2012). Canniff (1999) cited that language is the strongest symbol of culture and expresses the full range of behaviors and beliefs that represent a distinct culture. It is the marker of an ethnic identity and creates a sense of belonging within an ethnic group (Tran, 2014). However, the U.S. is a 
“graveyard' for languages (Rumbaut, 2014, p.2). Social activities in school do not provide a space to use the ethnic language skills (Tran, 2014). Thus, the loss of fluency in the home language is common, especially in college as students are moving away from their home. This can happen in early grades as well, as seen in Canniff's (1999) study. Cambodian language was the barrier for April, which prevented her from integrating and understanding her culture (Canniff, 1999).

The loss of language fluency and decline in religious practice for college students were also found in Tran's (2014) study on Southeast Asian college students. Social activities did not provide space for speaking or to practice religion on a college campus (Tran, 2014).

\section{Like-Minded Friends}

Friends and classmates are also noted as important factors in promoting academic achievement (Guiffrida, 2003; Palmer \& Maramba, 2015; Tang et al., 2013). They support each other during difficult times in college (Lor, 2008). Friends from student organizations can provide social and emotional support (Guiffrida, 2003; Tang et al., 2013). Friends can connect students with academic support, act as a support group, and help develop a sense of ethnic pride (Guiffrida, 2003). Cherng, Calarco, and Kao’s (2013) study found that the students with resource-rich best friends whose mothers are college-educated are more likely to graduate with a four-year degree, regardless of the students' family resources and other school factors. These like-minded friends can 
provide access to the cultural and material resources to support the students going and completing college. Southeast Asian students draw on social capital from families and friends to support academic success (Lor, 2008).

In summary, the academic success of Southeast Asian students in higher education derives from their academic and social experiences. The academic experiences include high school experiences, transition challenges, and college experiences. High school experiences contain college prep courses, extracurricular activities, outreach programs, and teachers and counselors' interactions (Blanchard \& Muller, 2015; Clark, 1998; Fester \& Perna, 2010; Sharpe, 1999; Strayhorn, 2014; Uy, 2011). College transition challenges remain an issue for many students in the U.S. due to a mutual lack of respect for both school and college in terms of curriculum and expectation of student preparation (Clark, 1998). To survive on campus, many Southeast Asian students reach out to other students who share similar history and struggles (Chhuon \& Hudley, 2008).

The social experiences of Southeast Asian students consist of refugee experiences, cultural expectations, and like-minded friends. Refugee children saw their parents' journey, hardships, and sacrifices as their motivation and inspiration to persist in school (Lor, 2008; Truong, 2014; Uy, 2011). Although their parents could not help them with their schoolwork or guide them through the U.S. education system, their parents were their key supportive system through their academic journey (Uy, 2011). Many Southeast Asian parents desire to maintain their culture, to keep their heritage language 
alive, and to ensure their children know about and participate in religious ceremonies and traditions (Canniff, 1999; Gomez, 2005; Millhollen, 1994; Norasing et al., 1999; Vue, 2013). These parents value education and teach their children to respect their elders (Bempechat \& Omori, 1990; Canniff, 1999) and provide moral support as a motivation for their children to succeed $(\mathrm{Uy}, 2011)$. Southeast Asian parents have high expectations that their children will finish high school and will be able to contribute to the family's income (Uy, 2011).

This study, therefore, builds upon the existing literature on Southeast Asian American academic success by examining the characteristic patterns of academic success of Southeast Asian college graduates in terms of identity and agency in their cultural worlds and how they develop patterns that lead to academic success. 


\section{Chapter Three: Methodology \\ Introduction}

This chapter reviews the methodology design, participants, instrumentation, data collection, and analysis appropriate for responding to the following two research questions: (a) "What factors contribute to the academic success of Southeast Asian students" and (b) "How do Southeast Asian students interpret these factors and what significance do they have in their lives?"

\section{Purpose of the Study}

The study was conducted using a mixed methods approach to examine the experiences of Cambodian, Hmong, Lao, and Mien heritage college graduates, which they interpreted as keys to their academic success in higher education. An explanatory sequential mixed methods design was employed. It involved collecting quantitative data followed by qualitative data, with both data sets viewed as being in dialogue.

This chapter examines the methodology used to conduct this study. First, the research design and research questions are summarized. Second, my role as a researcher is addressed, followed by an explanation of the context of the study. Third, the population and sampling strategy used to select participants for the study is reviewed, including a detail of paths to protect the human subjects in my study. Finally, the data collection and data analysis processes are examined. 


\section{Research Design}

As described by Creswell and Plano Clark (2011), an explanatory sequential mixed methods design focuses on a sequential approach, which applies to a two-phase approach and begins by conducting the quantitative phase and is followed by a qualitative phase. Although the explanatory sequential design generally places priority on quantitative data over qualitative data (called follow-up explanations variant or denoted as QUAN->qual), this study prioritized qualitative data over quantitative data (called participant-selection variant and denoted as QUAL->quan). This design allows the researcher to focus on examining the experiences of Cambodian, Hmong, Lao, and Mien college graduates qualitatively but needs the initial quantitative results to identify and purposefully recruit the best participants (Creswell \& Plano Clark, 2011).

Adapting this design had two rationales for prioritizing qualitative data over quantitative data. First, the purpose of this study was to examine the experiences of Cambodian, Hmong, Lao, and Mien college graduates by telling their stories and by what they perceive as their key factors for their academic success. A key feature of this study was to ask the participants to identify their motivations, perceptions, sociocultural interactions, and their impacts on academic achievement. Miles, Huberman, and Saldana (2014) supported this purpose that "the researcher attempts to capture data on the perceptions of local participants from the inside through a process of deep attentiveness, 
of empathetic understanding, and of suspending or bracketing preconceptions about the topics under discussion" (p. 9).

A second rationale for prioritizing qualitative data over quantitative data was due to the limited amount of research literature available on the four communities. I found limited research literature on the four ethnic groups that compared how these college graduates achieved their academic success and how these findings compared to other Southeast Asian college graduates who share similar characteristics, such as Cambodian, Hmong, Lao, and Mien college graduates (Canniff, 1999; Chhuon \& Hudley, 2008; Gordon, 2012; Gomez, 2005; Her \& Gloria, 2016; Lor, 2008; Millhollen, 1994; Norasing et al., 1999; Tran, 2014; Truong, 2014; Uy, 2011; Vue, 2013; Xiong \& Lam, 2013; Xiong \& Obiakor, 2013; Yang, 2012).

As mentioned before, the qualitative aspect of this study plays a leading role for the quantitative data (QUAL-> quan). While the quantitative data allowed the researcher to compare the data of Cambodian, Hmong, Lao, and Mien college graduates by gender, each ethnic group, and a combined group from an overall perspective, the qualitative data centered on the participants' experiences.

Implementation of study procedures proceeded in stages. An initial online survey was posted on Facebook and emailed to individuals across the four communities (Cambodian, Hmong, Lao, and Mien) who were the focus of investigation. The fourth community (Mien) was added when two individuals from the Mien community reached 
out to the researcher requesting their community to be included in this study as a separate group. Once the responses of 136 participants were received, survey data were analyzed. From the survey respondents, 19 participants were identified for interviews. Interviews were over the phone, and audio recorded. Data collection occurred during Fall 2016. The researcher conducted the data collection. There were potential issues that emerged differentially with the four communities studied. For Cambodian participants, some might be personally acquainted with the researcher, potentially affecting validity of responses. For Hmong, Lao, and Mien participants, the researcher's Cambodian heritage could be a barrier to full honesty in responses.

\section{Role of the Researcher}

The researcher in this study is a refugee herself, a first-generation university student, and the only person in her family of five siblings to graduate from college; therefore, the study has meaning for her. The researcher has been substantively involved with Cambodian community service and has participated in numerous events in collaboration with Southeast Asian community organizations.

As a Cambodian researcher studying Southeast Asian college graduates, the researcher viewed her relationship with the participants as colleagues and working professionals who shared her similar experiences. The researcher also sensed a reciprocal view as she spoke with them. Although the interview was conducted over the phone, the researcher felt the connectedness across the four ethnic groups throughout the 
conversations as if she had known them personally for many years. The researcher learned not about only their academic journeys to higher education, but also came to know them as persons. As a result of this, she was able to build relationships and share resources. For instance, she shared a link to one of the Lao participants who was looking to connect with the Lao community in Northern California. She also gave information about a tuition waiver benefit to one of the participants who worked at a university but did not know about it. She further encouraged a few participants who were either going through graduate school or thinking of going to a graduate school to continue with their pursuits.

This sense of closeness and shared background enabled the participants to open up honestly about their experiences. Thus, this is likely that the validity of the study was enhanced by the closeness of the relationships that were built.

Initially, the researcher did not know how the data would fit into the study's stated theoretical framework. Frankly, initially she did not understand the framework as well as she wanted to. However, the data itself helped deepen her understanding of the framework as she began to subject the data to theoretical analysis. Using the framework for a Southeast Asian population that it had never been used before, was thus in itself a contribution of this study to the literature. In addition, the data of the study reveal that Southeast Asian students reached out and helped each other across the four ethnic groups to become motivated and succeed in college in this study. The Asia Pacific Coalition and 
the Southeast Asian Student Coalition played an important role in connecting these four groups. This finding represents another worthwhile contribution to the literature.

Furthermore, the data show that Ethnic Studies played a major role in creating a level of critical consciousness among Southeast Asian students about their histories and the impact of their histories on their refugee experiences as they navigated through the educational system. This new knowledge motivated them to become involved in their communities and to succeed in college. Thus, the finding about the relevance of Ethnic Studies programming to academic success and community involvement is a final important contribution of this study to the literature.

Because the researcher has direct personal links to the study's purpose and its population, she has taken multiple steps to minimize her bias. The study employed focused data collection and frameworks based on an articulated theoretical framework (Creswell \& Plano Clark, 2011). Holland et al.'s (1998) theoretical framework is based on activity theory, and the instruments used in this study are also guided by activity theory (Jonassen \& Rohrer-Murphy, 1999; Roth \& Lee, 2007). Since both the instruments and the framework of the study are guided by an articulated theoretical framework based upon activity theory, there is reason to expect that researcher bias would be reduced. Furthermore, interview data is used to triangulate the survey data, thus further building validity. 


\section{Research Questions and Sub-Questions}

An explanatory sequential mixed methods design was employed to examine the experiences of Cambodian, Hmong, Lao, and Mien college graduates (Creswel \& Plano Clark, 2011). In the initial quantitative phase of the study, survey data were collected from Cambodian, Hmong, Lao, and Mien American adults who are refugees or come from a nuclear family of refugees, have completed high school, and have graduated from a four-year college. In the subsequent qualitative phase, semi-structured interviews were used to investigate the motivations, perceptions, and the sociocultural interactions of the participants - and their impacts on academic achievement.

This study's quantitative research question is guided by the following question:

- What factors contribute to the academic success of Southeast Asian students in higher education?

The study's qualitative aspect is supported by the following research question:

- How do Southeast Asian students interpret these factors and what significance do they have in their lives?

For the quantitative research question, college graduate data were collected, including general background, family struggles, goals and expectations, social interactions, and overall key factors. These variables are based on the participants' selfreported data that were captured by the online survey, Qualtrics, provided by San Francisco State University. The researcher collected data from October 26 to December 
15,2016 , and compared the data by gender and by overall key factors by each ethnic group and a combined group.

\section{Context}

Cambodian, Hmong, Laotian, and Mien college graduates were selected for this study, because they have the lowest four-year college attainment rates among Southeast Asian communities and share a similar experience of refugee status and struggle for success. The work of Holland et al. (1998) on identity and agency in cultural worlds is used to explore their motivations, perceptions, and sociocultural values that contributed to academic success. Understanding the patterns of success in higher education of these groups could be helpful to enhancing college academic success of other Southeast Asian Americans.

The researcher has been serving the Cambodian community since January 2012, when she founded the Cambodian School of San Francisco. She won the Jefferson Award in February 2016 and the Courage and Leadership Award from the Devata Giving Circle in March 2016 for her community service. The researcher has also participated in the Southeast Asian Arts \& Culture Public Forum Summit in June 2014 and the annual Asian Heritage Street Celebration for the last four years. The researcher thus has easy access to Southeast Asian communities, and she uses that resource to recruit participants. 


\section{Participant Selection}

The participant pool consisted of Cambodian, Hmong, Laotian, and Mien male and female college graduates over 21 years of age who are refugees or come from a nuclear family of refugees. From the survey data, 136 Southeast Asian adult male and female college graduates, 57 Cambodians, 32 Hmong, 20 Lao, and 27 Mien, were collected. Twenty-one participants were initially selected for follow-up interviews. However, two of the interview participants were removed from this study because their experiences were out of the scope. One interview participant's family came to the U.S. via a fake marriage. The other family had a different refugee journey and were eligible to stay in the U.S. via a fake marriage as well. Thus, 19 interview participants were finally selected for this study, with 5 Cambodian, 5 Hmong, 6 Lao, and 3 Mien college graduates.

The researcher employed a purposive sampling method. Study participants were identified through Southeast Asian community organizations, Southeast Asian temples, and social media. The researcher attended the annual Asian Heritage Street Celebration to recruit participants. At this event, the researcher presented a brief introduction to the study to request participation. Participation is voluntary. The researcher also posted the recruiting text (see Appendix A) on Facebook along with a link to the survey questions. The researcher followed up with those individuals who agreed to participate. 


\section{Ethics and Protection of Human Subjects}

A research protocol was submitted to Office for the Protection of Human Animal Subjects and it was approved with expedited review. As a Cambodian community leader, an activist, and a doctoral student, I am in a position of power with respect to the community members in general but am in a position of colleagues and community members with respect to the participants since all of them would have attained at least a bachelor degree and have some community involvement. Regardless, before collecting data, I informed my network of contacts whom I would solicit as my participants to help locate my potential participants the purpose, scope, and nature of my study. A consent form (see Appendix B) was sent and at least verbal consent was obtained from each participant before interviewing. Participants were assured that this study would purely be voluntarily; if they decided not to participate, there would not be any negative consequence whatsoever.

A minimal risk found by the IRB was a risk of loss of privacy, which would be addressed by using pseudonyms for all the participants that only has any meaning to the researcher. The risks of uncomfortable emotions would be eliminated by letting all the participants know that they did not have to answer any question that made them uncomfortable and they were free to ask me any questions or stop the interview at any time. 
Pseudonyms were used for all participants to protect the confidentiality of the data. Transcribed data were kept at the researcher's home to avoid loss of data and possible breach of confidentiality. All printed data not stored on the researcher's password-protected computer were locked in the researcher's desk in her room at her home in San Francisco, California. Every participant was notified of these procedures and assured that the data would only be used to determine the patterns of success of Southeast Asian students in higher education.

Data collected from the survey and audio recordings made during the interviews were stored in a password-protected file on the researcher's computer. Once de-identified transcriptions have been made and data sorting sheets have been completed, all data recordings and raw survey data collection would be destroyed. Only the researcher and her faculty advisor have access to the data. The data were encrypted and stored in the researcher's password-protected computer and were kept indefinitely for research purposes consistent with the study. Names of individuals were changed in the final report. The participants were notified of these procedures and risks in the consent forms.

In the case that sensitive topics might come out of the interview, the participant was advised to talk to his or her health care provider. If the participant did not have a healthcare provider, the researcher advised the participant to seek help from Asian Health Services (AHS) or Asian Community Mental Health Services (ACMHS) at the below locations. AHS is a community health center that provides primary care, including 
medical, dental, and behavioral health to low-income families in Alameda County. ACMHS "provides multicultural and multilingual services, empowering the most vulnerable members of our community to lead healthy, productive and contributing lives" (http://www.acmhs.org/).

Asian Health Service 818 Webster Street Oakland, CA 94607

(510) 986-6800 for Medical Services

Asian Community Mental Health Services

310 8th Street, Suite 201

Oakland, CA 94607

(510) 869-6000

\section{Data Collection}

Data collection procedures included surveys and interviews. The primary quantitative instrument used is a survey created by the researcher using Qualtrics, a survey tool provided by San Francisco State University. The primary qualitative instrument used was an interview protocol (over the phone). Both instruments were developed by the researcher, guided by applying Holland et al.'s (1998) work on identity development in figured social worlds. The researcher's dissertation Committee Chair, Professor David Hemphill, reviewed the instruments, which were also pilot tested for content-related evidence of validity with one Hmong participant and one Lao participant. The instruments were not pilot tested with the Mien community since it was added after. the data collection had started. 
The survey took about 15 minutes, the interview between $30-90$ minutes, and a possible follow-up interview about 30 minutes, for a maximum total commitment of two hours and 15 minutes. The study took place at a time and place that was convenient to the participants. Interview was semi-structured and included open-ended questions that explored participants' experiences with success from high school to a four-year college (Fontana, 2008; Turner, 2010).

The researcher used social media and email to recruit Southeast Asian college graduates to fill out surveys in Qualtrics. She also conducted individual interviews with 21 of the college graduates who have completed the survey but only selected 19 interview participants for the scope of this study.

The researcher maintained a reflective journal to document emerging patterns and understandings to inform data analysis. Journal entries were made on a regular basis, including following each data collection event. An electronic cataloging system was used to track and catalog interview data. Dates, times, and pseudonyms for all interviews were recorded in the filenames.

This study uses two sources to triangulate the data: quantitative survey data and qualitative interview data (Creswell \& Plano Clark, 2011). Quantitative data were used to identify broad patterns of success of a substantial sample of Southeast Asian students (136 individuals). Qualitative data were used to unpack examples and more detailed patterns of success. 
Potential validity threats to the study are minimized by using a relatively large sample size of 136 surveys for quantitative data, triangulated with 19 interviews from the four ethnic groups for qualitative data. Interview participants were chosen from the initial quantitative phase study to follow up in the subsequent qualitative phase (Creswell \& Plano Clark, 2011).

Although the items on the survey and interview tools are unique to the target population and created by the researcher (see Appendices C and D); the contents of the items are guided by Jonassen and Rohrer-Murphy's (1999) and Roth and Lee's (2007) application of activity theory, upon which Holland et al.'s (1998) theoretical framework was based. The instruments captured the following elements: (a) demographic information, (b) motivations and perceived contradictions, (c) social and cultural constructs, (d) structures of social interactions, (e) mediators, (f) social context, and (g) system dynamics of interactions. Findings from survey data and interview data were used to describe patterns of success of Southeast Asian students, thus serving as contentrelated evidence of validity (Fraenkel, Wallen, \& Hyun, 2015).

The work of Holland et al. (1998) on identity and agency in cultural worlds of Cambodian, Hmong, Lao, and Mien college graduates may be unique to these groups. If most participants demonstrated similar patterns of success across the four ethnic groups from the survey data, then the findings would have some potential for generalization to other students within the four ethnic groups and other groups with similar characteristics. 


\section{Data Analysis}

Qualtrics was used to create an online survey form. The survey responses were exported in Excel. Quantitative analysis was conducted via Excel as the data became available. The researcher inspected the data and conducted a descriptive analysis of the variance of responses to each item on the instrument to determine the general trends in the data. The researcher then determined the distribution of the data to apply appropriate statistical analysis. The quality of the scores from the data collection instrument was also examined. Descriptive statistics were generated for all the major items on the instrument. The researcher also analyzed the data based on clustered categories of items from the survey instrument, and used descriptive statistics to address the research questions (Creswell \& Plano Clark, 2011).

For qualitative data analysis, Microsoft Excel was used to code data. In vivo coding was used to identify verbatim those data transcriptions that encapsule participant experiences (Saldana, 2013). The researcher employed descriptive and process coding to identify codes within each relevant segment of the data. Codes were stored in Microsoft Excel to be sorted, mapped, and re-coded after first-cycle coding, as the researcher rereads and reflects on the categories (Saldana, 2013). Pattern coding was used for the second-cycle coding to identify emergent themes (Saldana, 2013). Several rounds of pattern coding were used to reduce the total number of codes down to a manageable number of themes. 
Prior to conducting the interview, the researcher sent out an email to the study participants explaining the purpose and the nature of the study again and invited them to ask questions by responding to the email at marlai@mail.sfsu.edu or by calling the researcher at (415) 823-8824. The participants were then given as much time as they needed to decide whether to participate in the study, and were told that deciding not to participate would not have any negative consequences. The researcher emphasized that participation in the study was voluntary. If the college graduates decided to participate, they would be asked to sign an informed consent form (see Appendix B).

The methodology described in this chapter was designed and implemented to discover a deeper understanding of the experiences of Cambodian, Hmong, Lao, and Mien college graduates and their impacts on academic success. This study employed an explanatory mixed methods design, which focuses on a sequential approach, which applies to a two-phase approach that begins by conducting the quantitative phase and then a qualitative phase. The qualitative aspect focuses on examing the experiences and their impacts of the participants' academic success. It includes a sample of 19 college graduate partcipants. The quantitative data compare participants' key factors across each ethnic group and as a combined group. 


\section{Chapter Four: Report of Findings \\ Overview}

This chapter reports study findings. It is organized into three parts. The first section reports the college graduation demographics gathered for this study, including quantitative and qualitative data. The second part presents four salient participant narrative portraits to contextualize the findings. The third and most substantive part of the chapter reports findings on five key themes emerging from the study's data analysis, including (a) schooling experiences, (b) refugee experiences, (c) cultural expectations, (d) like-minded friends, and (e) identity in practice.

\section{Participant Demographics}

\section{Survey Demographics and Participants' Characteristics}

A total of 136 individuals participated in the survey. They consisted of four-year college graduates whose families came to the U.S. as refugees or were refugee relativesponsored. Their parents were Cambodian, Hmong, Lao, or Mien refugee immigrants. The participants attended both high school and college in the U.S., graduated, and earned at least a four-year degree. Figure 2 reports the survey data, which are made up of 57 (42\%) Cambodians, 32 (23\%) Hmong, 20 (15\%) Lao, and 27 (20\%) Mien. The following demographic characteristics were gathered: (a) gender, (b) age range, (c) highest degree earned, and (d) parents' highest educational attainment. 


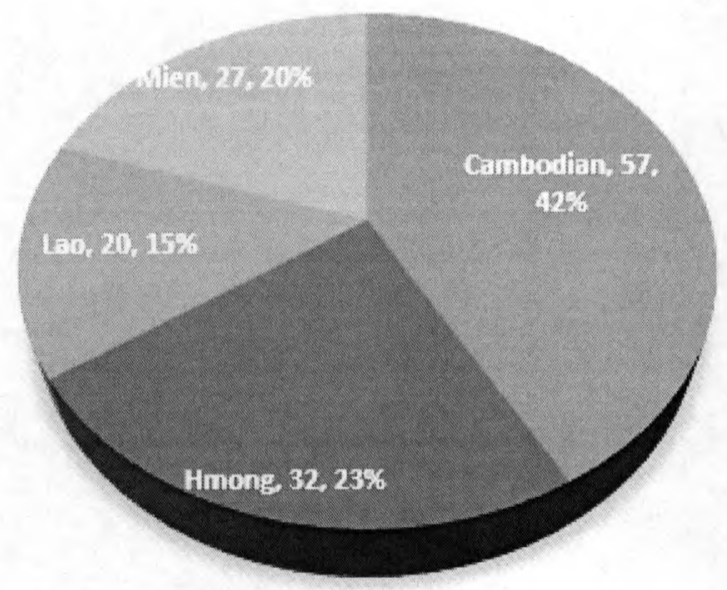

Figure 2. Total survey participants.

Gender. Of the total survey participants ( $\mathrm{N}=136), 71 \%$ were females and $29 \%$ were males. Figure 3 describes gender among the four ethnic groups. Each group shows higher response rates for female participants. Cambodian and Lao participants have the same gender distributions of $70 \%$ female and $30 \%$ male. Hmong participants have the highest female response rate of $81 \%$ female with $19 \%$ male, while Mien participants have the lowest response rate of $63 \%$ female with $37 \%$ male. 


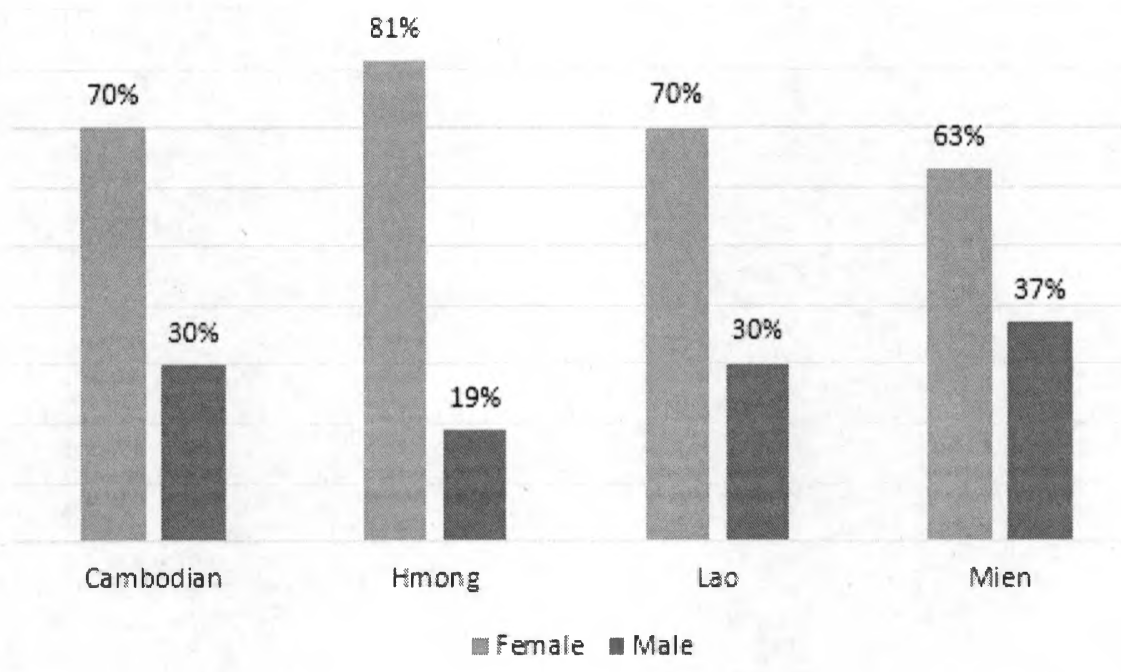

Figure 3. Gender of survey participants.

Age. While most participants are female, they are also young and have received four-year degrees within the last 12 years (Figure 4). Seventy-three percent of the participants are from 22 to 34 years of age, $23 \%$ from 35 to 54 years of age, and $4 \%$ from 45 to 54 years of age. Among the four ethnic groups, Mien participants have the highest response rate of $96 \%$, and Lao participants have the lowest rate of 55\% for those from 22 to 34 years of age. Hmong and Cambodian participants fall in the middle at $84 \%$ and $61 \%$ respectively. Conversely, Lao participants have the highest response rate at $40 \%$, while Mien participants have the lowest rate at $4 \%$ for those from 35 to 44 years of age. Cambodian and Hmong participants fall in the middle range at $32 \%$ and $13 \%$, respectively. Only a small percentage of participants across the four groups fall in the 45 to 54 years of age range. 

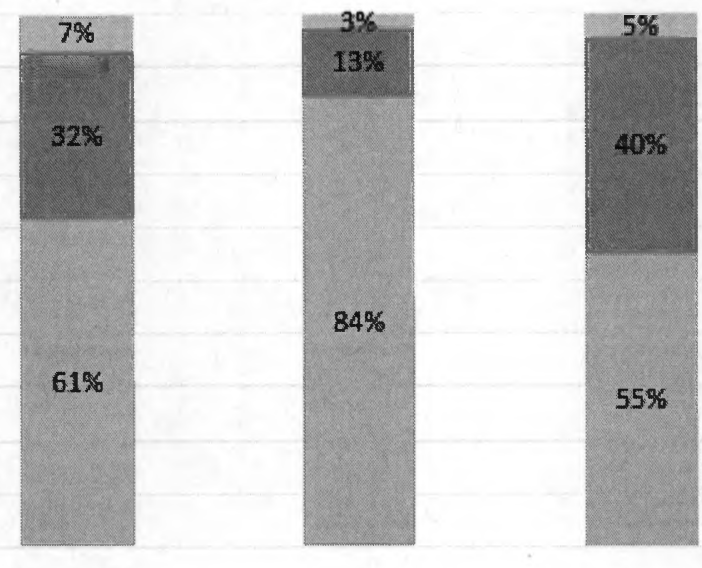

Cambodian

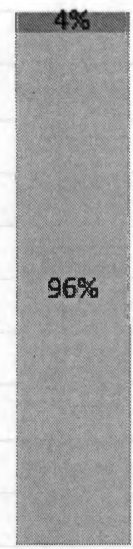

Mien

an 22 to $34=35$ to $44=45$ to 54

Figure 4. Age range in years of survey participants.

Highest degree earned. Beyond the four-year college degree, many participants $(37.5 \%)$ have earned an advanced degree (see Figure 5). Among the four ethnic groups, $53 \%$ of the Hmong participants earned a graduate degree, while only $19 \%$ of the Mien participants did so, $40 \%$ of the Cambodian participants and $30 \%$ of the Lao participants earned a graduate degree. 


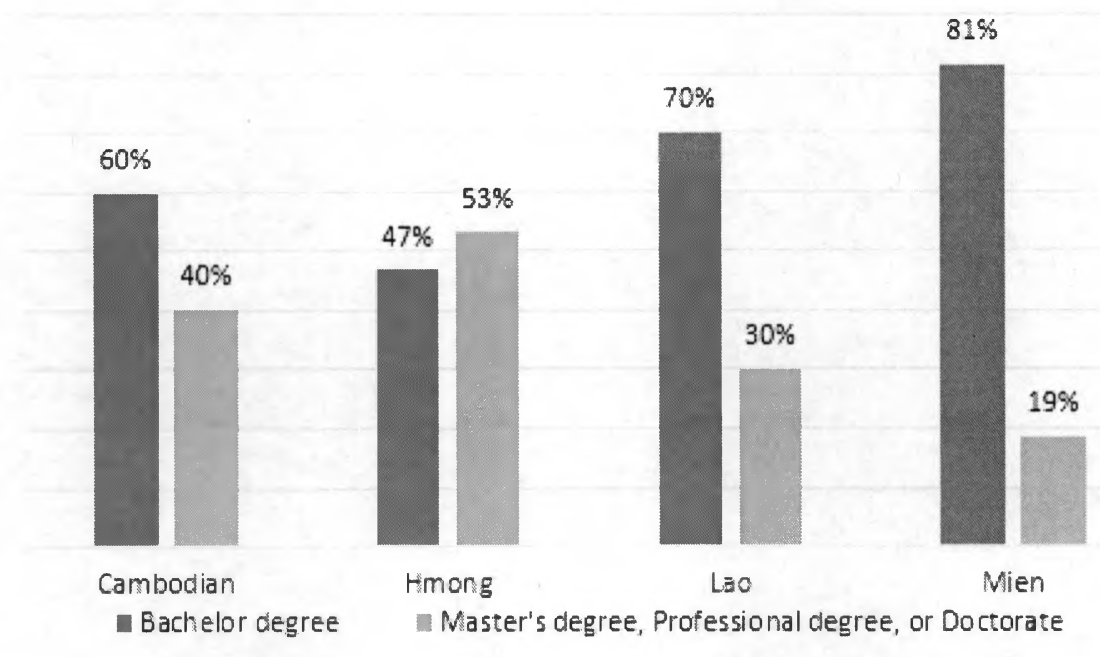

Figure 5. Highest degree earned by survey participants.

Parents' highest educational level. While $37.5 \%$ of the participants earned a graduate degree, $60 \%$ of their parents had less than a high school education (see Figure 6). Twenty-three percent of the parents completed high school and $8 \%$ completed a twoyear or a four-year degree. Two parents had a graduate degree. The Mien participants' parents had the highest percentage $(78 \%)$ of those with less than a high school education, while Lao parents had the lowest percentage at $40 \%$. Hmong parents had $72 \%$ with less than a high school education and Cambodian parents had 51\%. Lao parents graduated from high school at a $35 \%$ rate, while the Mien parents graduated at an $11 \%$ rate. Cambodian and Hmong parents graduated high school at rates of $26 \%$ and $19 \%$, respectively. 


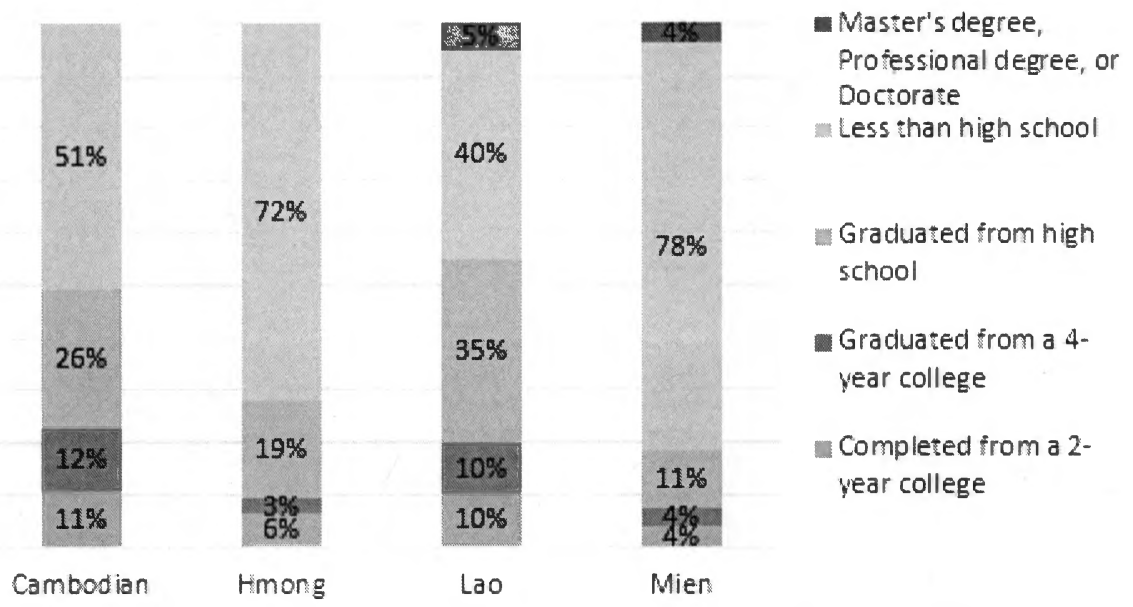

Figure 6. Parents' highest educational level of survey participants.

\section{Interview Demographics and Participant Characteristics}

The 136 survey participants were asked at the end of their survey questionnaire if they were interested in participating in an interview. Nineteen were selected from those who were interested: 5 Cambodians, 5 Hmong, 6 Lao, and 3 Mien. Fifty-eight percent of the interview participants had earned a graduate degree. Cambodian participants had all earned a graduate degree, while the Mien participants had earned a bachelor's degree. The Hmong and Lao interview participants had earned either a bachelor's degree or a graduate degree. In terms of gender, Hmong interview participants were all females, while the other three ethnic groups were a mixture of genders. As for age range, four of the five Cambodian participants were from 35 to 45 years old, while the other three groups were mostly from 22 to 34 years of age (see Table 1). 
Table 1

Interview Participants and their Characteristics

\begin{tabular}{|c|c|c|c|c|c|}
\hline Name $^{*}$ & Ethnicity & Gender & Age Range & Highest Degree Earned & Parents' Highest Level of Education \\
\hline Bopha & Cambodian & Female & 35 to 44 & $\begin{array}{l}\text { Master's Degree in Ethnic } \\
\text { Studies }\end{array}$ & $\begin{array}{l}\text { Graduated from Medical School in } \\
\text { Cambodia }\end{array}$ \\
\hline Chenda & Cambodian & Female & 35 to 44 & Doctorate Degree & Less than high school \\
\hline Ponleak & Cambodian & Male & 22 to 34 & $\begin{array}{l}\text { Master's Degree in Industrial } \\
\text { Organizational Psychology }\end{array}$ & Less than high school \\
\hline Sathea & Cambodian & Male & 35 to 44 & $\begin{array}{l}\text { Master's Degree in Business } \\
\text { Administration and Education }\end{array}$ & Less than high school \\
\hline Vireak & Cambodian & Male & 35 to 44 & Master's Degree & Less than high school \\
\hline $\mathrm{HH}$ & Hmong & Female & 22 to 34 & $\begin{array}{l}\text { Master's Degree in Marriage } \\
\text { and Family Therapy }\end{array}$ & Graduated from high school (GED) \\
\hline Kaj & Hmong & Female & 22 to 34 & Master's Degree & Less than high school \\
\hline Npaim & Hmong & Female & 22 to 34 & $\begin{array}{l}\text { Bachelor's Degree in in Human } \\
\text { Development }\end{array}$ & Less than high school \\
\hline Paj & Hmong & Female & 22 to 34 & $\begin{array}{l}\text { Bachelor's Degree in Biology, } \\
\text { concentrating in Human Biology }\end{array}$ & Less than high school \\
\hline Xia & Hmong & Female & 22 to 34 & Master's Degree in Social Work & Graduated from a 4-year college \\
\hline Bounsy & Lao & Female & 22 to 34 & Master's Degree in Education & Graduated from high school \\
\hline Doungchanh & Lao & Female & 35 to 44 & $\begin{array}{l}\text { Bachelor's Degree in Hospitality } \\
\text { Management }\end{array}$ & Graduated from high school \\
\hline Keola & Lao & Male & 35 to 44 & Master's Degree & Less than high school \\
\hline Kham & Lao & Male & 22 to 34 & $\begin{array}{l}\text { Bachelor's Degree in Art and } \\
\text { Animation }\end{array}$ & Graduated from high school \\
\hline Malayvanh & Lao & Female & 22 to 34 & $\begin{array}{l}\text { Bachelor's Degree in Political } \\
\text { Science }\end{array}$ & Less than high school \\
\hline Saeng & Lao & Female & 22 to 34 & $\begin{array}{l}\text { Master's Degree in } \\
\text { Occupational Therapy }\end{array}$ & Completed from a 2-year college \\
\hline Liuz & Mien & Male & 22 to 34 & $\begin{array}{l}\text { Bachelor's Degree in Business } \\
\text { Administration }\end{array}$ & Doctorate from the L.S. \\
\hline Lowc & Mien & Female & 22 to 34 & $\begin{array}{l}\text { Bachelor's Degree in Social } \\
\text { Work and Ethnic Studies }\end{array}$ & Graduated from high school \\
\hline Zaih & Mien & Female & 22 to 34 & $\begin{array}{l}\text { Bachelor's Degree in } \\
\text { Community and Regional }\end{array}$ & Less than high school \\
\hline
\end{tabular}

*For confidentiality, the interview participants' names have been changed. 


\section{Participant Narrative Portraits}

Four narrative portraits were constructed to represent the range of academic experiences of the participants. These narratives portray individuals from each of the study's four ethnic groups: Chenda (Cambodian), Paj (Hmong), Keola (Lao), and Liuz (Mien). These individuals were selected to represent four unique experience profiles of college attainment across the four ethnic groups. They were not meant, however, to represent each ethnic group.

\section{Chenda: A Chameleon}

Chenda's academic journey to achieve college success involved being a good child, maintaining a life balance between Cambodian and American cultures, receiving unconditional support from family, being mentored by teachers and professors, understanding the figured world of her family's diaspora, and taking advantage of educational opportunities. Equipped with this knowledge, she became involved in social justice issues during college and later attended graduate school to study public policy and earn a doctorate in the learning field.

Being a good child to the family. Chenda's mother is Cambodian and Lao, and her father is Cambodian and Asian Indian. She was brought up in the Cambodian culture, which centers around being a good child to the family. Chenda made sure to present herself in ways that reflected what Cambodian culture expected, including dying her 
brightly colored hair back to black when she attended Cambodian cultural events. She felt she had to set an example for her siblings and be responsible for her family.

Chenda's path to college included giving birth to a young child during her senior year in high school. This clashed with Cambodian tradition, which values female chastity and moral reputation (Tran, 2014). Yet Chenda was also an American teenager, and she made choices counter to her culture that challenged her parents during her high school years.

Maintaining a life balance. Chenda's strategy has been to live a balanced life between two cultures. She has come to understand the differences between the two cultures, which enables her to navigate between the two successfully. For the things that she did not understand, she took classes to learn about them. Chenda also had academic friends to keep her focused in school and neighborhood friends to make her feel at home while in high school. She credits both worlds with shaping the person she has become.

Supportive family. Chenda's family played a critical role in fostering her love of learning and reading, although they could not help her with homework. Her mother taught her the alphabet and her grandmother told her stories. Her mother also gave her rides to the different activities so that Chenda could have enriched experiences.

Mentors. Chenda's mentors were critical in directing her to take college prep courses, which gave her enough credits to get into a UC campus, even though she missed 
school for half of her senior year due to her pregnancy. The mentors introduced her to different opportunities and steered her back when she went off course.

Figured world. Chenda saw the contrast between the world of her family and the academic world she encountered in college. There she learned about her parents' history and the politics that led to her family's diaspora. Once she learned about her family's struggles and sacrifices, Chenda felt obligated to act. Chenda learned how to bridge between her family's world and the academic world. To succeed, she knew she had to assume different roles when moving between the two worlds.

Space of authoring. Chenda became heavily involved in social justice issues, which sparked her interest in studying public policy to address those issues. She cofounded a Southeast Asian student coalition, created a summer institute to introduce high school students to her campus, and organized community forums to build awareness of deportation.

After graduating with a bachelor's degree, she went on to earn a master's degree and then a doctorate. Chenda then returned to work in her community in the issue area of higher education.

\section{Paj: An Assertive Mind}

Paj's educational journey included resisting her community's cultural norms and gaining educational access with the help of a mentor. She defied the odds of not being able to vote by seeking to make an impact, and she overcame initially not qualifying to 
study abroad to eventually become funded to study in that program. She faced numerous financial and academic challenges during college. Her family's struggles inspired her to work hard, and they created pressure to avoid failure.

Resisting cultural norms. Despite Hmong community cultural norms encouraging early marriage for females, Paj avoided this tradition with the support of her father. Her parents came to the U.S. while they were still young enough to adapt to the new culture as she and her siblings were growing up, although they adapted unwillingly. The pressure of cultural change enabled Paj, her siblings, and her parents to adapt. Ultimately, Paj married later than the Hmong norm, and she married a spouse from a different ethnicity.

Educational access. Paj was in a magnet program and participated in a debate team in high school. However, her father did not understand the value of such extracurricular activities and forbade her or her siblings to participate. In the 11 th grade, however, Paj resisted her father and returned to participate in the debate team, ultimately leading the team to success in a national competition. After that success, Paj's parents became more open to extracurricular activities.

Paj wished to challenge gender roles of Hmong women and thus pave the way for her two younger sisters. She resisted her father's wishes as she realized the importance of the high school debate team. This assertiveness led her parents to allow extracurricular activities for her younger siblings. 
Mentors. Paj's mentor saw great potential in her and went out of her way to expose Paj to opportunities, significantly influencing her life decisions. The mentor convinced Paj's parents to enroll her in a magnet program so that she would be better prepared for college. She also ensured that Paj would stay focused on academic success. Ultimately, Paj became a mentor herself and returned to the school where she was once a student.

Space of authoring. Paj became politically and socially conscious during her first two years of college. She became involved in a voter registration campaign, although she could not vote herself. Paj did not let her ineligibility to vote stop her from making an impact during the 2008 presidential election. She headed a coalition to register more than 10,000 students to vote. This experience gave her added voice and confidence. Paj was subsequently funded to study in Namibia, even though she held a refugee passport that made her technically ineligible to study abroad. She was deeply impacted by her study abroad experience.

Challenges. Paj struggled financially in college because of her family's lack of resources, and she ended up taking out loans. Paj was surprised at how academically unprepared she was in math and science compared to her peers from more privileged high schools. Despite her initial knowledge gap, she was determined to overcome the challenges by increasing study time and intensity to catch up with her classmates. 
Failure is not an option. Paj was inspired by her family's struggles and wartime survival to take on and pay off loans for her own education. Her parents' survival efforts kept her motivated, but her family also put pressure on her not to fail. Paj could not talk to her parents about her academic challenges, so she sought support from other students to cope with her school struggles.

Paj now holds a bachelor's degree in biology with a concentration in human biology and she plans to apply to a medical school. She summarizes her academic journey:

I think for me, the commitment to learn academically means more than just you and a textbook, and that means being able to harness opportunities that make you more confident in the classroom. It means challenging what you're learning and thinking outside of the box, and that really means having support, having people who will support when your interpretation is different, having people like mentors who will ... open up opportunities, guide along the way, and validate me.

\section{Keola: A Second Chance}

Keola's educational journey began with a supportive Lao family. His parents kept him out of negative neighborhood effects by involving him with the family's work. He got his second chance through an outreach program, which enabled him to compare the worlds between his family and his institution. While in college he took an opportunity to study abroad. Mentors were a big part of his educational journey throughout college and graduate school.

Supportive family. Keola's parents instilled the value of family, which was the only possession they had. They encouraged their children to do their best and to work 
hard; they focused on everything that Keola and his siblings did. Keola's closeness to his family, especially his mother, helped him maintain a positive outlook.

Parental intervention. Keola grew up in a low-income neighborhood, but his parents shielded him from negative neighborhood effects by involving him with the family's work at a young age. This work limited Keola's free time, while also preventing him from experiencing the negative influences of his neighborhood. Even though he still spent time with community friends, they did not unduly influence him due to his strong family ties.

Outreach program. At first Keola was not interested in school, and it was hard for him. He was active in sports but barely graduated from high school. His path appeared to be the military or a community college. However, his sister encouraged him to apply to a California State University (CSU) campus through the Educational Opportunity Program (EOP). This offered him a second chance by providing the support he needed to succeed in college.

World making. College was a different world for Keola, and this newness became a source of motivation. He took advantage of the educational opportunity and worked hard, knowing where he came from and seeing his parents' struggles. He realized that education could give him better life chances.

Study abroad. Keola took the opportunity to study abroad. He lived in Florence, Italy, for a year. He extended his graduation and added a minor so he could study abroad. 
Studying abroad allowed Keola to learn about himself and to see life from a different perspective.

Mentors. Keola broke out from the cycle of poverty because he had mentors in his life. His mentors included family, teachers, counselors, friends, and individuals whom he worked with at EOP. Keola's EOP mentors helped him navigate college life and graduate school. They became friends and were like family to him. Keola went to work himself at EOP to offer the same support to younger students that he had received.

Keola had a strong family foundation that shielded him from negative neighborhood effects. He found a second chance to go to college through EOP, which helped him compare the worlds of his family and his univesity. While in college, he took an opportunity to study abroad. Mentors were a big part of his educational journey throughout college and graduate school. Like Paj, Keola sought to give back by working at EOP where he had once been a student.

\section{Liuz: A Survivor}

Liuz is a second generation Mien American. Although his parents earned advanced degrees in the U.S., he first had to learn from his own mistakes to see the importance of a college degree. After facing multiple challenges, he developed the drive to complete college. He credits his parents for their constant reminders to pursue higher education. 
Second generation. Liuz's parents came to the U.S. when they were young, and they went through the U.S. educational system from elementary school through university to earn advanced degrees. His mother holds a master's degree and his father a doctorate degree. Being exposed to the American culture and having attended school in the U.S., Liuz's parents were assimilated into the American culture. Being of the second generation, Liuz considers himself an American.

Liuz's parents expected him to take full advantage of all the resources available to him and pushed him toward academics. Yet Liuz did not understand the hardships his parents had experienced and took things for granted. Academics were not in his mind, and he only wanted to spend time with this friends.

The drive. Liuz did not have any particular goals while growing up, despite his parents' academic urgings. He felt it was a journey that he had to take by himself. He attended a community college and came close to being expelled, though multiple events combined to drive him toward a college degree.

Liuz's friends exerted a stronger influence on him than his parents did, despite their educational attainment. Staying connected with his friends who had not gone further in school enabled Liuz to observe their struggles, and he concluded that he did not want to follow their path. In addition, being demoted in a warehouse job and expelled from community college ultimately drove him toward a college degree. 
Professional student organization. When Liuz transferred to a CSU campus, he was angry at being away from everything he knew. He was overwhelmed with going to school full time, working, and joining extracurricular activities. At the same time, a childhood friend committed suicide. Liuz wanted to drop out, but his participation in an organization for students in his major (business) helped him persist. His friends in the group had a strong influence on him, and helped him succeed in college.

Supportive family. Liuz further credited his persistence in college to his parents, who daily reminded about the importance of getting a degree. Because his parents had gone to school in the U.S., they knew what Liuz needed to do to succeed and guided him accordingly. They influenced him to take AP courses to be ready for college.

Intentionality (making choices). Getting a college degree was not easy for Liuz. Motivation was necessary for him to succeed. He used the calendar in his phone to plan his schedule and stay focused.

Self-reflectiveness (personal agency). Liuz developed a sense of agency by recalling a recurring theme from a speaker at his father's commencement ceremony: "Keep working hard, don't expect anything from it, and in the end, everything will come to you." His college degree represents for him the hardships he had to overcome.

Overcoming personal challenges made obtaining a college degree meaningful for Liuz. It made him see that he could still have a good future if he worked to achieve what he wanted in life. 
The preceding portraits present the different paths of four Southeast Asian Americans who successfully pursued higher education. Chenda learned to balance her two cultures while Paj resisted her family's cultural norms and sought to impact political issues that other people thought could not be addressed. Keola received a second chance, while Liuz had to learn from his own mistakes before he realized the importance of ${ }^{*}$ college. They also share common themes. Having mentors and family support were important for all the participants.

\section{Findings by Theme}

Five main themes emerged from the data analysis including (a) schooling experiences, (b) refugee experiences, (c) cultural expectations, (d) like-minded friends, and (e) identity in practice.

\section{Schooling Experiences}

Three sub-themes were identified in the area of schooling experiences: (a) high school experiences, (b) transition challenges, and (c) college experiences.

\section{High School Experiences}

Key high school experiences included college prep courses, outreach programs, extracurricular activities, and teacher and counselor interactions.

College prep courses. College prep courses offered at local high schools are designed to prepare a student for college courses, and $84 \%$ of the participants took college prep courses. These participants gained access to college prep courses in multiple 
ways. Kham was tracked into the courses by his teachers beginning as early as third grade. Bounsy was tracked since elementary school through a GATE program, which pushed her into the college prep track in high school, ultimately leading her to the UC system.

Kham: My teachers told me ... there is this program that you should be in because you're really good at this. I got that in the third grade. There's even a program that taught you extra math and science for kids who could do the higher level of math and science which I did. And then at the end of the year, they would also give them extra tests. When you got those extra tests and your scores is a certain amount, you got pre-accepted into this program in middle school. And then you got pre-accepted into another program in high school.

Bounsy: Because I did well in elementary and then in middle school, I was tracked at a young age to be put in GATE classes and AP classes, and so, because of that and because I'm an overall good student and that I don't act up and I'm not disruptive, teachers and counselors paid attention to me more. And so, I was very fortunate that ... I was already pushed into a track and supported at school to go on to UC.

In addition to Kham and Bounsy, Sathea, Saeng, Vireak, Chenda were also tracked into college prep classes through various paths. Vireak, for instance, went to a better school in a more privileged area where he and all his friends were in AP classes:

Vireak: There was this certain crowd that was in all the AP classes. They all happened to be from this certain part of the city where the schooling system was much better. I was a part of that group, kind of. It was just me and a couple other immigrant kids that hung out together. I just hung out with those guys. They were my friends.

Saeng and Kham explained the benefits of being in college prep classes:

Saeng: [...high school] was already like mapped out for me in a way. I didn't really have to fight ... or to prove that I was smart enough to be able to qualify to take this class and that class. So, it's just like an almost like an unspoken 
consensus when you're in like AP classes and you're in the advanced level classes that you'd all be going to like a four-year university as opposed to going to like a two-year college or a state school. And so, ... I just chose to apply only within California and only within the UC system...

Kham: Because I went to a really smart high school [Magnet High School] and there were very smart kids plus my environment that I was in, I was really lucky to go to... A lot of the people who ran everything were super smart and ... there wasn't a lot of harassment for trying new things. I think that happens a lot in high school, especially for kids who are different. I could tell because when I took traditional high school classes that was very much like that.

On the other hand, those partcipants who were not tracked into college prep courses did not share the same experience. Kaj, Doungchanh, and Keola were the three among the 19 interview participants who did not take college prep courses in high school. Kaj did not have a connection with any of her teachers. Doungchanh was busy working at her parents' restaurant in high school. Keola was not fond of school; PE was his favorite subject.

Kaj: I didn't connect with any of my teachers from 7 th-12th grade... I have no idea because most of the teachers that I went across, they must not have thought much because there was no moment where you connect... You're ... going to the motion. You don't rock the boat. They don't pay attention to you. So, you're not the excellent student, but you're not the one that's disrupting the class.

Doungchanh: You're taking a school load and then working full time. So, I literally did not have any time to go see counselors... So, my regret is that I didn't take advantage of that a little bit more, but ... I was ... working and that's all I knew. And maybe if there were counselors and all the resources available to me, my life would be completely different.

Keola: School was always difficult for me. My favorite subject was PE. I barely graduated high school. I was a pretty good kid, and I was pretty active. In school, I did a lot of sports, but school is always difficult for me. Until I found out later 
on when I got to college that I have a learning disability like towards the end of my undergrad.

Connection with the teachers, availability of the counselors, and curriculum engagement appear to have determined whether Kaj, Doungchanh, and Keola got onto the college prep track; yet, they did not have the same opportunities as those who were in the college prep courses.

To add to the data from the interviews, $76 \%$ of the survey respondents reported taking college prep courses in high school. The Lao participants had the lowest percentage and the Miens had the highest percentage (see Figure 7). The same percentages of Cambodian and Hmong survey participants took college prep courses in high school. When comparing college prep courses taken by gender, a higher percentage of female survey participants took college prep courses than male survey participants. Mien survey participants had the largest differences between female and males, at $94 \%$ and $60 \%$. Cambodian and Lao survey participants had the smallest differences (4\%) between females and males. 


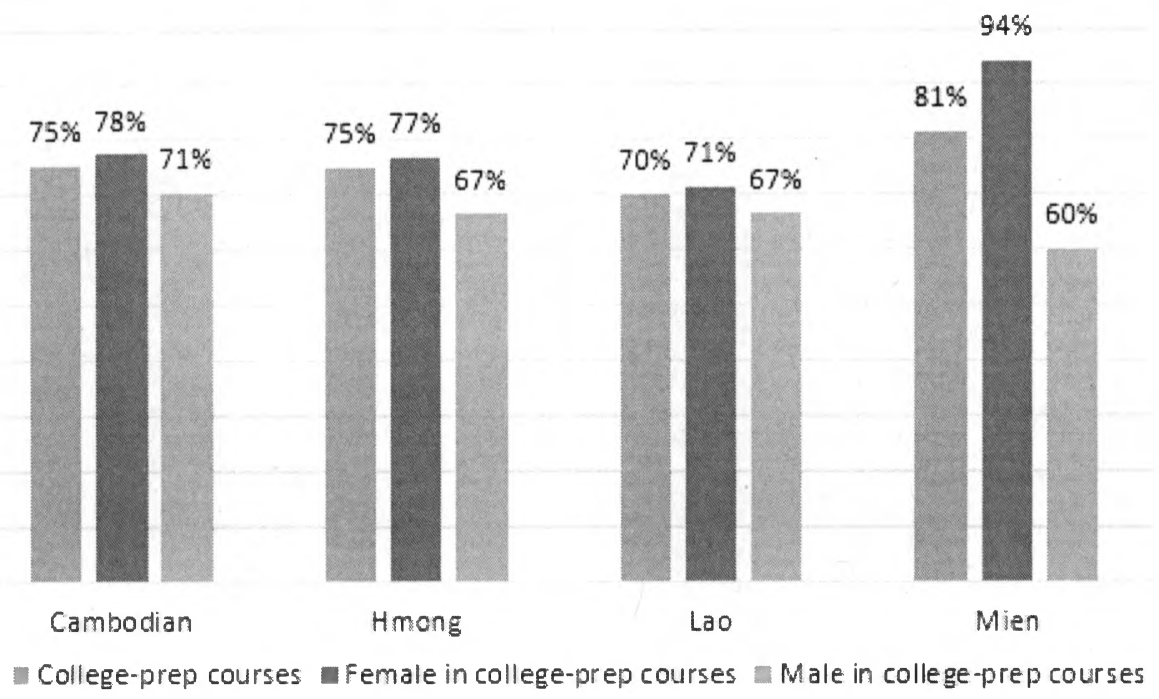

Figure 7. College prep courses by gender for survey participants.

Many of the participants who took college prep courses in high school were already tracked into college preparation beginning in elementary school. Being tracked into college prep courses challenged them and set the expectation of going to college after high school. In addition to college prep courses, some participants participated in outreach programs.

Outreach programs. Early academic outreach programs were created to reach out to students of color and to inspire and motivate them to prepare for college (Roberto, 1997; Strayhorn, 2014). Many of these programs have developed into curriculum-based programs to address the specific interests of the students (Roberto, 1997). Forty-two percent of the interview participants were involved in outreach programs, including Upward Bound, AVID, summer school, and EOP. 
Upward Bound. Bopha, Chenda, and Zaih were in Upward Bound, which gave them access to mentors, exposed them to the college environment, and helped them with the application process. They each discovered the program in their own unique ways.

Bopha: In middle school or in junior high at the time, I was also involved in Upward Bound ... that helped with the whole college and post high school process. And Upward Bound counselor has really assisted in terms of just the application, the essays, the fee waivers, et cetera. All of which was completely unknown to me otherwise.

Chenda: And he [teacher] also took interest and ... encouraged me to join a program called Upward Bound. And so, I did ... and that's when I got even more exposed to like colleges and universities.... in the summer we go spend time on university campus, classes and so forth. And then,... I got to go see colleges and universities. I don't think my parents could ever have done that for me.

Zaih: My mom ... came across that [Upward Bound flyer...] and she had me applied. But I feel like participating in that program helped me a lot ... because it provided me with some access to mentors and also counselors that were much more accessible than at [high school] because there are so many students.

These students experienced college life during high school by staying and taking classes on a college campus during summer and by visiting other colleges and universities. They also received tutoring and advising services.

$\boldsymbol{A}$ VID. Npaim was in AVID during high school, which helped her with time management, study habits, and with college selection and application. Npaim explains:

I think I wouldn't have done it without them because some of the skills that my AVID teacher was teaching me in high school. ... she taught us time management; she taught us how to organize our binders... So, that was like developing study habits. ... she made us do college research and ... not just pick our top five, but she even worked with us on how to put together a letter of recommendation folder. I think that if I didn't have their support, I wouldn't even be able to achieve my first goal of just getting into college. 
Npaim credited her AVID teacher for getting her into college. She also attributed her good study habits in college due to the time management and organization skills that she learned from AVID.

Summer school program. Kham was in a summer school program beginning in middle school. He developed his love of learning and found his best friend in the program. Kham described his summer program:

I think when I was younger like around middle school, my mom would send me to summer school which is like $\$ 40$ or $\$ 100$ for the whole summer, and there was no grade. So, it wasn't about self-esteem, how smart you were, but you got to learn new things every day. It would be like cool things about Native Americans... It was more a culture of learning and having fun. ...that's where I find my friend. ... when I was learning, I got to get away from being poor... You're definitely going to a nice school. You're going to field trips. You get to pet animals. It's not sitting at home.

Attending a summer school program was also a way for Kham to get away from his neighborhood and to build his interest of learning. He learned new things without the pressure of grades.

$\boldsymbol{E O P}$. Keola got accepted to a CSU campus via EOP and through a special admission program. This gave Keola, who had barely graduated high school, a second chance to attend a four-year college, along with the resources to succeed

Keola: EOP, that's how I got through college, is through ... a special admission in Cal State-Northridge, meaning they took ... a little bit under a hundred students whose grades weren't that good. Our test scores weren't that good, but ... they saw some hope in us. They give us a second chance [and have a...] strong EOP program... connected to all over the university. All those resources that I needed to help me, tutoring and everything else guiding me, and just as supporting me. 
Keola took advantage of this second chance by working hard to achieve success in college.

Like the interview participants, $50 \%$ of the survey participants participated in an outreach program. The Cambodian survey participants had the lowest participation rate at $42 \%$, while the Mien had the highest rate at $63 \%$ (see Figure 8 ). Female survey respondents had higher participation rate in outreach programs than their male counterparts across the four ethnic groups. Mien survey participants had the largest difference between female and male in the outreach programs at $76 \%$ and $40 \%$, respectively. Cambodian participants had the smallest difference between female at $45 \%$ and male at $35 \%$.

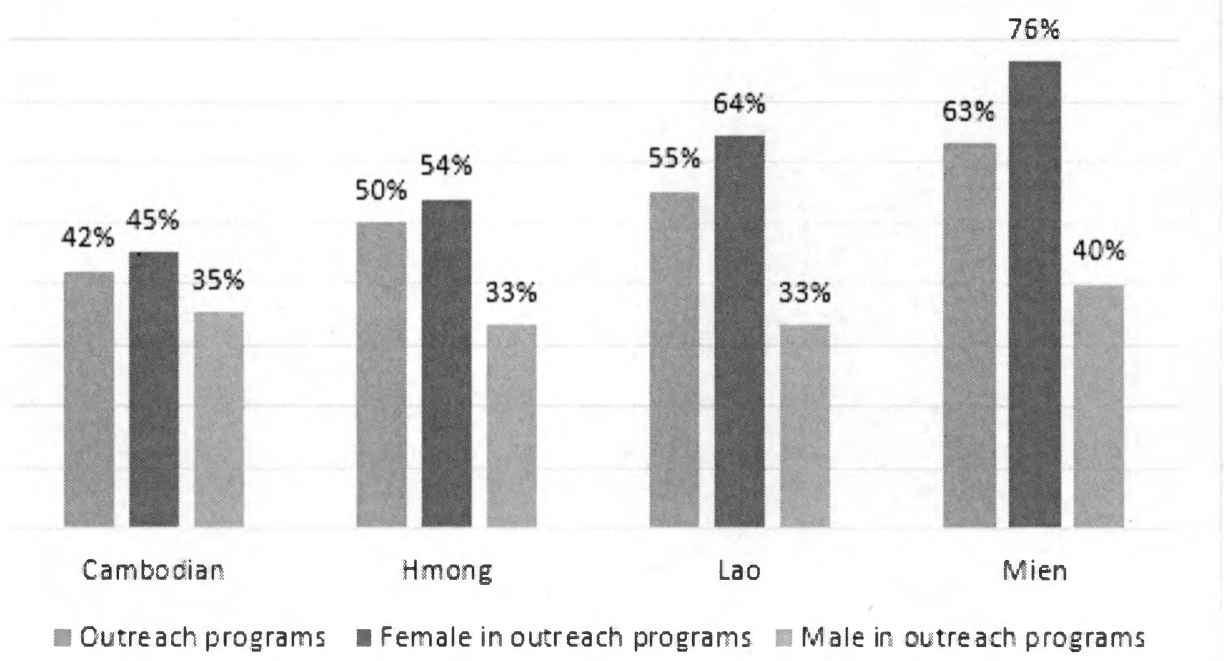

Figure 8. Outreach programs by gender for survey participants. 
However, when comparing participants in the outreach programs, $84 \%$ of them were also in college prep classes while only $16 \%$ of the participants came from general classes. All of the Mien survey participants in the outreach programs were also in college prep courses. Most of the Cambodian, Hmong, and Lao survey participants were in the college prep courses at $75 \%, 88 \%$, and $73 \%$, respectively. When comparing by gender, all of the male Hmong (2), Lao (2), and Mien (4) survey participants were in college prep courses. Sixty-seven percent of the male Cambodian survey participants also took college prep courses (see Figure 10).

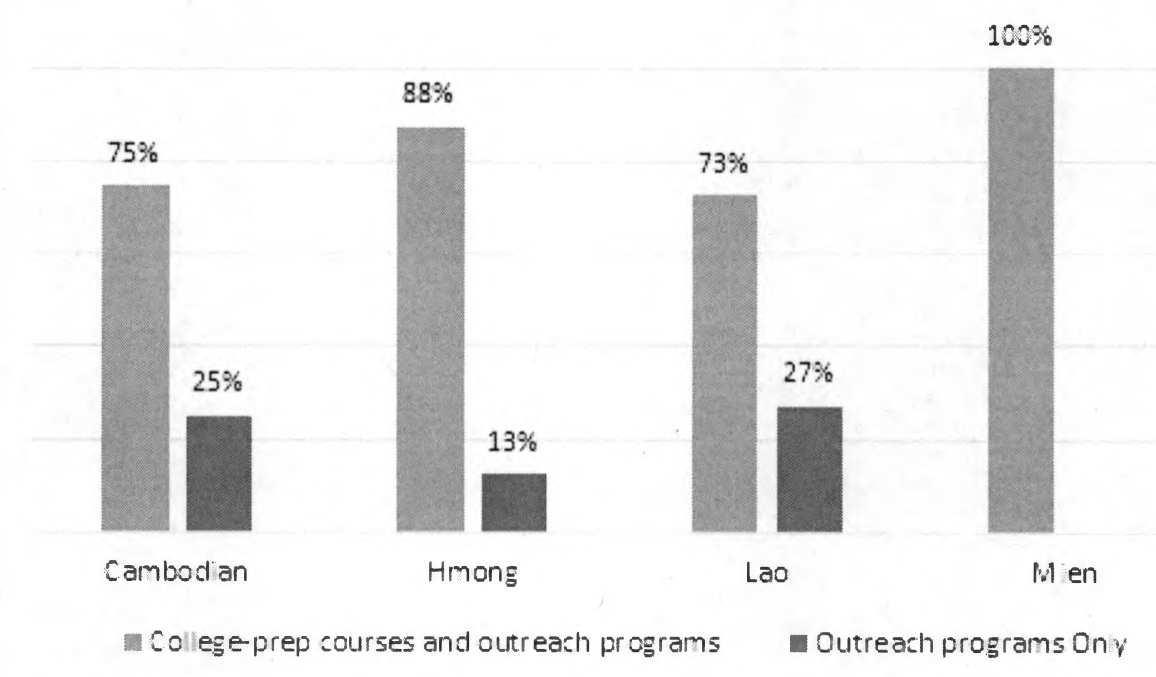

Figure 9. Outreach programs and college prep courses for survey participants. 

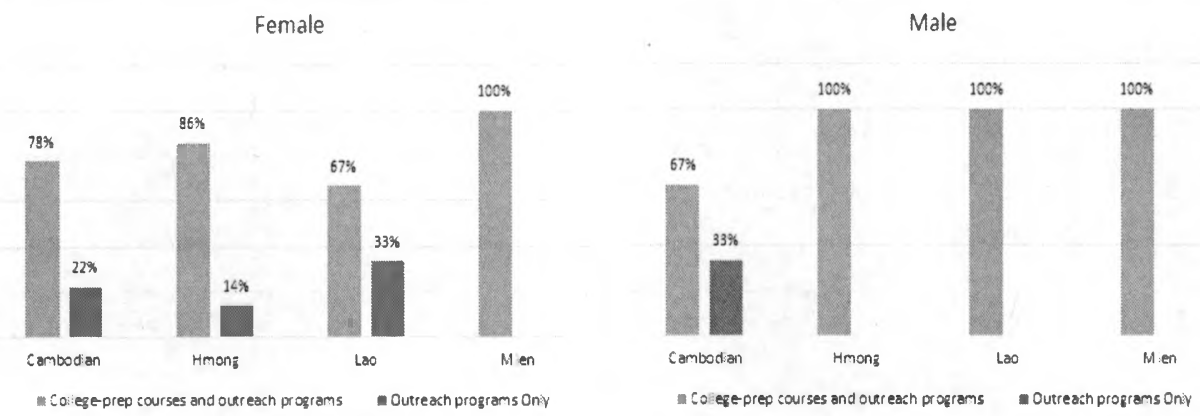

Figure 10. Outreach programs and college prep courses by gender for survey participants.

The three interview participants (Kaj, Doungchanh, and Keola) who were not in any college prep courses were also not in any of the outreach programs either. Kaj and Doungchanh ended up at a community college after high school. Kaj participated in Extended Opportunity Programs and Services (EOPS) when she attended a community college and then EOP when she transferred to a UC system. Doungchanh also went to a community college after high school before transferring to a CSU campus. She still did not have any time to see a counselor in college. She sought guidance from her friends and used free resources. Keola's path after high school was either going to the military or a community college, but his sister convinced him to apply to a CSU campus through EOP under the California State University Northbridge program. The 16 interview participants who were in college prep courses, whether they were in an outreach program or not, went to four-year universities. 
Based on these data, the students who already gained resources from college prep classes received additional resources from outreach programs. Bopha, Chenda, and Zaih were in college prep courses and in the Upward Bound program. Zaih did not really need the support from the Upward Bound program because she also had resources at her school.

Zaih: When I was in high school, ... I don't really need this program. I think I can get by myself and using resources in my high school. ... Upward Bound ... helped me in terms of relationships that I have with people, the exposure to different types of experiences. Like, they took us on a college tour. They really helped us through the application process. It's very easy to get lost in a big high school like [high school name].

Outreach programs helped students succeed in high school and transition to college. A summer school program allowed Kham to discover his love of learning that led him to pursue his passion in high school and college. Upward Bound and AVID helped Bopha, Chenda, Zaih, and Npaim prepare for their college application process and enhance their chance of getting into college. The EOP special admission program helped Keola get into a four-year college. Kaj used EOPS at a community college and EOP on a UC campus. Npaim also participated in EOP while she attended a UC campus. Lowc attended a summer bridge program for her UC campus.

Extracurricular activities. Extracurricular activities play a growing role in the college application process (Sharpe, 1999). Students are commonly advised to choose extracurricular activities in high school to influence college admissions officers (Proefriedt, 2010). 
Eighty-nine percent of the interview participants participated in extracurricular activities. Although they may have benefited personally from these activities, Chenda and Bounsy stated that they participated for the specific purpose of applying to college. They learned the importance of extracurricular activities for college applications from college prep courses, college fairs, admissions counselors, and outreach programs.

Chenda: Lots of different school activities. Oh, my gosh, it probably drove my mom crazy. I was in student government. So, throughout my years, I did the club stuff, community service; I did like Habitat for Humanity. I did those things really not because I understood it was like good to do them, there's pure inherent good, but because that's what colleges wanted to see.

Bounsy: If I only did go and work on my classes and I didn't have extracurriculars, I don't think I would've gotten in, especially because my SAT scores were also really low. And, so, without be involved in clubs, yeah, I don't think I would've gotten into a UC.

These students knew that extracurricular activities would enhance their chance of getting into college. However, Kaj and Doungchanh did not participate in any extracurricular activities.

Eighty-six percent of the survey participants were also involved in extracurricular activities. Across the four ethnic groups, the Lao survey respondents participated at the lowest rate $(75 \%)$ while the Cambodian survey participants participated at the highest rate $(91 \%)$ (see Figure 11$)$. Hmong and Mien survey participants engaged in extracurricular activities about the same rate of $85 \%$ and $84 \%$, respectively. Like the case of outreach programs, most of the students in college prep courses participated in extracurricular activities. The Lao survey participants had the lowest participation rate of 
$71 \%$, while the Cambodians had the highest rate of $93 \%$. Hmong and Mien participants had approximately the same level of participation at $88 \%$ and $86 \%$, respectively. When comparing by gender across the four ethnic groups and the three categories, a higher percentage of female survey participants had extracurricular activities than their male counterparts, except for Hmong participants (see Figure 12). All the male Hmong survey participants in college prep courses participated in extracurricular activities, while $85 \%$ of female Hmong did so.

\section{Extracurricular Activities}

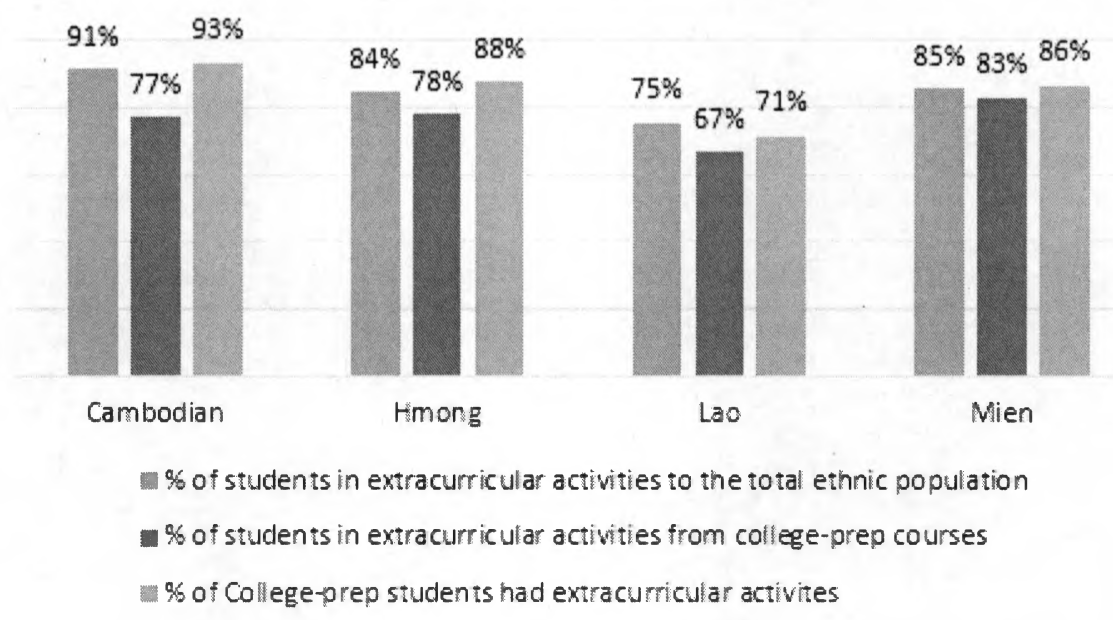

Figure 11. Extracurricular activities for survey participants. 
Female in Extracurricular Activities

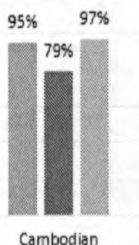

F\% of stidents in exiracurricular activities io the toral ethnic popilation

w\% of College-prep students had extracurricular activites
Male in Extracurricular Activities

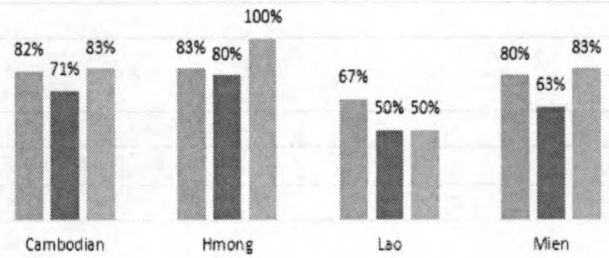

WE \% of sidents in extracurricular activities to the tota ethnic population - \%of students in extracurricular activities from college-prep courses W\% \% of College-prep siudents had extracurricuar activines

Figure 12. Extracurricular activities by gender for survey participants.

Teachers and counselors. Teacher and counselor perceptions of students impact

their interactions with their students. This section covers teacher interactions and perceptions, counselor perceptions, and student perceptions of teachers.

Teacher interactions. Students often spend more time with their teachers than with their families. Positive interactions with teachers can influence students' academic careers (Allen, Gregory, Mikami, Lun, Hamre, \& Pianta, 2013). Kaj’s teacher ingrained in her the importance of going to college beginning in elementary school. Going to college was thus a natural progression for her. Kham's teachers told his parents to put him into a program where he was taught extra math and science. This enabled him to be pre-accepted into a similar program in middle school, and then in high school. Npaim's teacher spoke to her parents about the importance of taking honors classes in middle school so that she could take AP classes in high school to prepare her for college. Sathea's teachers wrote him letters of recommendation for college, and allowed him to 
use their rooms to study. Zaih felt that her Upward Bound teacher took time to care about her and was warmer than her high school teachers.

Kaj: I think it came from my White liberal teachers. They tell you that, "go to school, make something out of yourself, go to college." You don't even know what the heck college means. That's what they just kind of say all the time, so you're just like okay. I know I have to go to college because you go to college. I think that was ingrained early on like kindergarten to 6th grade, ... go to college thing.

Npaim: So, I had this teacher that really believed in me....I remember going to open house. Not only did they coach me, but they also spoke to my parents; they're like she needs to be in these honors classes. And then, for our teacher to push us so much and for us to win [the history day competition] for the county, it just made us ... boost ... my motivation.

Chenda still keeps in touch with the teachers who were helpful during her academic career. These teachers were culturally aware and knew how to help her on her journey. She also had professors who helped her stay on track.

Chenda: I'm just grateful to the teachers; even I keep in touch now who were really instrumental. I was amazed that ... I had a history teacher who when he taught the Holocaust, he gave me extra reading to read about the Khmer [Cambodian] Rouge and asked me to write a separate paper about drawing comparisons. And one of my mentors pulled me aside ... and she told me not to lose that focus because for grad school she said, "they're not going to care how much community service."

In addition, both Chenda and Bopha had a Cambodian female professor who inspired them. This professor gave them hope to succeed because she was one of the few Cambodian professors who had completed higher education.

Chenda: And in particular there is a professor at [UC], Prof. [Kunthea] who really helped inspire me, and she's a Khmer [Cambodian] woman and that matters, you know, for individuals like me... who's connected to that. 
Positive teacher interactions can boost students' self-esteem and open doors to new opportunities that students might not have discovered otherwise. Positive interactions can encourage students to explore their own history, and Southeast Asian teachers as role models can also be quite important.

Teacher perceptions. Teacher perceptions of students can influence student academic outcomes (Blanchard \& Muller, 2015). Perceptions of students can either be helpful or harmful for students. If students are perceived positively, then they are more likely to receive attention and support from teachers. However, if teachers perceive students negatively, then students will receive less attention and support. For example, because Bounsy performed well in school, her teacher gave her attention and support. Bopha was one of the top students in her class, and she felt that this brought her greater support from her teachers.

Bounsy: She [teacher] would say things like, "Oh, here comes my favorite student" and then other teachers around her would be like, "You know there are other students around, right?" So yeah, when she wrote me a letter of recommendation for scholarship, she wrote in there, "If I had a daughter, I would want her to be just like Bounsy" and that was because I did so well in school and because I was an obedient student.

Bopha: I'm probably one of the top students, and I was well behaved. ... I felt like I did receive special treatment from teachers. They would trust me like, "Oh, ...you want to leave to go to the library? Sure, go ahead." I wasn't going to the library.

On the other hand, Bounsy's sister, who attended the same school, did not receive the same treatment from her teachers because she was not perceived positively, although 
she performed well in school and on tests. Bopha's friends with whom she cut class also failed receive positive treatment from her teachers.

Bounsy: But my sister on the other hand, was not an obedient student. She did really well in school and on tests. She was very rebellious and talked back a lot, and so, when she came into the same high school, they expected the same thing with her and when she was not like that, they would tell me like, "Your sister is very different from you, and she's not someone that we could handle" because my sister would walk out of class if she gets angry and slams the door.

I cut school every now and then. I never got punished for that and ... my friends who I cut class with didn't get the same treatment.

Most of the interview participants $(84 \%)$ perceived teachers and counselors positively in ways that impacted their academic careers. Smaller numbers of the survey participants (37\%) reported that their teachers influenced their expectations. Perceptions of their teachers' assumptions varied across the four ethnic groups. Many Hmong students (89\%) perceived their teachers viewing them as having a high academic potential, while $38 \%$ of Lao students perceived them in this way (see Figure 13). In contrast, $50 \%$ of the Lao students perceived that their teachers saw them as needing extra support while the Hmong students were perceived as not needing any extra support. 

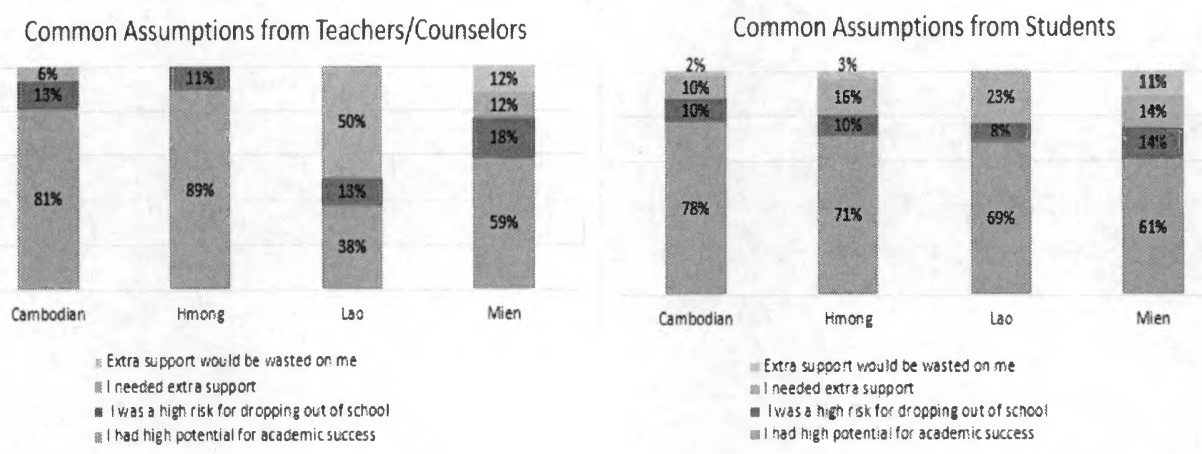

Figure 13. Common assumptions from teachers (counselors) and students for survey participants.

Figure 14 compares the teacher's perceptions by gender. Sixty-eight percent of the teachers selected were from female survey participants. Teacher's perceptions also varied by gender. Although only $32 \%$ of male students overall were selected, $100 \%$ of male Cambodian and male Hmong students were perceived as having a high potential for academic success, while $100 \%$ of male Lao students were perceived as needing extra support. These negative perceptions were unlikely to translate into students receiving extra support. 

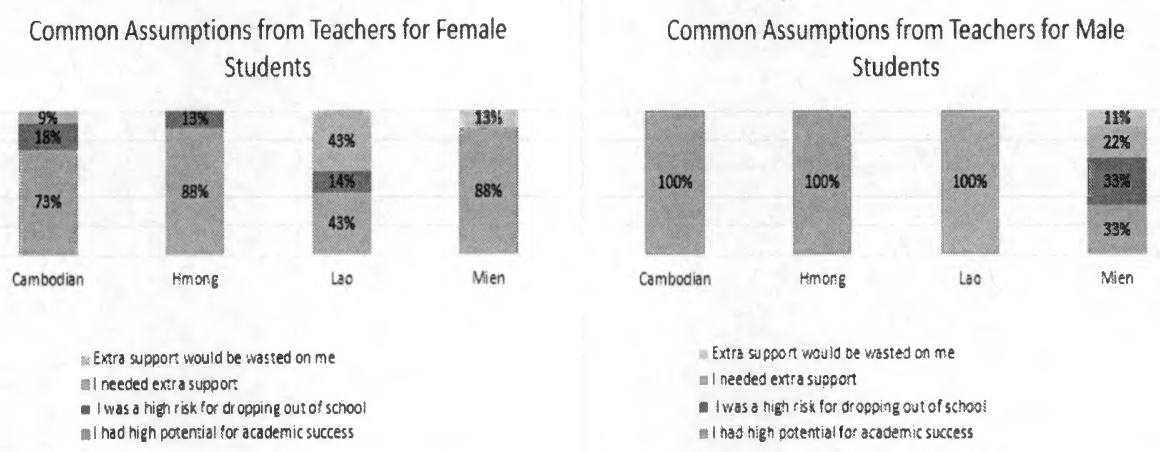

Figure 14. Common assumptions from teachers (counselors) and students by gender.

Counselor perceptions. College information does not appear to be shared equally with all students (Clark, 1998). The information shared depends on the perceptions of counselors about the student ability. College information, including scholarships, is likely given to those students who are seen as high achieving (Kaj, Hmong college graduate).

Bopha's counselor focused on her and gave her more attention because she was a high-achieving student. When she told her counselor that she wanted to apply to Ivy League schools, her counselor was fully supportive. Similarly, Hli's academic counselors encouraged her to meet with them, invested their time to learn what she was interested in, and worked to prepare her for college.

Bopha: I have to say I know that my high school counselor at the time focused much more or gave me more attention because they knew I was like a high achieving student. So, I definitely felt like I got more attention from them because I was like, "Oh, I want to apply to Ivy League schools. Oh, you're one of the few. Let me help you." I think that was definitely the case.

Hli: I've had really good counselors in high school all the way through to college. ....in high school, they would pull me to go meet with them and that I'm talking about like academic counselors. ... I remember the one from high school really 
invested in ... what you are interested in learning... and really trying to prep and prepare me for where I wanted to go for college.

By contrast, Bopha's Mien friend from Upward Bound who told her to apply to Ivy League schools did not receive the same attention from her counselor. When her friend told the counselor that she wanted to apply to Ivy League schools, her counselor told her not to set her goals so high. Bopha's other friends from Upward Bound did not receive the same encouragement from their counselors either. Moreover, Lowc's counselor never talked to her about scholarships, while Kaj did not receive any help to prepare for college or to apply for financial aid.

Lowc: I don't think I was ranked top 10 at my high school. I don't think I even understood what that meant. A lot of resources like scholarships ..., the counselor didn't talk to me about those things. Like I found out about those things after I became a college adviser, knowing that there's all these scholarships and these resources but some schools decide to give it to certain students that they feel were ... super high achieving.

Kaj: I feel like you do get lost in the system. So, there is no offer like let's go to your family or let's go visit universities. None of that was ever put out there for me because I was not in anybody's radar and I wasn't in those classes that would have prepared me or that would have given me those extra tidbit of how to apply for financial aid or scholarship.

Teacher and counselor perceptions can translate into resources that students do or do not receive. Figure 15 compares school resources and student needs among the four ethnic groups. Lao participants report receiving school resources at the lowest rate $(40 \%)$, although they had the highest level of teacher perception that they needed extra support (see Figure 13). Instead of receiving equitable resources, schools appeared to neglect Lao 
student needs at the highest rate $(25 \%)$ when compared across the four ethnic groups (see Figure 15). Cambodian, Hmong, and Mien ethnic groups received approximately the same level of school resources.

\section{School Resources and Student Needs}

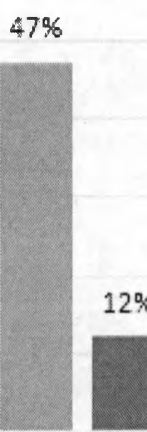

Cambodian

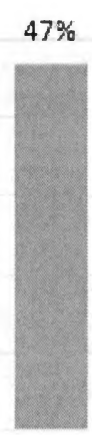

Hmong

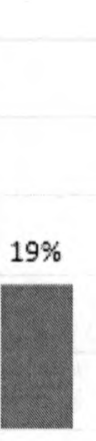

sources

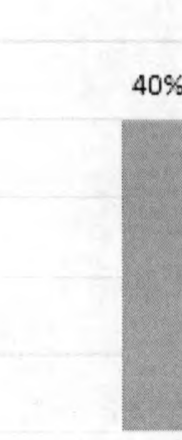

LaO
$48 \%$

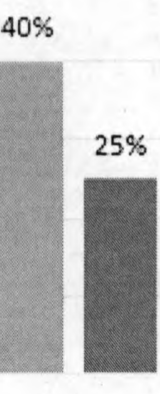

$25 \%$

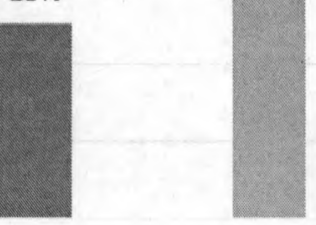

Mien

$11 \%$

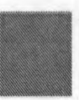

Schoolignored student needs

Figure 15. School resources and student needs for survey participants.

When comparing school resources and student needs by gender, $33 \%$ of male Lao students whose teachers perceived them as needing extra support were ignored by their schools (see Figure 16). Conversely, male Cambodian students and male Hmong students whose teachers perceived them as having a high potential for academic success received the highest percentage of school resources. Male Cambodian students received the highest percentage $(41 \%)$ of school resources and had the lowest percentage $(6 \%)$ of student needs being ignored by their schools among the four ethnic groups. However, 
female students received a higher percentage of school resources than their male counterparts across all four ethnic groups. Female student needs among the four ethnic groups were mixed. Female student needs for Cambodian and Mien were ignored at a higher percentage than their male counterparts, while a lower percentage of female Hmong and Lao student needs were ignored by their schools. Female Mien students received the highest percentage (59\%) of school resources and had the lowest level of student needs being ignored.

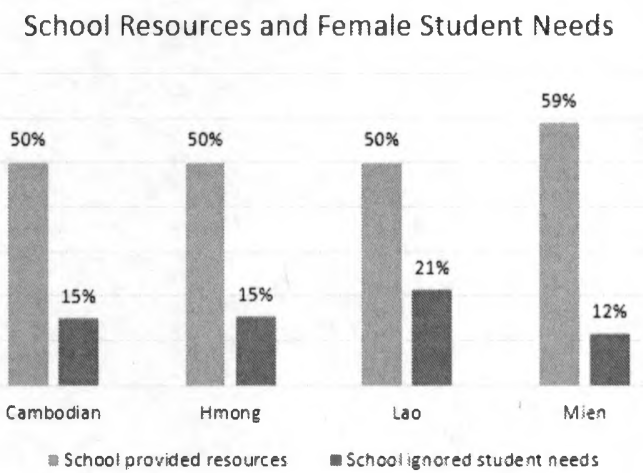

School Resources and Male Student Needs

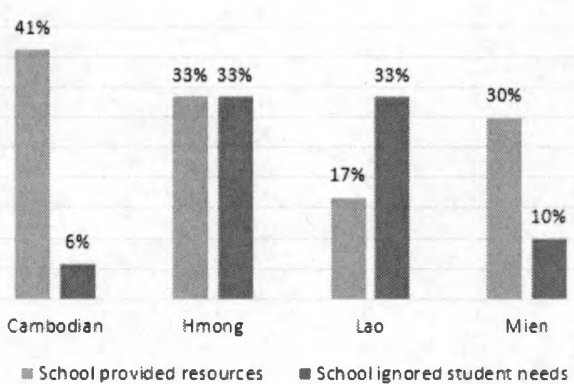

Figure 16. School resources and student needs by gender for survey participants.

Student perceptions. Teachers' opinions and actions matter to their students, which can impact their academic performance. At the same time, students interact with their teachers based on their perception of how their teachers view and interact with them. Positive perceptions motivate students to open up to their teachers and showcase their creativity. Hli could only identify five teachers of whom she had positive perceptions throughout her academic career. 
Hli: There is only like a handful of teachers. I would say ... like five of them where I actually felt like I could be honest ... and I could be myself in those academics and that I would [not] be penalized for. So, ... I had a really good rapport with them and I had a relationship that was more than just a teacherstudent relationship. You know that they actually take time to actually learn about what was important to me...

Students' negative perceptions of their teachers can shut students down. They may view their teachers as being more interested in getting the good teacher evaluations, and emphasizing academics over individual students. Students may then perform the minimum of what is asked of them. Hli had a negative perception of many of her teachers throughout her academic career. Kaj felt ignored by her teachers and counselors.

Hli: Whereas, other teachers, ... I guess they were more interested in ... getting the good teacher report or having the ... higher pathway. And so, the academics was so more important than the individual students themselves. So, ... I was just working to get the grade, and so, I gave them what they wanted. I would be more devoted to the teachers that were more accepting of what I would give than the teachers that felt like there was only one way of doing something...

Kaj: I feel like you do get lost in the system. So, there is no offer like let's go to your family or let's go visit universities. None of that was ever put out there for me because I was not in anybody's radar, and I wasn't in those classes that would have prepared me or that would have give me those extra tidbit of how to apply for financial aid or scholarship.

High school experiences were different for various students. Mostly, students who were tracked into college prep courses or attended high schools where college prep courses were part of the curriculum had more access to college information. They were told that extracurricular activities were important for their college applications. Many of these students also had extra resources from outreach programs to help them prepare the 
college application. However, the three students who were not tracked into college prep courses did not have the same level of access to college or financial aid information. These students were also not involved in any outreach programs, nor did they participate in any extracurricular activities.

\section{Transition Challenges}

The transition to college is a challenge for many students in the U.S. due to a mutual lack of respect for both school and college in terms of curriculum and expectation of student preparation (Clark, 1998). Transition to a four-year college was difficult for 17 of the 19 interview participants across the four ethnic groups, despite many of them having taken AP and honors classes in high school (Hallett \& Venegas, 2011). Their transition challenges included a curriculum gap, academic support, the quarter system, feelings of isolation, lack of cultural awareness, and emotional challenges.

Curriculum gap. The high school courses, especially science and math, that the participants took often failed to prepare or bridge them to the first classes they were required to take in college. This in turn extended the timeline for graduation beyond four

years. This curriculum gap may be seen to consist of a content gap, a structural gap, and a special treatment gap.

Content gap. The content gap has to do with the gap in academic content between high school courses and college introductory courses. Many high school courses, including AP and Honors classes, do not bridge well with the introductory courses in a 
four-year college. Sathea was advised by one of his high school teachers that he did not need to take calculus in high school. Thus, when he took calculus in college, he was competing with other students who had already taken college calculus in high school. Therefore, Sathea felt unprepared, even though he took AP and honors classes in high school.

Sathea: The transition from high school to college was actually really tough. I think that ... the public high schools don't really prepare well for college because ... I got an advice from one of my ... teachers where ... I did pre-calculus and that hurt me because ... UC calculus ... is not the first time they're taking calculus. So, they [the students] thought I was taking it in high school. I had realized even though with AP and honor classes, I wasn't really prepared for the level. It's just the rigor ... and this was on test taking; it kind of like caught me by surprise. So, I ended up leaving where I actually had 3.7 GPA when I left.

Sathea ended up dropping out from his UC campus after completing his first semester despite a high overall GPA. Subsequently, he attended community college and then transferred to a private university.

Saeng took her first chemistry class in her Junior year in high school. However, when she took introductory chemistry class in college during her first year, she suffered.

Saeng: there's like orientation, and they basically ask you what's your major, I'm going to tell you what classes you're in. ...I'm considering doing NeuroScience. And then, the girl was like, you have to take Chem 1A or else you're not going to graduate within four years. ...I took chemistry as a Junior, and ...I didn't know if I can handle that. And ... this girl was just telling me that I had to take this. I took it, and I suffered. And while ... the people around me, I don't think they knew my pain. I was initially going to do a hard major and then after ... I had to take chemistry and biology, my first year in college was really hard. 
Paj also struggled with her science and math classes. She recognized that while all the students were good, some in the class would still get lower grades. She was not sure whether she was simply bad in these classes, or if her high school had not prepared her well for them.

Paj: What challenging was academically, at least in the sciences and the math, ... putting all of the A students together, someones to get the lower grade and that's difficult ..., but I felt really oddly super prepared for the humanities portion. All of my classes ... that had anything to do with non-science or math, I felt that I really excelled... That was very surprising, ...either I was really bad at science and math or something was going on that didn't really prepare me...

Paj's first year on a UC campus was the hardest transition for her. She took introductory biology and chemistry courses in the same semester, which were notoriously hard. She struggled and received her first $\mathrm{C}$ grade ever.

Structural gap. This gap describes the differences in class structures between high school and college. Sathea, for instance, was in a calculus class of about 500 students in college, which was taught by a professor and then followed up by sessions taught by a graduate student assistant. Bopha was shy and never raised her hand in her class of a hundred students.

Sathea: My biggest struggle was trying to figuring out how to learn calculus in a public school [UC school] where they're really 500 students. So, you're just learning something on your own, and you're just going for lecture, and then you have a session where you'd have a graduate student instructor teaching you, but it's not the same as a professor teaching you.

Bopha: I really started to feel unprepared because I knew I was doing and competing with students who had private education and came with the private tutors. So, ... knowing this has totally affected my confidence in my classes and 
my academic performance. So in classes, I'm really shy. In a lecture hall of hundred students even, I never raised my hand. Even in sections where you were in a section of 20-25 students ... where your grades are based on your participation, I was always afraid to speak up because I just felt like I was not in a place academically to speak, and this takes a long time for me to build, even by the time I was in senior year, I still wasn't confident enough to feel comfortable to speak out and to speak out in sections.

Special attention gap. This gap had to do with the special treatement that students received from their high school teachers and the expectations from their college professors. Bopha was one of the top students in her class and felt that she received special attention from her teachers because she was viewed as a "good student." She felt that she often got automatic "A" grades on her papers. Yet when she got to college, she was told that her writing was not up to par.

Bopha: Once I reached college where everything was critiqued. My writing was not up to par because in high school, no one ever stopped me... You need to organize your thoughts a bit more. This isn't a coherent essay. I never really got that at all in high school. It wasn't until I got into college and it was like a slap in the face. I was being told my writing was not great. I was like, "What? What do you mean? I always got A's" because as I said, I always expected to perform well, and so, no one ever stopped me.

Academic support. Bopha felt lost in her Ivy League college because she did not have the Upward Bound program to help her anymore. She also felt unprepared because she came from a public school.

Bopha: I started to feel more lost because I didn't have this grounding and the network and the resources. I didn't know where to go. Because once I arrived, there was no more Upward Bound to tell me, "You need to go ask this person in this office for information." And I really felt unprepared in college and also because I felt I came from a public school. 
Although Bopha's Ivy League university offered a freshman program and other supports for students of color, Bopha ignored them all. She mistakenly thought that the programs would cost her money that she did not have.

Quarter system. For Npaim, the new UC campus where she studied was organized on a quarter system that seemed to zoom by. She felt that she could have done better in a semester system.

Npaim: It was like four years of just zooming by, and there's no stop. So, I feel ... I would have done better if I were to go to a college that was a semester system. But, yeah, but then I feel like I was already there, stick with it and just go through it and just finish. So, that was my motto when I went ... there... it was very fastpaced. ...I feel like I'm always barely making it. I feel like I'm always cramming for class. I'm always pulling all my night to finish a paper. It made me realize, oh, man, college is no a joke.

Feelings of isolation. College represented a big difference from high school for many Southeast Asian students, in part because they frequently came from high schools with limited resources. Xia attended a UC campus with a large proportion of White students, and Malayvanh encountered a large population of Asian-American students. They both felt that they did not belong on their campuses.

Xia: I went to college at [a UC campus]....that was a really big difference for me because ... going from a high school with ... ethnic minority made of students to [UC school] where there is a lot of Caucasians. Even though ...Asian-Americans are considered one of the higher minority groups that are represented at [UC school], I didn't feel that way because I saw a lot of Caucasian students.

Malayvanh: It was very tough being surrounded by ... the Asian population at [a UC campus] that is actually larger than the White population which is something that you don't see in the UC. So, it's like I was surrounded by the most Asians I've 
ever been. I felt like I can't connect with them because the Southeast Asian population was very very low.

Saeng also felt isolated during college, because her dormitory was filled with affluent students whose levels of privilege were expressed by the clothes they wore, the things they owned, and the resources they had to eat out regularly.

Saeng: And it's very isolating to experience that especially when you're living in the dorm surrounded by certain types of people, and you can see the privilege because of the clothes they are wearing or the things that they owned. And the things, the money that they have to eat out all the time.

Kaj's journey through higher education was lonely. Because she was not a high-

achieving student in high school, she did not have friends to study with. Her journey from high school to a community college was made alone. Yet she "gritted her teeth" and pulled herself through to get into a four-year college.

Kaj: My academic even in high school was a very solo journey. It's not like I have friends and AVID or I had friends who are like my study buddies. No, it was a very solo activity on my own Saturdays and evenings. Community college was really the case. I didn't even have that Hmong Club network. It was me going to campus, doing my classes, coming back home, and going to my work. I just did, and I just grit my teeth and just try to get through because I wanted to go to four years.

Faculty lack of cultural awareness. Xia felt intimidated by her professors. She

had a hard time explaining to her professors why she wanted to write papers about the

Hmong community. She felt that they did not understand the significance of her people.

Xia: Whenever I would write papers about Hmong people, I felt like it was really hard to make the professors understand why I wanted to write about Hmong people. Yeah, because they didn't understand the significance... I think it was just a really big difference, and I definitely feel intimidated. I think I only went to one 
office hour the whole four years that I was at [a UC campus]. And it was only because I was failing the class and went to the professor for help, but I was just really intimidated.

Paj was the only Hmong student in her program, which was filled with privileged White and Asian students. It was hard for her to connect to a support group within her program.

Paj: I was the only Hmong student in the program and the program was filled with lots of students who were White and rich or like the Chinese or the Japanese community students that are also very wealthy, and that's really hard when you're that one Hmong student who's trying to connect to a support group.

Emotional challenges. Emotional challenges can severely impact students' academic performance if appropriate support is not provided. Chenda's journey to higher education included giving birth to a child during her senior year in high school. She raised her child while in college.

Chenda: My journey also included a young child. So, I had a son [in] my senior year. So, that was also difficult to navigate. So, my college trajectory wasn't your traditional one because I was raising a child at the time I was going to school. ...having a diverse group of people who care about you and who are able to link you up to support system is important.

Fortunately, Chenda had a group of friends who linked her to a support system that enabled her to get through college. Otherwise, her college success would not have been possible.

A childhood friend of Liuz's committed suicide just as he was transferring to a CSU campus. The resulting emotional distress caused him to consider dropping out of school and returning home. He hated everyone and the school as he was away from his 
family and everything he knew. He also felt overwhelmed because for the first time in his life he was studying full time, working, and joining a professional organization.

Liuz: When I first transferred over there [CSU campus], a childhood friend committed suicide as well. So, just all of that happening at the same time was just really difficult for me, but I remember I wanted to drop out of school so bad. I wanted to go back to [city].

Emotional challenges can threaten student persistence in college because they can come on top of other transition challenges. Appropriate support can help build persistence in college.

The foregoing transition challenges were real for Southeast Asian students, especially the curriculum gap, which was felt by 17 of the interview participants. Vireak was one of the few participants who did not find the college transition challenging. His strategy for getting through college was to simply focus on the timeline that was given to him and study hard.

Vireak: I just went through the motions, went through the program. I kind of did what my friends did. I tried to find my interest. I tried to get good grades in college. I just did what everyone else did.

Vireak went to an affluent high school outside of California where rigorous courses, including AP and honors classes, were a regular part of the curriculum. His friends were also high-achieving students and came from rich families. Thus he modeled himself on his friends, and his high school appears to have prepared him well for college.

Kham also had a relatively easy transition from high school to college. $\mathrm{He}$ majored in art, where he worked on what he loved. Kham took AP classes that were 
above his level in high school. He also learned the study skills from his college prep courses and already put them into practice in college.

Kham: It [college] was much easier because in high school, I had ... all these advanced placement classes [...that] were like college based [and] were way above my level. Because I had learned all these techniques from studying ... all the time in school at college prep high school, ... when I got to the college level, I wouldn't even study for classes. It was really weird. You only have to study for maybe two or three classes. And ... I like art classes a lot because it's project based. ... I didn't have to waste my time doing AP physics or stuff like that ... because I already got a credit in it. As an art major, I could just then take all the art I wanted.

\section{College Experiences}

College was difficult, a struggle, and a lonely place for many of these Southeast Asian students. Many of them were away from their families for the first time. They no longer had their families as a support system, and they often felt isolated on campus. To survive, many reached out to other students who shared their history and struggles. These students encountered at ethnic student organizations and professional student associations, which were often activist- and social justice-oriented, and through study abroad experiences.

Ethnic student organizations. Southeast Asian students often joined ethnic student associations to remind themselves of their goals and commitment to push their community forward. Malayvanh and Kaj joined ethnic associations as a way to connect to their roots.

Malayvanh: Like in college it's so difficult and a struggle, and it was very lonely for me because I was like away from family. So, it was nice to find a group of 
Southeast Asians, so I could connect to. They're be like my family away from family.

Kaj: I'm all about ... Hmong power and ethnic studies and students of color, and I realized that's my comfort zone.... I got to meet other Southeast Asians

... and other people who go through that same struggle with you and kind of understand where you come from. It was good to also meet people who are also as passionate about bringing things back to the community. Something we always said in college was to know your history, know your roots, know your struggle not just yours but your family, you community. And if you do that you'll always come back and help out.

Professional student organizations. Some students also joined professional

student associations focused on particular professions in order to network and prepare for life after college. Malayvanh joined a student organization for her major. Liuz joined a business student organization, which helped him stay in college.

Malayvanh: besides the Southeast Asian organization, I was also president of the business organization... and I feel like that also helped me with especially finding work after college. So, I joined this business organization ... for 3 years and then got more involved and then eventually became president. And it was really good because what we focused on was like resume workshops, job interview skills, and then finding internships that will help you find a job later.

Liuz: I remember I wanted to drop out of school so bad... and the reason why I didn't do that was because of the people that I met at school from my business organization. They gave me a support system. I felt like it gave me an advantage... You gained ... these traits and these attributes based from all of these things that you're doing, realizing like in terms of time management, how to conduct yourself on other people, and how to present yourself.

Malayvanh learned how to manage personal finances, write a resume, and do a job interview through her professional organization. She also learned about people in marketing, investment bankers, and other topics. She found her first job as a business 
analyst through this network. Liuz met people at his business organization who became his support system.

Activist- and social justice-oriented. Some students were deeply affected by the injustices they saw in their communities. They sought to take what they had learned and channel their concerns into social action.

Chenda, for instance, co-founded a Southeast Asian student coalition to advocate for social justice issues. She created a summer institute for Southeast Asian high school students that organized forums to build awareness of deportation.

Chenda: I fell in love with the social justice aspect of it and ... got introduced to public policy as an avenue to address social justice issues that I cared about. And so, we started the Southeast Asian student coalition... Eight of us co-founded that to help bridge and also advocate for issues. We also created a summer institute where we brought high school students into [UC campus] to expose them. The other was around the issue of deportation. We organized ... and ... did ... forums to bring this issue to light.

In college, Chenda learned a lot about her parents' history and the geopolitics that caused her family's diaspora. Her primary goal was to build educational opportunity, because it can be an equalizer. She felt her experience was rich, because what she learned in the classroom mattered in real life.

Like Chenda, Lowc developed an outreach program to expose high school students to her UC campus and the college life experience. She also provided political and educational workshops and coordinated a high school mentorship program. In 
addition, she participated in student government, ran for the senate, and was the first

Mien senator in her college.

Lowc: We did outreach and specific program. We brought students on campus to do shadow nights and shadow days where they stayed in the dorms. We did political workshop, educational workshop that was like my first year. And then I got more involved with the Southeast Asian community... I coordinated the high school mentorship program where we met with students every Saturday. And then my senior year, I got involved in student government ... but through our community, I ran for senate and ... was the first Mien senator at UC School.

Paj was exposed in college to ideas that built her political and social

consciousness. Like Lowc, she was involved in student government. She led a voter registration campaign to register over 10,000 students to vote during the May 2008 election, although, she was not eligible to vote.

Paj: Being a refugee, you always know that there's a political thing to your life. That's the reason why your parents are displaced for like that. So, I joined the student government at [UC campus] and ... that year was also the 2008 May election... So, then I ended up being able to lead that part of the project. It was ... the day when the polls closed down, I was literally still working the poll and I couldn't even vote; and ... if all these folks voted, then ... that makes up for one of us not being able to vote.

Social justice issues emerged across the four ethnic groups as members of each group were involved in community organizing and exposing high school students from their communities to their campus life. They also advocated for their communities on social issues.

A supportive campus network. Because college campuses can be lonely places for Southeast Asian students, having a community of other students that shares the same 
struggles enables them to feel connected and safe on campus. Saeng met a network of ten students from the four ethnic groups in her freshman year and remained connected to them, for all four years of college. Chenda's supportive community stretched beyond the four ethnic groups. She took the chance to include people from a range of backgrounds who genuinely cared about her. She called them her "personal board of directors."

Saeng: You come to the realization really fast about how different you are from the people there. And, in terms of like seeing culture as well as like your socioeconomic standing. So, my sister who had already been at [a UC campus] for two years decided that ... we should join like the Lao club on campus. ... And so, we did and ... that was my freshman year .... There were probably like ten of us: ... Lao people, ... Cambodian [people], ... Hmong people, and Mien people. And so, ... I was active in that for my whole four years.

Chenda: I always talk about this concept of having a personal board of directors. ...you find people that challenge you in different ways, but who genuinely ... care about who you are and how you develop. I think that's ... a great blessing of life. ...creating this personal board of directors is taking a chance and knowing that it can't be with people who look like you or from the same background as you. A lot of the people in my life that helped me have been like White men and sometimes White Republican men.

A supportive community did not always mean simply associating with other students from the same ethnicity on campus, though support groups were mainly found from among the four Southeast Asian ethnic groups. Southeast Asian Student Coalition groups also appeared to offer a consistent platform for students to work together and encourage each other to persist in college.

Mentors. Mentors are individuals who care about a person and want the best for the person and person's family. They articulate high expectations, alert one to 
opportunities, and steer one away from obstacles. Chenda's mentor was a professor who emphasized the importance of grades, while Paj's mentors helped her with life choices such as avoiding early marriage and to pursue programs outside of her neighborhood.

Chenda: And I think she [professor] gave me the best advice. Make sure your grades don't slip because grad school - the story you tell about all these stuff you did isn't going to matter if you have like a 2.0 GPA. I felt like that was the best advice. So, it impacted me in the sense that it got me to a point where I almost lost track of my experience, but again I had to say, I was just lucky to have people to be able to be like let set you straight when you kind of veer off your path.

Paj: I was excited that a lot in some ways ... of the life decisions and opportunities that l've been exposed to and taken advantage of [came from] these mentors in life. They really ... expected a lot, and I think they saw so much potential, and they wanted to make sure that I didn't stumble on things like, for example, get married too early and not be able to pursue these things. Mentor pushed me into the program; although the program was out of the neighborhood.

Study abroad. Although students who do not come from privileged backgrounds may tend to refrain from studying abroad because of the expected higher costs and limited benefits (Lörz, Netz, \& Quast 2016), Keola and Ponleak, for instance, took the opportunity to study abroad during college. Keola lived in Florence, Italy, for a year. He extended his graduation and added a minor so he could study abroad. Ponleak studied in the South of France for a year, while adding a second major in French.

Keola: I ... took the opportunity to study abroad. I lived in Florence for a year. ... because ... I'm a refugee [and] if you would have told me [when] I was in high school that I would be able to live in another country and travel the world, I would have thought you were crazy. ... when I went to study abroad, I extended my graduation because I wanted more experience in my undergrad. So, I picked up a minor, so I could study abroad. I was already in my mid 20 s. I was older than a lot of them [other students], but I grew and learned so much being out there. 
Ponleak: during the winter break, I went to France for vacation. I thought it was pretty good so when I came back, I started to take more French classes. And I ended up actually going to study abroad in France for a year. In the beginning, it was definitely hard .... After that month, I definitely felt comfortable taking the bus, going to the supermaket speaking French. And then since I had taken a lot of French classes, I also decided to double major in French. It was definitely fun, a life-changer.

In summary, the Southeast Asian students' schooling experiences started in high school, and the types of courses they took influenced their overall schooling experiences. If they were tracked to AP and college prep classes, as was the case for most of the participants in this study, they had access to the college information. They learned the importantce of extracurricular activities and external outreach programs to enrich their experience for the college application. Because they were in AP classes, they were also perceived as high-achieving students. This perception led to enhanced resources and tracking leading to admission to research-level universities. Those students without access to college prep classes could feel lost in the educational system during high school and could be tracked toward the military or community colleges. Two of the three students who did not have college prep classes went to a community college and then transferred to a four-year campus, following a lonely academic path. A third student found a second chance through EOP.

Once in college, most participants still felt unprepared, despite their academic backgrounds. Many found that their sequence of high school classes did not bridge well with college courses. This sometimes prevented them from graduating within four years. 
They often felt isolated on campus, and they sought to overcome this by connecting with other students of similar backgrounds. Some of the students had mentors who guided them on their paths and introduced them to a range of opportunities. In addition, being involved in their communities motivated many of them to persist in college.

\section{The Refugee Experience}

The refugee experience emerged as a significant finding involving four major subcategories: (a) refugee resettlement and migration, (b) family struggles, (c) family successes, and (d) keys to academic success.

\section{Refugee Resettlement and Migration}

Once Southeast refugees were admitted to the U.S., the Department of State worked with multiple domestic non-profit organizations to resettle them (Department of State, January 20,2017). Many of these organizations were concentrated in the Northeast, Florida, and California. The decision to place specific refugee families is determined by the Department of State and the resettlement organizations based on information obtained from interviews, security screening, and medical screening. Whether refugees had relatives living in the U.S. was also taken into consideration. Below are some of the ways that the families of students in this study were resettled in the U.S.

Vireak: I believe it was a combination of being sponsored by one of my dad's cousins, as well as the Mormon Church.

Hli: I think it was a church who sponsored them [parents] to come to America. 
Doungchanh: We were sponsored by the church and then I had an uncle that was in Canada that was trying to help expedite that also because he was a sponsor also.

Lowc: They [parents] got here in '86. So, they came here as refugees, but they actually had at that point ... to have a sponsorship. So, we had some family friends that actually sponsored my parents and the Catholic church that both sponsored my parents to come to the U.S.

Gordon (1987) observes that the placement of Southeast Asian refugees was also driven by the preferences of federal policy-makers, who encouraged the dispersal of Southeast Asian refugees throughout the U.S. to speed their assimilation and ease the impact on individual communities. This pattern is supported by data from the participants in this study.

It is also evident from the data in this study that the services the participants' families received did not appear to be sufficient for all family members to be able to transition successfully to life in the U.S. or enable them to become self-sufficient as expected by the government.

Xia: So, I've spoken to my dad ... and he said that the International Rescue Committee (IRC) helped them when they first got here. So, he said that the help that they gave was not helpful. ...they supplied them with all the material things that they needed like forks, spoons, and plates, [and] bikes, but he said that all the basic skills to survive here in the U.S., they were not taught. ...they didn't even know where to go to buy certain things.

Zaih: It was hard. They [parents] didn't speak the language. It was just challenging navigating a different world. My father's family is in [local city] so I think maybe that's part of the reason why [we moved]. They didn't have much money, so we were living in not great neighborhood where there's some violence and some crazy people. We turned into welfare. 
Many refugee families had to move to be with their relatives and ethnic communities to help them navigate in a new world. Many of the refugee families in this study were initially placed away from their relatives and from their ethnic communities. This caused them to move once they were resettled in a pattern of secondary migration (see Table 2). Four families migrated to be with their relatives and to use them as their support system while navigating the new country. Five refugee families moved to be with their ethnic community, so that they could be with the people who spoke their language, to gain access to the resources of those who had arrived in the U.S. earlier, or for job opportunities that would not require English language skills. Hli's family, for instance, moved from New York to Oregon, and then to California. They did so to obtain more public assistance, to find a place to practice their religion and culture, and to access community services. Kaj's family moved to get away from religious conversion efforts by their sponsors and to gain access to money for education. Only one family out of 15 , Doungchanh's, reported that they did not migrate to another place. Doungchanh's family was already placed in a diverse community with ethnic community resources (see Table 2). 
Table 2

Interview Participants' Family Refugee Resettlement and Migration

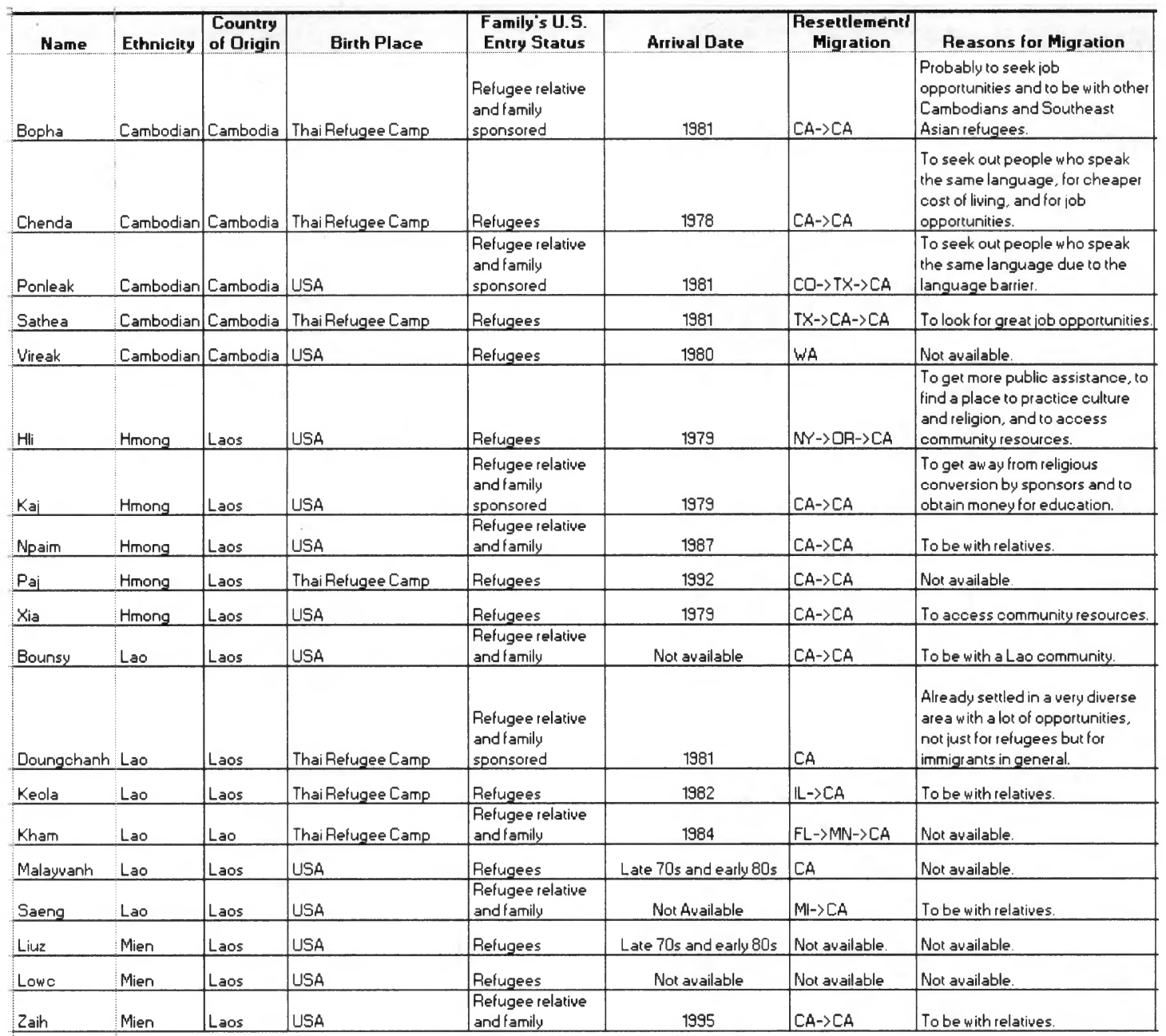

Refugee status. Of the 19 refugee college graduates in this study, seven (37\%) were born in Thai refugee camps but arrived in the U.S. at a very young age. The rest (63\%) were born in the U.S. In comparison, $54 \%$ of the survey participants were born in the U.S. A higher percentage of the Hmong (63\%) and Mien (70\%) populations were 
born in the U.S. than the Cambodian (46\%) and Lao (40\%) populations (see Figure 17). Refugee children were not only born in their country of origin and in Thai refugee camps, but one Cambodian survey participant was born in a refugee processing center in the Philippines.

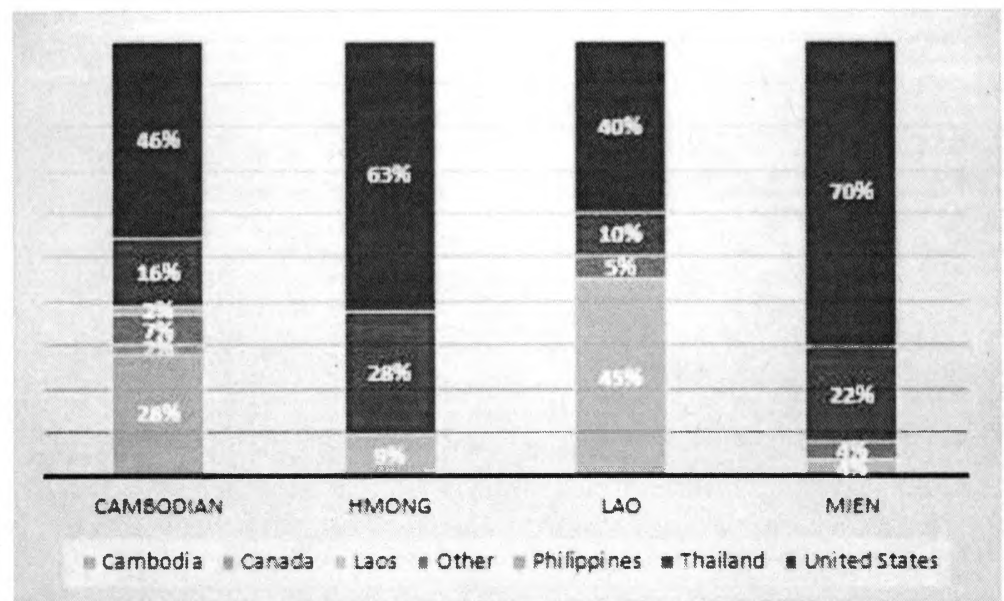

Figure 17. Survey participants' birth country.

The participants' families arrived in the U.S. between the late 1970s and the mid1990s as refugees or "refugee relative family-sponsored." For those who came through under the refugee relative and family-sponsored category, they were eligible for refugee benefits (see Figure 18). 


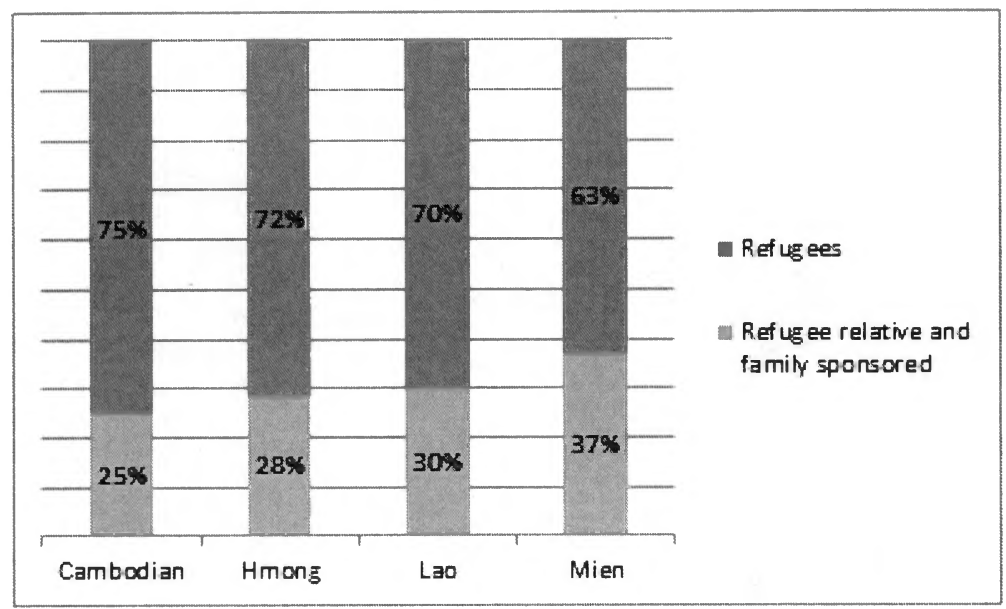

Figure 18. Family's U.S. entry status of the survey participants.

\section{Parents' Struggles}

This section describes the following major barriers that Southeast Asian parents experienced in the U.S.: (a) language barriers, (b) financial barriers, (c) educational barriers, (d) and mental health issues.

Language barriers. Learning the English language was the biggest challenge across all the 19 participants' families, except for one participant's family whose parents had gone to school in the U.S. and attained advanced degrees. Six (32\%) of the 19 participants' parents knew some level of English (see Table 3, Table 4), which is in line with the survey responses at $32 \%, 30 \%, 33 \%$, and $32 \%$ for Cambodian, Hmong, Lao, and Mien participants' families (see Figure 19).

Chenda's mother, for instance, could speak enough English to get by. Npaim's father knew some English and found work. Xia's father worked hard to learn English. 
Keola's mother spoke English better than his father, and they worked in different jobs. Like Keola's mother, Saeng's mother spoke English better than her father, and both of her parents were working. Lowc's father went to high school and worked in different jobs. Lowc's mother was not fluent in English and found work as a nanny. Many parents often relied on their children to translate for them. Hli, for instance, had to translate for her parents while growing up. Knowledge of English played a key role in determining job access for the families in the study

Financial barriers. Because of language barriers, many family members could not find jobs or worked in low-paying jobs that led to reliance on public assistance. Approximately one third of the survey participants' families relied on public assistance (see Figure 19). Thirty percent of the Hmong survey participants' families depended on public assistance, $28 \%$ of Lao and Mien, and 25\% of Cambodians. Yet, the assistance they received was generally not enough to support their families. They had to work to supplement their income or to get off the public assistance. Many families ended up living in low-income neighborhoods, public housing projects, or Section 8 housing (rental housing assistance).

To make ends meet, many parents worked in multiple jobs and had relatives watch their children while working. Some parents could not hold stable jobs, but some held multiple jobs. Kham's mother worked in three different jobs while taking care of five children and a grandmother, which left Kham and his siblings home to themselves 
with no role models. Paj's mother had to work at two different jobs at one point; the only time Paj saw her mother was before 6:00 a.m. Many parents worked in jobs such as seamstresses; clothing, food, and vegetable sellers; house-keepers; maintenance workers; and farmers.

Because refugee families struggled financially, some families had their children involved in their work, including picking fruit, selling vegetables at farmer's markets, selling food, and cleaning houses. Some children had to work during high school to earn spending money and help parents pay bills. Sathea, for instance, worked full-time from 3:00 p.m. to 11:00 p.m. as a janitor during high school. Vireak worked at his parents' donut store beginning in fourth grade, and subsequently worked as a bag boy at a grocery store at the age of 15 or 16 . Kham worked in high school on weekends.

Because of the language barrier and low-skilled jobs and the lack of finding jobs, refugee families suffered financially. To make ends meet, they used all their resources, including their children.

Educational barriers. Refugee parents were required to attend adult English class when they resettled in the US. Sathea's mother participated in California's Greater Avenues for Independence (GAIN) Program, which was required to keep her public benefits (see Table 3), but it did not lead her to be self-sufficient. Bopha's father had a medical degree from his country but could not pass the medical exams to restart his medical studies. Because he was already educated from his country, he changed his 
career path from being a medical doctor to an accountant. Paj's father attended night classes and enrolled in a pharmacy tech program. Chenda's mother studied and did homework with her children. Kham's mother went back to school 12 years after resettlement and became a nurse. The rest of the parents were busy working multiple jobs to make ends meet and had no time to continue their education.

Mental health issues. Mental health issues have been reported to be common among refugees, especially Cambodians (Ngo \& Lee, 2007; Um, 2003; Yang, 2004). One of the 19 participants' parents had mental health-related issues compared to $17 \%$ of the total survey responses (see Figure 19). Comparing across the four ethnic groups, Cambodian refugee families had the highest rate of reported trauma-related ailments at $21 \%$, while Lao refugee families had the lowest rate at $11 \%$. Mien and Hmong refugee families were at $18 \%$ and $12 \%$, respectively. Ponleak's family experienced traumarelated issues; his mother tended to worry excessively. She worried about simple tasks, such as driving home and going to the mall or the supermarket, and she got anxious about getting lost, getting in an accident, or navigating the roads of her city. 
Table 3

Parents' Struggles for 19 Interview Participants Part 1

\begin{tabular}{|c|c|c|c|}
\hline Name & Ethnicity & $\begin{array}{c}\text { Country of } \\
\text { Original }\end{array}$ & Parents' Struggles \\
\hline Bopha & Cambodian & Cambodia & $\begin{array}{l}\text { 1. Language barrier: Mom and dad didn't have much English. } \\
\text { 2. On welfare: Deficiency in English affected the ability to find work. } \\
\text { 3. We were getting Section } \$ \text { Housing. } \\
\text { 4. Educational barrier: Dad wasn't able to pick up on his medical degree. } \\
\text { 5. Dad didn't want any associatizon with Cambodia. }\end{array}$ \\
\hline Chenda & Cambodian & Cambodia & $\begin{array}{l}\text { 1. Language barrier. Mom's English is pretty good to get by. } \\
\text { 2. Grandmother helped to take care of us and looked after us. }\end{array}$ \\
\hline Ponleak & Cambodian & Cambodia & $\begin{array}{l}\text { 1. Both parents were working all the time, counting on relative to watch over bids. } \\
\text { 2. Mom was selling clothes through temple and Cambodian network. } \\
\text { 3. Dad had a hard time adapting, went back to Cambodia. } \\
\text { 4. Mom worried exces sively. }\end{array}$ \\
\hline Sathea & Cambodian & Cambodia & $\begin{array}{l}\text { 1. Language barrier: Mom didn't work due to a huge. } \\
\text { 2. Mom attended G.AN program to keep public benefits. }\end{array}$ \\
\hline Vireak & Cambodian & Cambodia & $\begin{array}{l}\text { 1. Language barrier. Paents didn't speak English and couldn't read very well. } \\
\text { 2. Parents struggled with how to give me a good education. } \\
\text { 3. They struggled with just American ideologies. }\end{array}$ \\
\hline Hli & Hmong & Laos & $\begin{array}{l}\text { 1. Language barrier. } \\
\text { 2. On welfare. } \\
\text { 3. Access to Westem medicine. } \\
\text { 4. The legal system. } \\
\text { 5. A very different world from what they grew up in. } \\
\text { 5. The technology its elf }\end{array}$ \\
\hline $\mathrm{Kaj}$ & Himong & Laos & $\begin{array}{l}\text { 1. Language barrier. Parents took ESL adult classes. } \\
\text { 2. Parents became farmers }\end{array}$ \\
\hline Npaim & Hmong & Laos & $\begin{array}{l}\text { 1. Language barrier: Dad knew some English and found work. Mom took care of hids at home. } \\
\text { 2. Mom worked as housekeeper. } \\
\text { 3. Mom constantly dropped off bids at different schools. }\end{array}$ \\
\hline $\mathrm{Paj}$ & Himong & Laos & $\begin{array}{l}\text { 1. On welfare: Mom didn't go to school or work but dad and siblings went to school. } \\
\text { 2. Parents were depressed over financial things. } \\
\text { 3. Mom worked two jobs at some point. Only time to see mom was around } 6 \text { a.m. } \\
\text { 3. Dad worked as a security guard at assembly line jobs. }\end{array}$ \\
\hline $\mathrm{Xia}$ & Hmong & Laos & $\begin{array}{l}\text { 1. Language barrier. Dad worked really hard to learn how to speak English. } \\
\text { 2. Dad sent the majority of money he made to his family in Thailand. } \\
\text { 3. Dad would drive illegally without his license. } \\
\text { 4. Parents experienced some discrimination early on. } \\
\text { 5. Family was on the government assisitance for a few years. }\end{array}$ \\
\hline
\end{tabular}


Table 4

Parents' Struggles from 19 Interview Participants Part 2

\begin{tabular}{|c|c|c|c|}
\hline Name & Ethnicity & \begin{tabular}{|c|}
$\begin{array}{c}\text { Country of } \\
\text { Original }\end{array}$ \\
\end{tabular} & Parents' Struggles \\
\hline Bounsy & Lao & Laos & $\begin{array}{l}\text { 1. Language barrer: Fard for parents to get jobs. } \\
\text { 2. Mom worked as a card club manager. Dad had his own video store. } \\
\text { 3. Parents didn't have much money, had to apply for footstamp and Medical assistance. }\end{array}$ \\
\hline Doungchanh & Lao & Laos & $\begin{array}{l}\text { 1. Language barner: Parents are smart people; we re going to make it no matter what. } \\
\text { 3. On welfare: Family on welfare for several years. } \\
\text { 4. Mom went to work at Thai restaurants. Mom continued to work in Kitchen. Dad worked in } \\
\text { maintenance. }\end{array}$ \\
\hline Keola & Lao & Laos & $\begin{array}{l}\text { 1. On welfare : Family was on welfare for several years. We lived on wellare but still that wasn t } \\
\text { enough. } \\
\text { 2. Mom spoke better English than dad and did a different bunch of jobs. } \\
\text { 3. Mom worked and I helped her when I got older; cleaning house, selling Lao food. }\end{array}$ \\
\hline Kham & Lao & Lao & $\begin{array}{l}\text { 1. Mom worked three jobs, including a lot of night shifts. } \\
\text { 2. Home is chaotic. Mom worked; bids were home in charge of the house with no role model. } \\
\text { 3. Father died three months after arrival. Mom had to raise five bids and grandmother. } \\
\text { 4. Mom was on welfare. }\end{array}$ \\
\hline Malayvanh & Lao & Laos & $\begin{array}{l}\text { 1. Language barrier: Kids had to figure it out for parents; even when we're really young because we } \\
\text { bnew more English than they did. } \\
\text { 2. We never really grew up with our parents because they were always working. }\end{array}$ \\
\hline Saeng & Lao & Laos & $\begin{array}{l}\text { 1. Language bamer. Dad s English wasnt very good and mom leamed to speak Englash better. } \\
\text { 2. On welfare: Parents were on welfare for a while. } \\
\text { 2. Parents worked various shifts, including night shilfts. }\end{array}$ \\
\hline Liuz & Men & Laos & $\begin{array}{l}\text { 1. Parents got to the U.S. young and attended elementary and middle school in the U.S. } \\
\text { 2. Mom got a bachelor from (UC school] and dad got a doctorate from [private university]. } \\
\text { 3. Mom and dad were working. }\end{array}$ \\
\hline Lowc & Mien & Laos & $\begin{array}{l}\text { 1. Language barrier. Not being able to speak the language, it's hard for you to be able to get a job. } \\
\text { 2. Mom is not super fluent in English, and so she works as a nanny. } \\
\text { 3. Dad went to high school and he speaks English to be able to get different jobs. }\end{array}$ \\
\hline Zaih & Mien & Laos & $\begin{array}{l}\text { 1. Language barmer. They didn t speak the language. It was just challengyng navigating a different } \\
\text { world. }\end{array}$ \\
\hline
\end{tabular}




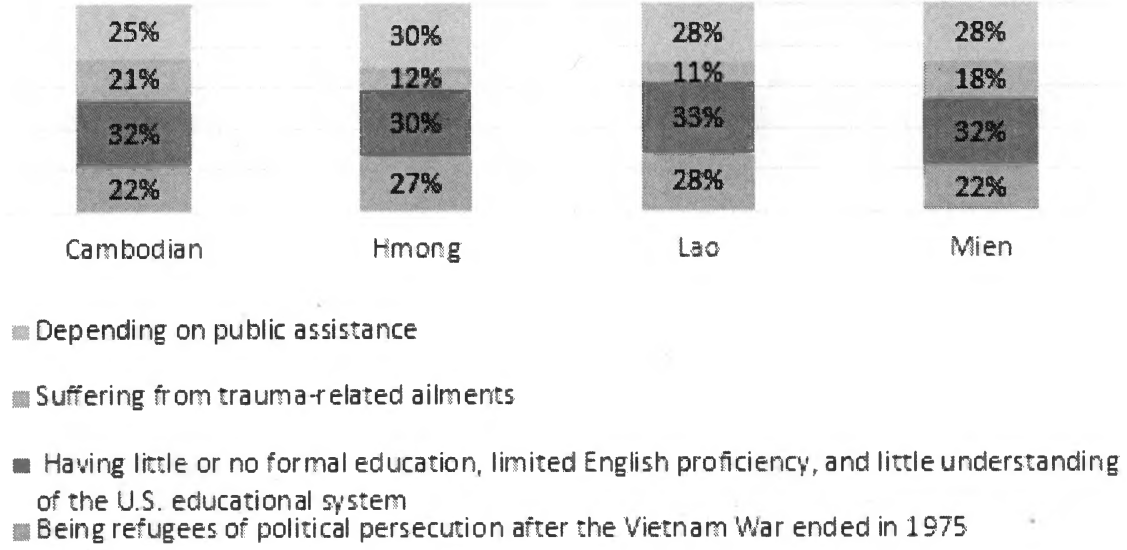

Figure 19. Family struggles of survey participants.

\section{Parents' Progress}

Despite the foregoing challenges, some refugee families were able to adapt to the American culture and became successful and self-sufficient (see Table 5). In this study, nine (47\%) families became successful, seven (37\%) families became self-sufficient, and three (16\%) families remained struggling.

Refugee success. Despite the challenges that Southeast Asian families faced, 9 of the 19 families overcame their challenges. They overcame their struggles by changing their career paths, opening a business that was familiar to them, and continuing their education (see Table 5).

After failing medical exams multiple times due to the language barrier, Bopha's father, for instance, chose a different career path. Instead of trying to becoming a doctor, 
he enrolled at a community college, transferred to a state college, and earned a bachelor's degree in Business Accounting. With this degree, he found a county job in his local area and has been working there for the last 15 years. Bopha's mother worked in her family's donut shop or a sandwich shop on the side.

Liuz's parents came to the U.S. when they were young and went through the U.S. educational system from elementary school to earn advanced degrees. His mother holds a master's degree and his father a doctoral degree.

Ponleak's mother went from selling clothes to managing a donut store, to owning a donut store. Hli's parents started a farming business and were able to build their life on that foundation. Eventually, they purchased their own home. Kaj's father started a nonprofit business and had all his children write grants for him. Doungchanh's parents opened a successful restaurant business in one of the more affluent neighborhoods in Northern California.

Paj's father attended night classes and got into a pharmacy tech program. He now works on call with a well-known hospital in California. Kham's mother went back to school 12 years after resettlement, became a nurse, and got remarried. Zaih's parents were younger and were able to assimilate and learn things more quickly. They went to adult school, and now her mother can read and write English and speak fluently. Her father can understand, but his language ability is limited. 
Self-sufficiency. Some refugees overcame their struggles by being self-sufficient, which is the government goal set for all refugees. Families in this study became selfsufficient in two ways (see Table 5).

Both parents were able to find and hold stable jobs, although those jobs might still be low-skilled and low-paying. Chenda's parents did their best. Her father worked, and her mother worked as a seamstress, which enabled her to stay home. Both of Xia's parents started working and went off food stamps in the mid-1990s. Their children got older and had jobs to help them. Saeng's parents found stable manual jobs. Liuz and Malayvanh's parents are both working full-time.

Npaim's parents are still struggling, but they are doing better. All their children are older, have jobs, and can help themselves and their parents. Lowc's parents also overcame their challenges through their kids. Lowc supports both of her parents and family financially.

Still struggling. Despite their parents' struggles, their children were able to persist in school and graduate from college (see Table 5). Sathea's parents, however, never overcame their struggles. They have been poor for their entire lives. His mother works as a farm laborer. His father cannot work due to a war injury. Sathea's parents live in a Cambodian enclave, which sheltered them from the mainstream U.S. world. Bounsy's mother speaks English better than her father, but her parents' economic 
conditions have not improved. Keola's mother has done different types of jobs; she

worked as a housekeeper, nanny, and did farming work.

Table 5

Parents ' Progress of 19 Interview Participants

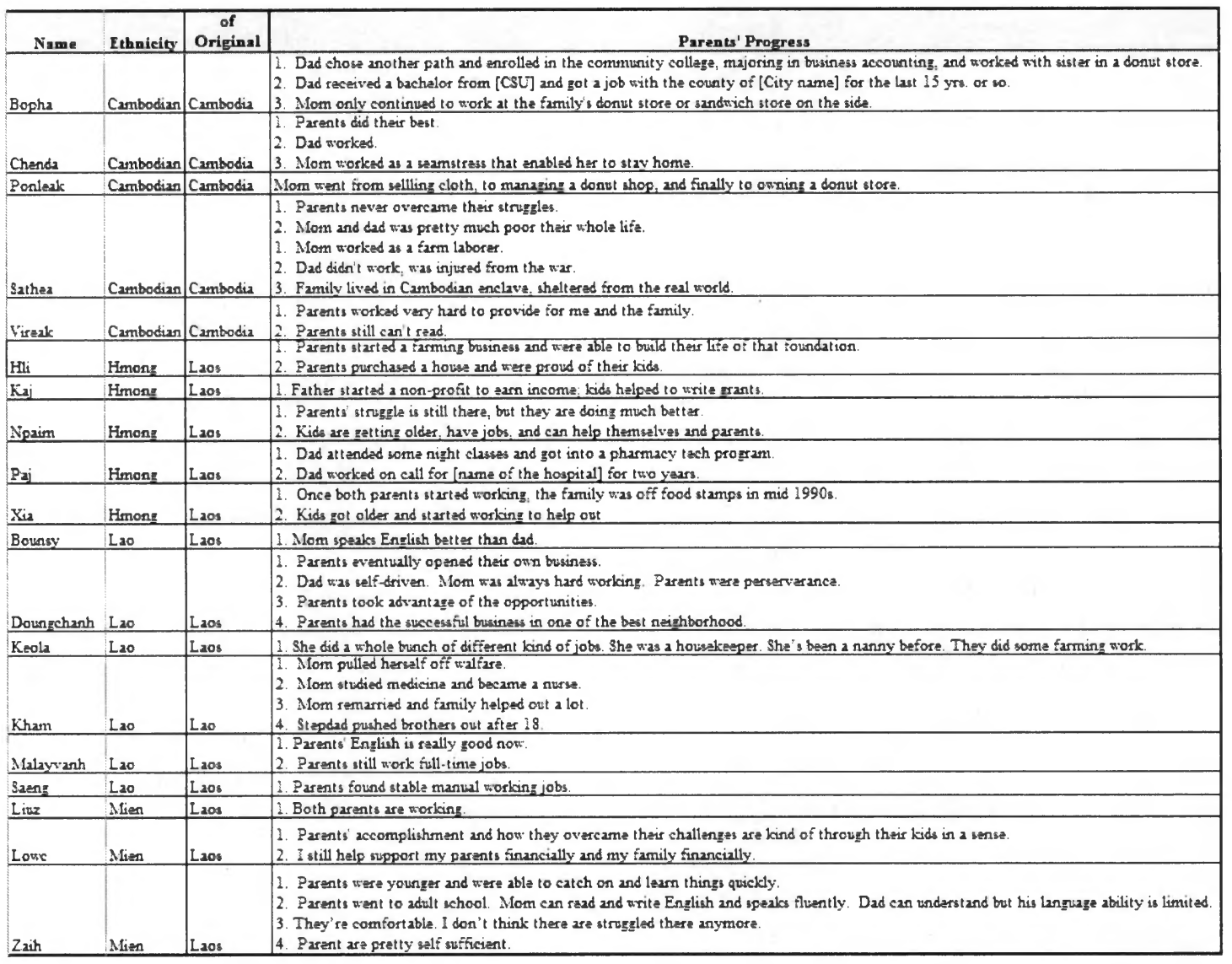

\section{Keys to Refugee Children's Academic Successes}

There are a series of five keys that participants employed to overcome challenges and achieve their academic success. These keys fell into the following categories: (a) 
refugee inspiration, (b) family obligations, (c) "failure-is-not-an-option," (d) "not being a statistic," and (e) parental prevention.

Refugee inspiration. Understanding their parents' history of war and their struggles to support their families can provide students with powerful motivations (Lor, 2008; Truong, 2014; Uy, 2011). This knowledge can also offer strength and encouragement to persist in pursuing education. It can help children see their challenges as things to be overcome and seem minimal compared to what their parents have gone through.

Hli: My family inspired me ... because if your family has gone through so much. You know that you, too, can also have the ability to do that. ...bad grade doesn't ... mean much when you think back on your family trying to survive a war. I need to commit, and I need to refocus myself because this is minimal in comparison to what my parents have gone. ... growing up with this kind of a story and seeing these experiences, ...there's a very strong part of me that ... I've got to work hard.

Lowc: My parents didn't have that opportunity to go to college. [Knowing] their challenges of being refugees of not speaking the language [and] of the cultural differences ... pushed me to make sure that I finish college... My challenges are nothing compared to what my parents had to go through. ...just knowing where I'm coming from ... motivated me to keep going; although there are constant setbacks and challenges in education. I feel like there's plenty of things to celebrate.

Understanding the history and the strength of their families and communities helped Southeast Asian students build a strong foundation as individuals. With this foundation, they retained the motivation to pursue their dreams. It made their challenges bearable and kept them focused. 
Family obligations. Refugee children also witness their families' struggles, such as their inability to speak the language, the challenge to find and hold a stable job, and the need to navigate a new world. After seeing their parents' struggles, the students were motivated to mature and become independent quickly so that they could help their parents (Lor, 2008; Truong, 2014; Uy, 2011). Completing a college education is expected to enable them to get a good job and help their parents financially.

Chenda: Once you learned about ... your parents' struggles and you're able to see and feel their sacrifice, I can't see like why you couldn't ... do something. And ... also when you're given an opportunity, you have to use it.

Bounsy: My goal ... was ... to make a lot of money to be able to buy my parents a house, so that they weren't struggling, trying to pay rent. ... My dad lost his job, and ... he didn't have a lot. ...growing up, I ... wanted to go to school, to get a good job, and to help pay for my dad to have a house.

Failure is not an option. Refugee children often feel a unique responsibility to help their families out due to the struggles they have encountered. The children tend to carry this responsibility throughout their educational path, even after college. Failure or success is no longer about themselves; it is about their family. When presented with this situation, they have no choice but to move forward and succeed. Many of the participants felt this way.

Bopha: I feel like, I had no other choice because I knew that my parents were helping ... to pay for some of it (college cost).... knowing that I would be completely disappointing them if anything were to happen. ...dropping out was just not an option. ... I didn't see other options at all, even if as much I felt like I didn't belong there or like I felt I was failing my classes. ...I had to survive it... 
Kaj: I always say to myself, failure is not an option because I have too many people riding on me. I cannot shame my dad. I cannot transfer to [UC campus] and not graduate and come home without a degree. That was not even on the table. It's like no. It ... helped keep me there and keep me motivated. There's just too much to lose. I think you just knew you got to stick to the fight and make it work.

Not being a statistic. Refugee families are poor and often live in low-income neighborhoods, which can be filled with violence and lack of opportunity. Many of the participants' parents had to work multiple jobs and often left their kids to be watched by their grandparents or relatives. Some of their children were attracted to criminal activity and ended up incarcerated. Some had children early and had to start working to support them. Thus, a college path was not always in their minds, because most of their friends never went to college. Nine of the 19 interview participants spoke out about their lowincome neighborhoods and acknowledged their negative effects. Some who had friends and siblings in gangs said that this encouraged them to avoid that lifestyle.

Kaj: I do not want to be a statistic. And to me, being a statistic meant being 16 like my older sister, getting married, having a bunch of kids, having an abusive husband, and a controlling in-law. I'm not trying to live that life. That life is not for me.

Liuz: hearing that message from my friends, seeing their struggles that they ... go through trying to make ends meet. I think all of that played a part in me deciding to go to college. I felt like that wasn't for me, and I wanted something more, and I felt like to obtain that. The route that I wanted to follow is to go through school.

In a low-income neighborhood, it is not uncommon to see children shot or young people having children. The neighborhood effect can have a strong influence on children, but some children could overcome this influence. Instead, the participants 
pursued healthy relationships. They were reaffirmed in what they did not want to be when they saw hardships of their friends or siblings.

Parental intervention. In addition to children seeking to avoid the problematic lifestyles of their friends and siblings, parents sought to influence their children to stay away from negative neighborhood effects by using available resources.

Ponleak: They [parents] used to drop us off at the library like every Saturday or Sunday and leave us there all day. So, they'd drop us there at like 9:00 AM or 10:00 AM until the library closes, like 5:00 PM. And during that time, I read a lot of books and magazines. So, ... it could have affected my education in some way.

Doungchanh: My dad made the conscious decision [...of] not going to let them [his children] grow up in the [Asian ghetto community]. ... we grew up in a nonAsian ghetto community. He [...also] went to the school district and that was our ... assigned school for myself and my two brothers. But, he was adamant about it and [...said] they're not going to [local high school]... They're going to go to this school that I chose for them, or they're not going to school.

Parents did what they knew best to provide to their children. Ponleak's parents dropped him and his brother off at the library every weekend while Bopha's parents kept her way from her neighborhood kids. Hli and Zaih's parents stressed the importance of schooling and going to college to their kids. Doungchanh's parents moved to a different community and demanded that their children be placed in a better resourced school.

Supportive family. Supportive parents were key in this study. There were also a few cases of supportive siblings. Parents supported their children by reminding them to do their homework, getting a tutor if they could afford it, or helping them with their homework. They also helped their children with everything they needed for school, 
including relieving them from doing chores or working. This study confirms the existing literature that parents of successful students provide encouragement, set high expectations, and expect their children to attend and graduate from college (Akiba, 2010; Ngo \& Lee, 2007; Tang et al., 2013).

Chenda: [Parents] couldn't help me with my homework ... but ... if I said, I needed to do ... something for school, ...they are always very supportive of anything related to school. So, ... they were always kind of big on school and making sure that ... I did everything I could to ... increase my chances of getting into school to the extent that my mom was like, ... you don't have to do any chores ..., as long as, I was doing well in school.

Npaim: They [parents] pushed [education] a lot in our household; ... even though they don't speak English but always supported us. They're like, okay, make sure you do your homework. ... if they can't help us with our homework because it's in a different language, they will find someone [...who] could tutor us. So, they were always supportive in that way... because of their support that's why I'm doing so well in school. So, I think that's because they instilled in me, I persevered. So, you got [it] as a motivation continuing into college.

Hli: I've got to work hard, and my parents emphasized education, like no tomorrow.

Taking advantage of educational opportunities. Many refugee parents recognize the value of education and want their children to have opportunities for education. However, many parents did not have much education in their own countries. For this reason, they encouraged their children to take advantage of U.S. educational opportunities.

Sathea: Having the opportunity [while] growing up [with] parents who didn't have much to give but at the same time, ... you start realizing the worst thing you can get in life is ... growing up poor and then not having an opportunity. 
Npaim: I wanted to get to college so much ... because ... I'm the first generation. ...my [parents] never had ... schooling. They never went to school and had education. They were farmers, and that's all they know how to do.

Zaih: They [parents] always told us, "no matter what, we have to go to college." They came ... to the United States because of the opportunity they didn't have back in Laos.

Many refugee parents told their children about the lack of educational opportunities in their home countries and how hard they had to work at low level jobs because they did not have an education. Their children also saw the struggles that their parents had to endure due to the lack of education. Some refugee children also worked with their parents, doing manual labor. Some parents also had to work in multiple jobs, and others could not find jobs or hold stable work. These parents vividly demonstrated what the lack of educational opportunities had done to them, and they encouraged their children to go to school to achieve a different life. In addition, those few parents who had the opportunity to go to school either in their home country or the U.S. showed their children the benefits of being educated.

In summary, refugee experiences substantially impacted the academic success of the Southeast Asian college graduates in this study. These experiences originated from the refugee children's understandings of their parents' history and struggles, as they used this knowledge as an inspiration to make a difference for their families by persisting in school. When they saw their parents' sacrifices and hard work, they were motivated to help their families overcome their hardships by persisting in school (Lor, 2008; Truong, 
2014; Uy, 2011). The children took ownership of family responsibility by realizing that failure to succeed in school was not an option for them.

Many refugee families lived in low-income neighborhoods that were filled with violence and lacked opportunities. Friends or siblings who were gang members served as negative examples that reinforced the importance of education as a path to prosperity. Some refugee parents were aware of the neighborhood effects on their children and pursued strategies to prevent their children from being affected by the influences, including moving out of the neighborhood, challenging school districts, and creating a strong home foundation for their children.

Supportive parents were keys to the refugee experience, although most parents did not know how to help their children with their homework or guide them through the educational system. Yet, they helped their children with everything that they could. This included finding tutors and relieving them from chores or working. These parents demonstrated what lack of educational opportunity had done to them, telling their children that their lives could be different if they took advantage of the educational opportunities in this country.

\section{Cultural Expectations}

Many Southeast Asian parents seek to maintain their culture, to keep their heritage language alive, and to ensure their children know about and participate in religious ceremonies and traditions (Canniff, 1999; Gomez, 2005; Millhollen, 1994; 
Norasing et al., 1999; Vue, 2013). Cultural expectations are tools they use to support children (Her \& Gloria, 2016; Yang, 2008). In this study, cultural expectations are comprised of the following four sub-themes: (a) family values, (b) ethnic culture, (c) gender differences, and (d) religion and language.

\section{Family Values}

Southeast Asian parents have limited human and cultural capital to offer to their children and lack educational experiences to guide them, but they can provide moral support as a motivation for their children's academic success (Uy, 2011). A high proportion of the survey participants indicated that their parents lacked financial resources, English language proficiency, and knowledge of the educational system to guide their children (see Figure 20). However, most parents were said to place a high value on education, providing support and encouragement as a motivation for children to finish school (see Figure 20). 


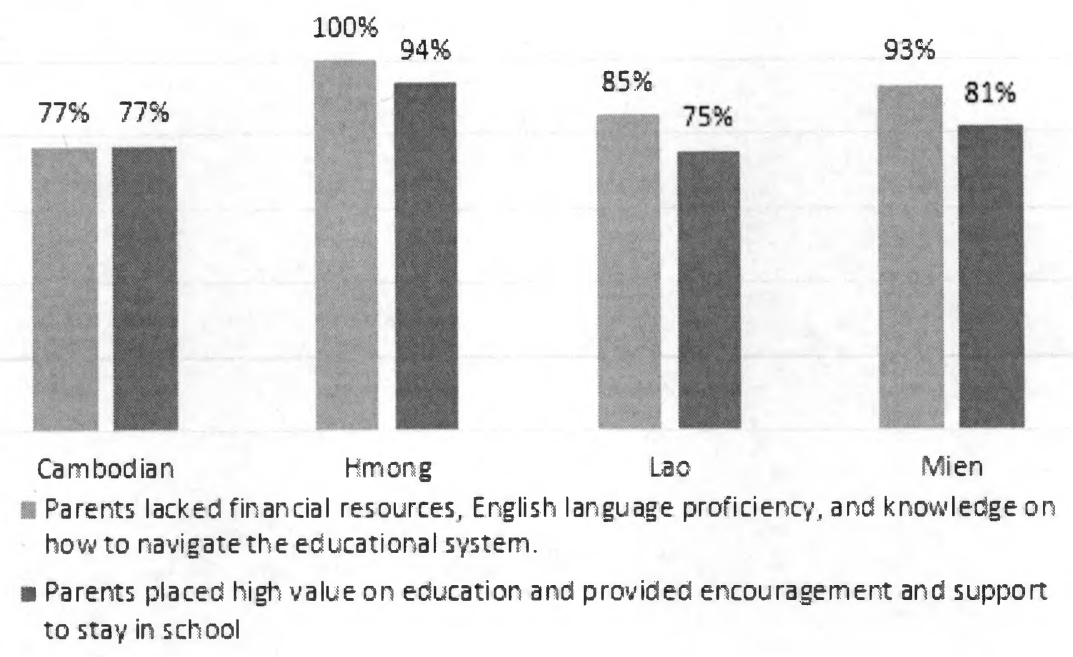

Figure 20. Parents' educational expectations and obstacles for survey participants.

Educational values. Educational values are emphasized by parents across all four ethnic groups. Parents view education as an important tool for an upward social mobility and the most important asset to succeed in America. They use whatever resources they have to help their children succeed (Canniff, 1999; Lor, 2008; Moua \& Lamborn, 2010; Peng \& Solheim, 2015). Parents play a major role in their children's education, even though they may not have sufficient human and cultural capital to help their children navigate the U.S. education system (Lor, 2008; Uy, 2011). (See Figure 20).

Chenda: I'm immersed in a family that values education even if they don't understand all of what it entails. ...education ... starts with the family. At least, my experience is my mom has been instrumental in really emphasizing the fact that ... in times of turmoil, you can lose everything, but you can have your knowledge to rebuild.

Bounsy: I ... didn't have a lot of chores growing up because my mom was so concerned with us doing good in school that we didn't have to wash the dishes or 
learn how to cook and all of that. ...my mom just wanted us to get straight A's to eventually get into good colleges because she knew that's what we needed to have to survive in America...

Educational expectations. Like other Asian parents, Southeast Asian parents have high expectations for their children (Uy 2011). The parents in this study expected their children to do well in school by graduating from high school, going to college, and obtaining a high-paying job. Good paying jobs were generally referred to as doctors or lawyers, especially by Cambodian parents. Good paying jobs were also equated to working in an office and using knowledge from school instead of working in laborintensive jobs like their parents.

Bopha: In high school, I wanted to go to college and be a lawyer. That's all I knew because that was kind of what was expected of me. ...the expectation from my education didn't just come from my dad but also from my extended family members, ... also trying to advise in some way indirectly to my dad to mean what I should set for myself.

Npaim: [Parents] they're like, get your education, so that you don't have a very labor intense job, so that you guys sit in your office all day and use your brain instead of using physical work.

Parents are their children's cheerleaders that keep them focused and serve as a source of motivation during difficult times (Lor, 2008). These parents believe that education would lead their children the farthest in terms of their future careers, although they do not know what their children's futures would look like.

Three parents in this study did not understand basic U.S. social institutions or their children's schooling experiences and thus did not have clear expectations for their 
children, although they believed the importance of education. Sathea's parents did not know what schooling meant, but they scared him of going to jail if he did not go to school. Kham's mother did not have clear expectations for him but encouraged him to go as far as possible with his education. Lowc's parents expected her to do well but did not have high expectations for college, because no one in family had gone to college.

Sathea: I think it [learning the importance of doing well in school] was mostly from TV and movies... Every time I brought home a report card, no matter how great it was, I think to them [parents], it doesn't really mean anything. So, after a while, I never showed them my report card... [However,] they would say things, "if you don't go to school, they can put me in jail." So, a lot of that was from my parents but also when you feel very powerless in society, you just want to conform because ... I didn't want to get kicked out of school.

Parents' expectations have a great influence on their children's expectations.

Figure 21 compares the levels of parental influence on the four different ethnic groups from survey responses. Hmong and Lao parents had the highest reported levels of influence on their children's expectations at $91 \%$ and $90 \%$, respectively, Mien parents had the next highest at $81 \%$, and the Cambodian parents had the lowest at $79 \%$. 


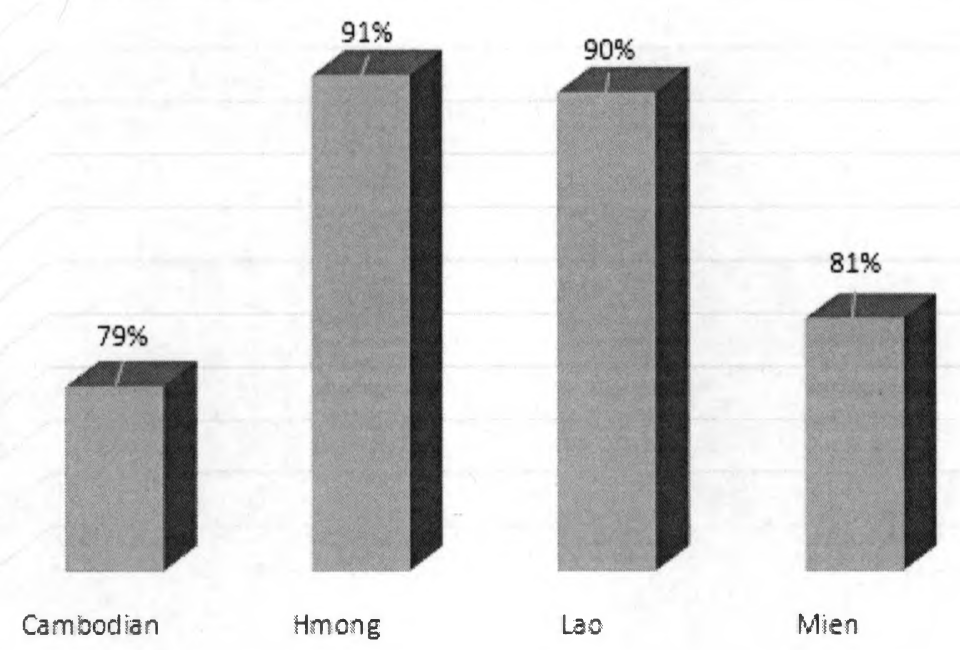

Figure 21. Parents' influence on self-expectations for survey participants

\section{Ethnic Culture}

Families shared similar cultural goals across the four ethnic groups; these included to preserve culture, heritage, language, and religious traditions. Parents and elders are responsible for instilling cultural norms into their children in Southeast Asian cultures (Canniff, 1999; Gomez, 2005; Her \& Gloria, 2016; Lor, 2008; Millhollen, 1994; Norasing et al., 1999; Peng \& Solheim, 2015; Tran, 2014; Truong, 2014; Vue, 2013; Xiong \& Lam, 2013; Yang, 2012) and have the greatest influence on them (see Figure 21). Southeast Asian Americans also learn about their culture and traditions by being involved in their communities. Up to $67 \%$ of survey participants learned about their culture and traditions from people other than their parents (see Figure 22). They learned from student organizations more than they did from religion and language classes, except 
for the Lao participants, who gave equal weight of their cultural learning to student organizations and religion and language classes (see Figure 22). They appeared to learn the least about their culture and traditions from social gatherings (see Figure 22).

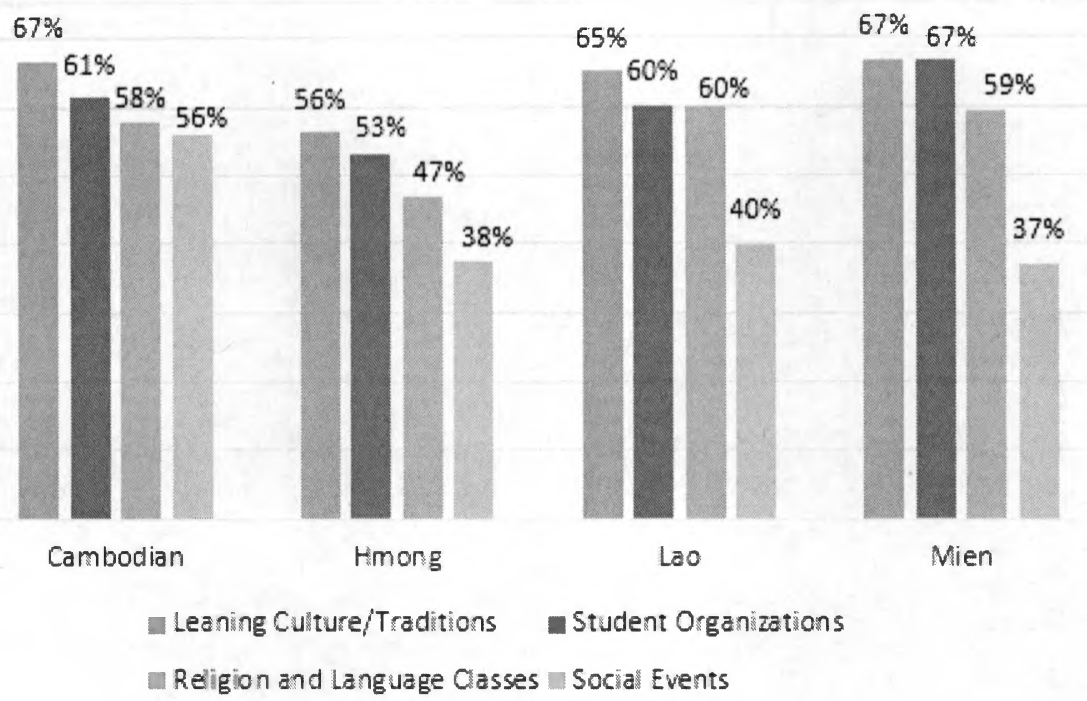

Figure 22. Other cultural influences for survey participants.

Cambodian culture. Cambodian cultural norms and values are centered on being a good child to the family, being responsible for siblings and parents, and living a balanced life (Canniff, 1999). One must respect the family and follow advice religiously so that the family will not lose face among community members.

Being a good child to the family. A good child follows Cambodian cultural norms, has a good character, succeeds in school, is loved by friends and teachers, and is generous with resources). When one is a Cambodian girl, reputation is everything (Canniff, 1999). Chenda understood that her reputation was at stake and made sure that 
she changed her hair color to black, which represented the hair color of a good girl, before participating in Cambodian New Year or other festivals.

Chenda: When it came time for cultural events whether it's our New Year or Pchum Ben (ancestral ceremony], ... I made sure my hair was black; otherwise, I'd have highlights in my hair or what not. But, I was very conscious of what, our community thought about or what my parents would think about people with certain hair color. I mean something as simple as that.

A good child is expected to be obedient, helpful around the house, and respectful to parents and elders (Canniff, 1999; Xiong, Eliason, Detzner, \& Cleveland, 2005).

Hli: The expectation was to be a good person. Above all else, you got to be a good person. ... be a moral person, be humble, [...and] always be willing to learn.

Malayvanh: My parents ... just wanted me to go to work. After I graduated college, I found a good job they're like pretty happy, pretty satisfied. ... and I'm doing it, so they're like very happy.

Lowc: I'm going to make my parents proud. I'm going to make sure that I get a job, so that I can support my family.

The results from the survey participants also supported this finding. Figure 23 compares the rewards that the survey participants expected after obtaining their higher education. The Cambodian and Lao survey participants rated making their parents proud as the highest reward expected after achieving their academic goals. Hmong survey participants gave it an equal weight to being a role model to their siblings and community at $91 \%$. The Mien survey participants rated it at $81 \%$, which is lower than the reward of being a role model for their siblings and community at $85 \%$. 
Family obligations. The oldest Cambodian children have responsibilities for their siblings and parents (Canniff, 1999; Chhuon et al., 2010; Truong, 2014; Truong et al., 2014; Uy, 2011), which make them accountable to succeed to help the family. Chenda and Bopha had responsibilities for siblings and parents.

Chenda: So, the family is interesting in a sense that I' $m$ the eldest. So, there is a whole set of expectations, right? In terms of making sure you take care of your parents, you set a good role model for your siblings and so forth, and you do well in school.

Bopha: As the kind, subservient oldest child and the daughter, ... my sense of responsibility is to not just only my parents but also to my siblings.

Being responsible for the family and a role model for siblings was also found in Hmong, Lao, and Mien students (Lor, 2008; Millhollen, 1994; Sengkhammee et al., 2017; Truong, 2014; Truong, Rios-Aguilar, Paik, \& Thomas, 2014; Uy, 2011; Xiong \& Lam, 2013; Yang, 2012). Keola was inspired to graduate from high school because his older siblings graduated and went to college. They guided him how to apply and get accepted into college. Xia applied to a UC campus because her siblings had applied to colleges and they could help her out financially. Like Zaih, her three younger siblings also graduated from a UC campus.

Malayvanh: Even though I was the middle child, I felt like I was the oldest child in the sense that I would always have to wake all my siblings to make sure that they went to school. And when my parents are working, I would have to make sure that they ate. If there was an issue with any of my siblings, their teachers would actually contact me. 
Hli: I needed to be a good role model for them [young siblings] - to always make sure that I had ... a healthy and a good relationship with them and that I needed to be a good role model for them. So, a good role model would be like I would stay in school, I would ... be financially independent, I didn't have to depend on other people, [and] that I could drive.

Because parents lacked basic education knowledge, Southeast Asian families relied on their older children to help their younger siblings through the educational system and be their role models. Several of the interview participants would have not been motivated to graduate high school or go to college if their siblings had not gone before as their role models. Hmong and Mien survey participants rated being a role model for siblings and community similar to or more important than making their parents proud (see Figure 23). Cambodian and Lao survey participants rated being a role model for their siblings and community lower than making their parents proud, at $75 \%$ and $70 \%$, respectively. 


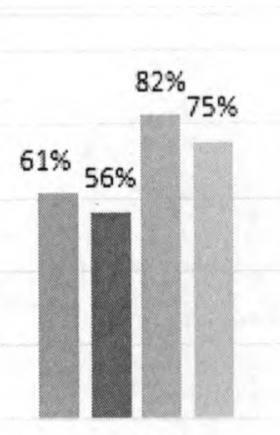

Cambodian

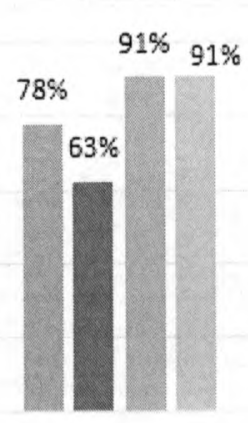

Hmong

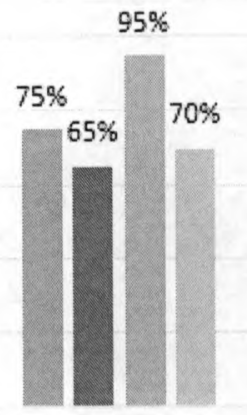

Lao

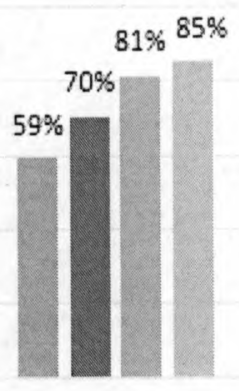

Mien

- Being able to support my family

Being able to support my family and community

Making my parent(s) proud

m Being a role model for my siblings and my community

Figure 23. Reward(s) expected to receive after achieving academic goals for survey participants.

Living a balanced life. The goal in life for a Cambodian person is to maintain a balance between the emotional fulfillment and the pressure to get ahead. This is a belief that success is possible when one lives a balanced life between two cultures (Canniff, 1999). Being a Cambodian American, Chenda had to balance her life between the American and Cambodian cultures. She recognized the differences between the two cultures and adapted to each respective context when navigating between them.

Chenda: I've become a chameleon, but ... being able to read different things. ...you behave [differently] when you're with your family [... and] with your community. There are cultural things; ... so making sure that ... I'm in tune to that. I'm also in some ways not typically traditional. So, I'm still learning to navigate that... You know when you go dine or done things at scholarship ceremonies, or you're having dinner with the chief people, I had to learn how to dine properly. That's not something that is in my [culture]--my culture just taught 
Khmer [Cambodian]. So, I had to go to classes to learn these etiquettes, so that's to live in a different culture.

Hmong culture. In Hmong culture, the well-being of the community and family ties often comes before the individual's needs and wants, and parents expect their children to perform family responsibilities (Peng \& Solheim, 2015). Maintaining traditions, culture, and religion is a key goal of the Hmong community (Vue, 2013). To maintain the well-being of the community and family, daughters are expected to stay home until they get married. Npaim's mother, for instance, could leave her family in Laos to go to Thailand, but only if she went with her cousins. This was to ensure that her mother was still within the extended family.

Npaim: He [grandfather] refused to leave Laos. So, my mom just got up and told ... my grandpa that," hey, I'm going to Thailand, I'm not staying here and he was like, well, okay, if you're going to go then your cousins are going, too. You can go with them." ... it's culturally that the daughter is not supposed to leave home until they get married, and it's frown upon.

Kaj has two sets of siblings, four each. One set is traditional, and the other is Americanized. Kaj contrasts the two sets of siblings and how her father felt when one of her sisters married a White husband.

Kaj: My family split four and four. The older bunch, you totally get it because they're ... the more traditional. Actually, my oldest sister is more traditional. So, she married young at 16-17. I barely knew her. And then my second sister... broke the barrier ... She married a White guy, which is not common ... so that made my dad lose face. 
However, when Kaj's sister went on to complete college, her community accepted an interracial marriage as a viable option for their children because they would be exposed to White culture by the new brother-in-law.

Kaj: She went against all odds. She graduated high school because that's where they met. They end up going to [CSU campus], graduate from there. That gave everybody afterwards, like okay, this is an option and also gave us the cultural capital by having a White brother-in-law. He taught us certain things, like he took us to basketball games, his White culture. So, from early age, I got exposed to White culture because I had a White brother-in-law.

Paj also got married to a non-Hmong person just one week before interviewing for this study. Although her parents accepted it unwillingly, this was preferable to losing face. Not only did Hmong children appear to adapt to American culture, but their community and parents also adapted and accepted their children's adaptations when those adaptations resulted in positive outcomes. This mirrors Peng and Solheim's (2015) study, which found that contemporary Hmong families are required to negotiate and adapt to the American cultural values.

Lao culture. Lao culture is said to value hard work, personal honor, and honesty (Norasing et al., 1999).

Keola: Just do your best and work hard and focus in school and everything. So, it's really our parents that pushed us.

Lao survey respondent: My grandmother's constantly encouraging me to do better for myself than my family could do for me and relying on me to support the family. 
Kham: So, I think ... I was 12. I didn't understand we were poor because ... you don't have a concept of it. My family, we never really complain about being poor because it's like a Lao thing.

Mien culture. Mien family roles are described as fixed and patriarchal.

Grandparents or elders take care of and teach the children to work. Traditionally, Mien parents and community value and transfer Mien gender roles and expectations to their children. For instance, formal education was traditionally only available to Mien males in Laos, and cooking and cleaning were the primary tasks for Mien females in Laos

(Gomez, 2005).

Lowc: My mom would say, "oh these are things that women should do, these are things that girls should do. These are things that you should do. You're good enough to be a good wife." So, a lot of times I remember growing up, ...I would rebel ... Why do I have to do all these things that my brothers didn't have to do? ... In our culture, you're at this age you're supposed to be married, you're supposed to have a family, [and] you're supposed to be a stay at home mom ...that was ... the priority for her [mother] from her family's perspective... She probably wasn't encouraged to go to school.

Although the Mien culture is centered on gender roles and expectations, similar practices may be seen across the four ethnic groups. However, each ethnic group practices its gender roles and expectations slightly different from each other.

\section{Gender Differences}

The practice of favoring a son over a daughter, as noted earlier, is rooted in Southeast Asian family practices, standards, and expectations, because a son is believed to bring luck and prestige to the family (Truong, 2014). 
Cambodian gender differences. Historically and before the arrival of Indian cultural influence, Cambodian women had a higher status and were more powerful than Cambodian men (Canniff, 1999). After a Cambodian female ruler met and married a Hindu prince, the status of Cambodian women was weakened (Canniff, 1999).

Cambodian parents now expect their daughters to be more responsible for maintaining proper behavior than boys (Tran, 2014). They are concerned about their daughters' chastity, because the Cambodian identity and culture is based on the purity of Cambodian women (Tran, 2014). Thus, Cambodian girls' reputations are protected in the community (Canniff, 1999). When Chenda rebelled and had a child in her high school senior year, it probably caused a loss of face for her parents.

Chenda: I wasn't this ideal teenager by any means, right? I'm very non-traditional in that. I was an American teenager and I gave my parents ... headaches and heartaches. I would say that I forever look at them and say now, "I am so sorry." I had a son in my senior year, so that was also difficult to navigate.

Bopha's father did not allow her to go out socially even with her high school

friends. If she had to be out, her father needed all the details of her outings.

Bopha: My dad would never outright say that he limited what I could do socially for example. I was never allowed to go out socially even like high school friends. I mean I was limited. He had to know every single point in time where I was, who I was with, if I was to go out. So, he really placed an eye on what I was doing and I think that it was a big part because I was female.

Bopha's father restricted her to uphold the Cambodian value of female purity. It is this value that causes some Cambodian parents to arrange early marriages for their daughters (Tran, 2014). 
Bopha's mother also consistently told her what she should or should not do.

Bopha: growing up I also heard my mom say, "Well, as a girl, you should be doing this and as a girl, you shouldn't be doing this and this and this." As much as I didn't like it, I had to admit that I think it influenced my way of thinking very much in terms of ... my sense of responsibility.

For a Cambodian woman, the most serious taboo of all is to have an intimate relationship prior to marriage, which probably explains why Bopha's father told her she could get raped if she was not careful.

Bopha: he [father] always used to say to me when I was growing up, "You need to be careful because you're going to get raped." I don't really know what rape means necessarily... I am not even around like 12 , he would say stuff like that to me and, I think, my being a girl always influenced the way they raised me and with some of the limitations they put on at least my social activity.

When it comes to education, however, Cambodians are said to believe that both boys and girls should have equal access to education (Canniff, 1999). Figure 24 shows that a slightly higher percentage ( $78 \%$ vs. $76 \%$ ) of female Cambodian survey participants' parents placed high values on education and provided support and encouragement to their children to stay in and graduate from school.

In the U.S., it appears that a Cambodian-American woman can establish her rights by being strong, well-educated, and free to make her own choices (Canniff, 1999). Chenda had a child while going to school but was also strong enough to surround herself with people who truly cared about her and could help her through college.

Chenda: My biggest limitation was having a child while going to school that was ... hard..., taking him to class, things like that. You ... surround yourself with people who genuinely care about you and when you do that, I think people are 
willing ... to help you -- we make meals together and share, you know, like one person makes one day. I had friends who didn't have kids who would ...help you. So, you learn with others ... how to be ... humble enough to accept help, too. This is not a journey by yourself.

Chenda went against cultural gender expectations, but still knew the importance of education. She went against the odds by raising a young child on her journey to complete her higher education.

In addition, Chenda made her own choice of a career. Instead of becoming a doctor as expected by her parents, she studied social welfare and Asian American studies, which were areas she was passionate about, for her undergraduate degree. After her bachelor's degree, Chenda went on to obtain a master's degree in public policy and finance management and then a doctorate degree in learning theories. She used her knowledge and skills to give back to her community.

Chenda: My exposure to what I've learned about the Khmer community and the issues and so forth while I was at [UC campus], but also as I honed my own skills and knowledge to be able to do something when I returned. So, when I came back to [local city], I worked in Higher Ed, continuing to have a foot in the door, working to serve the community, sitting on nonprofit boards, and so forth. So, it ...came a full circle for me

Chenda is an example of how historically Cambodian women could attain high status.

Hmong gender differences. Culturally and traditionally, Hmong girls generally get married between the ages of 13 and 20 (Lor, 2018). Kaj's sister, for instance, was married at the age of 16 or 17 . Xia thought that she would be too old to get married once she was done with college. 
Xia: I really thought that BA was the highest that I would go because a lot of my family members, especially the women in my family, my cousins I grew up with, they got married really young. And so, I thought that ... if I was done with college at 22 , I would actually be too old, yeah.

Both Paj and Npaim knew that if they were not married by a certain age, they would be considered "old maids." Their decision to go to college went against the odds of being able to get married after college. However, Paj did not want to get married early and be a good wife, even though her community might perceive her as an old maid if she did not get married by a certain age. Her father also supported her and did not want her to marry early.

Paj: When I was very young, I definitely didn't want to be the typical getting married early and be a good wife. ... you were an old maid if you weren't married at a certain time and this is something ... in the community when I was growing up... You had to look nice and wash the dishes, cook, and so these are the very expectation and I didn't want to do that whatsoever. Also, my dad was very, "You're not getting married early" and things like that very early on.

Paj thus resisted her culture's expectation of early marriage, which was instilled in her when she was young. Like Paj, the other four Hmong participants did not get married while pursuing their undergraduate degrees.

In addition, Hmong parents still encourage their daughters to advance their education (Her \& Gloria, 2016). Ninety-six percent of the female Hmong survey participants' parents placed a high value on education and provided support and encouragement to their children, versus $83 \%$ for males (see Figure 24).

Npaim: I was able to get into college [and being] the first girl because out of our relative, we don't have that much girl in our whole clan, ... I did this for not only 
myself, but I need to show other cousins that ... not only boys could go to school, you know, girls could, too.

Kaj: I never felt that you're a girl, you shouldn't go to school thing. It was like you better make sure those grades are together, and I didn't sacrifice all this, so you can all be messing around and stuff. So, my dad is the only son. With farming families in Laos, they can only afford one kid to go and because he's the only son he was the chosen one.

Some Hmong daughters question the gender role values and their fit, and negotiate their identities and roles between Hmong and American cultures (Peng \& Solheim, 2015). They expand the definition of being a good daughter to include successfully achieving a post-secondary education that can lead them to a career while maintaining their Hmong cultural legacy at the same time (Peng \& Solheim, 2015). Kaj questioned Hmong gender roles and took advantage of educational opportunities, which enabled her to become financially independent. She wanted to be able to support herself and not to be tied down due to lack of self-sufficiency. Xia joined a soccer team to show her parents that sports were not just for boys, and gradually her parents adjusted to this expansion of female gender roles.

Kaj: I want to be financially independent. I wanted to have a career where I didn't have to depend on a man for an income. And, I feel like I have accomplished that because ... my husband and I ... make our own income. But ... if I need to leave, I would be able to support myself. I would not have to stay in a relationship that I'm unhappy because I have a financial dependence. I wouldn't have to ask anybody for money if I wanted to buy a dress or makeup or some food. I can do whatever I want. It gives me that financial independence.

Xia: My parents were actually a little scared that I was joining soccer because ... at the time, they thought that sports was mainly a thing for boys. But, once I joined and I did okay ... that kind of reassured them because I feel like they were 
never really okay with a lot of the things I did. I just ... did it, and then once they saw me ... doing well or doing okay, they ... settled their fears.

Despite the traditions of early marriage, none of the five Hmong interview participants got married before they completed their undegraduate degree. Instead, they used going to school as a way to resist their culture and to show other girls that going to college was also an option. Thus, they expanded the definition of female gender roles to include high education, which could lead to financial freedom from men.

Lao gender differences. Lao women were traditionally given limited educational opportunities and were encouraged to get married early (Norasing et al., 1999). Figure 24 shows that a lower percentage (71\%) of female Lao survey participants' parents placed a high value on education and provided support and encouragement to their daughters to stay in school versus $83 \%$ for their sons. In addition, a lower percentage (79\%) of their parents also lacked financial resources, English language proficiency, and knowledge of how to navigate the U.S. educational system, versus $100 \%$ for male Lao parents.

However, this gender difference was not found among the six interview participants. Instead, girls were encouraged to succeed in school and to have a career.

Bounsy: I ...didn't have a lot of chores growing up because my mom was so concerned with us doing good in school that we didn't have to wash the dishes or learn how to cook and all of that. ...my mom just wanted us to get straight A's to eventually get into good colleges because she knew that's what we needed to have to survive in America.

Doungchanh: I'm the only girl as well and the middle child. So, I don't know if some of that influenced me, but ...we were going to succeed no matter what. And 
so, that was the expectations because that was my parents' expectations for themselves. So, they were very like great example of everything.

Mien gender differences. In Mien culture, women are expected to be responsible for household activities, such as cooking and cleaning, and to serve others before themselves; Mien men are expected to know and perform religious ceremonies (Gomez, 2005). Traditionally, formal education was only available to Mien males in Laos (Gomez, 2005). Some Mien parents still hold onto this tradition while living in this country. One survey participant commented that her family still believed in this tradition, which made it hard for her growing up. Another survey participant responded that her parents believed that investing in education for her was a waste.

Mien survey respondent: Growing up in a closed-minded family that migrated here was a big struggle for a girl. My mother didn't believe that a woman should even bother obtaining an education. Getting an education was a man thing and a woman was supposed to just learn to be a good wife. But I knew I had to do better than just depending on a man.

Mien survey respondent: My mother made it very clear that investing in my education was a waste. That I was just a waste of storage space until my husband's family come adopt me into theirs.

Gender roles for Mien women have changed due to the changing socio-economic environment of life in the U.S. This has enabled Mien women to take advantage of educational opportunities and to go college at higher rates than Mien men (Gomez, 2005). Like Hmong women, two Mien women from the survey commented that they succeeded in college to prove that Mien women could achieve higher education; it became a tool to equalize gender roles for women. 
Mien survey respondent: To let it be known that education is the key to success and to defeat the sexist basis of a woman should not get higher education.

Mien survey respondent: Being able to prove that it's possible for a woman to receive higher education and support my own.

In addition, all three Mien families in this study valued education and supported and encouraged their children to do well in school. Zaih's parents expected her to graduate from college no matter what. Lowc's parents expected her to do well in school and be a good student, but they did not know what to expect because they did not have anyone in their family who had gone to college before.

Zaih: Just knowing that we always take our education seriously and, without a doubt, we knew that we had to graduate college. There was never a question for us, you know, just reminding us to do well in school, to not slack off, and stay focused. They [parents] always told us, "no matter what we have to go to college." They came here to the United States because of the opportunity they didn't have back in Laos.

Lowc: My parents expected me to do well in school and to be a good kid. I know that growing up ... I'm supposed to be a good student. I'm supposed to do well in school. I didn't ... have people there to help guide me in terms of what career you're interested in. They were like, okay, go to school, but nobody even in my family outside of my immediate family like cousins or aunties and uncles ... went to college. So then, it wasn't really any like high expectations for college.

The data from the survey participants suggest that Mien families valued education and supported and encouraged their daughters to go to school and to do well in school, despite their traditional gender role differences. In fact, a higher percentage $(88 \%)$ of the female Mien survey participants' parents than the male Mien survey participants' parents 
(70\%) placed high values on education and provided support and encouragement for their children to stay in and graduate from school (see Figure 24).

The preceding findings across the four ethnic groups show that gender role expectations for women have changed. Figure 24 displays that Cambodian, Hmong, and Mien survey participants' parents had higher expectations for their daughters and approximately the same percentage of obstacles with financial resources, English language proficiency, and knowledge on how to navigate the U.S. educational system regardless of gender. Although a gender difference was not found among the six Lao interview participants, a higher percentage of Lao survey participants' parents placed a high value on education and provided support and encouragement for their sons $(83 \%)$ than their daughers $(71 \%)$ to succeed in school. Similarly, female Lao participants' parents had a lower percentage (79\%) than the male Lao parents $(100 \%)$ of obstacles with financial resources, English language proficiency, and knowledge of how to navigate the U.S. educational system (see Figure 24). 


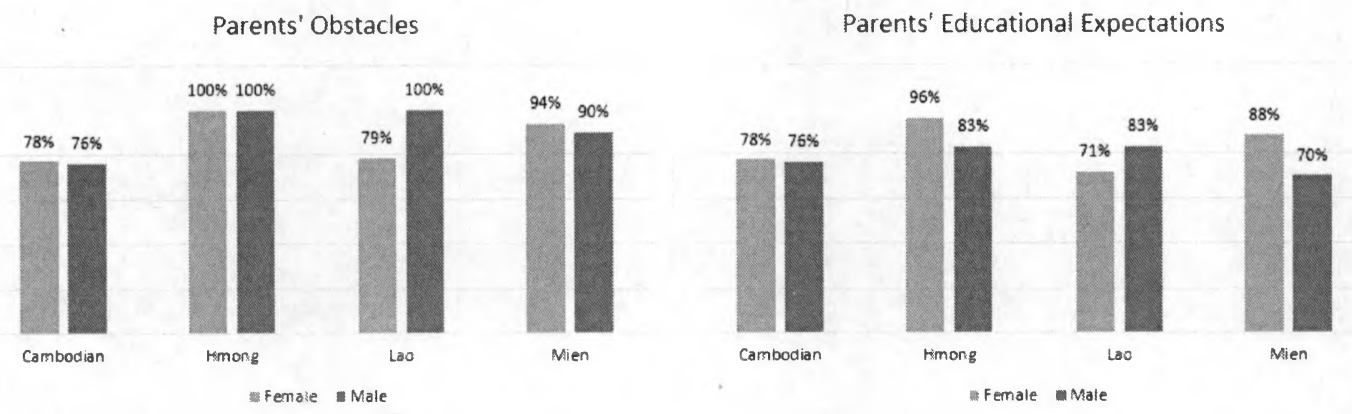

Figure 24. Parents' educational expectations and obstacles by gender for survey participants.

Gender roles and expectations were salient in this study across the four ethnic groups. Although the interview data of the six Lao participants did not show any gender differences, the data from the survey participants showed a large gender difference for Lao students (see Figure 24). Similarly, Gomez's (2005) study found that more women chose to take advantage of the educational opportunities available in this country than men.

\section{Religion}

For many Southeast Asian students, the source of spirituality and religion stems from Buddhism, particularly Theravada Buddhism (Ark, 2014; Canda \& Phaobtong, 1994; Canniff, 1999; Tran, 2014). The belief is that individuals are responsible for their own actions, and that the consequences of actions determine future lives (Canniff, 1999). In Buddhism, successful persons are those who rule themselves (Canniff, 1999). Thus, this Buddhist philosophy appears to be compatible with some 
expressed American norms (Canniff, 1999). The following section describes religious experiences by ethnic group.

Cambodian and Lao religion. Cambodian and Lao people generally practice Theravada Buddhism. Buddhist monks are responsible for maintaining traditional values and culture and generally earn a great respect for their good character (Ark, 2014; Canda \& Phaobtong, 1994; Canniff, 1999). When youth have no place to go, it is the monk's job to help them get back on their feet. For example, Doungchanh's father was raised in the temple when he became an orphan at the age of 12 .

Doungchanh: My dad was an orphan by the age of 12 . So, in Laos, he was raised in the temple for some time.

Buddhist temples are generally viewed with high respect, serving as meeting places for eating, socializing, and worshipping, while also offering psychological protection against loneliness and depression (Ark, 2014). As Cambodians, Chenda and Vireak found community cultural events mostly taking place at Buddhist temples.

Bounsy went to a Lao Buddhist temple with her parents for social gatherings and parties. Kham's grandmother went to a Lao Buddhist temple to worship and then came home to bless her grandchildren.

Bounsy: We went to the temples and stuff, but my mom and dad aren't very involved politically, more like socially and going to social gatherings and parties with the Lao families.

Kham: There's also a Lao temple nearby, so we're completely like yeah. And then, I still have my grandmother who's passed away like three years ago. But she 
was more matriarchal, religious person. She would go to temple, ... she would light candle, and she would come and bless stuff.

For some families, only the parents go to the temple while their children prefer to be left at home or to do other activities. Saeng's father was active in his Lao temple community, but she and her sister never wanted to go to the temple for fear of being stigmatized as gangsters.

Saeng: My dad..., now he's more active in the Lao community, but my sister and I ... never wanted to go to temple because of the stigma that was associated with kids who are at the temple. ...they're gangsters or they're ghettos or whatever. That was the stigma ... that they had.

The stigma Saeng feared could be due to a Buddhist temple and monks are known to be surrogate parents and role models for troubled youth (Canniff, 1999).

Keola's family had a strong connection to a Buddhist temple and monks that influenced their children to be active and to practice Buddhism.

Keola: Growing up I was very close with my mom. She always taught me to help others because my mom comes from a line of monks and those who work in temple. My uncle is a high monk in Laos. His teaching, growing up, and then going traveling for the first time ..., I thought that would be perfect learning more about Peace Corps where I can volunteer and help people and travel at the same time.

Hmong religion. Reference to religious practice was only encountered from one Hmong interview participant; the other four participants did not mention any religious practices. Hli reported practicing mindfulness to balance the multiple demands of student life. It is possible that Hli learned Mindfulness during college. 
Hli: Where am I feeling tension or anxiety or stress in my body, and utilizing a lot of the deep breathing and focusing on my breathing? So, that goes into that whole mindfulness piece, being mindful, doing things with a purpose. Those things help me to stay balanced.

Mien religion. Although most Mien Americans came from Laos, which is a Buddhist country, it does not appear that large numbers of Mien Americans practice Buddhist traditions. Research suggests that Mien religious traditions and rituals center around ancestor and spirit worship and recognition of the "owners" of land or earth (Millhollen, 1994). They believe in a Taoist system, which has enabled them historically to resist Chinese, Lao, and Thai Buddhism (Millhollen, 1994). The interaction with ancestral spirits and leader spirits is fundamental for many Mien decisions (Millhollen, 1994). However, religious practice was not found among the three Mien interview participants in this study.

To summarize, religion was not found to be a particularly salient factor in this study. Only a small number of interview participants reported engaging in spiritual practices. Survey participants also supported this lack of emphasis on spiritual factors in their communities. Only $35 \%(\mathrm{~N}=47 / 136)$ of them felt their community gave them a sense of belonging, and each of the ethnic groups rated its community the lowest for providing a sense of belonging for their academic success. (See Figure 25).

\section{Language}

While maintaining the home language has been shown to reduce cultural disharmony between parents and children, to preserve the culture and ethnic identity, and 
to create a sense of belonging, children of immigrants still slowly lose fluency in their language (Canniff, 1999; Gandara, 2015; Tran, 2014). Canniff (1999) noted that language is the strongest symbol of culture and displays the full range of behaviors and beliefs to represent a unique culture. It is the marker of an ethnic identity and establishes a sense of belonging to an ethnic group (Tran, 2014).

Kaj's father opened a Hmong school on Saturdays and Doungchanh's father opened Lao school on Sundays to preserve their heritage language. Although the Mien language was originally primarily a spoken language, it has been preserved by writing in Chinese and now in a Romanized form. As a Cambodian American, I also opened a Cambodian school on Sundays to teach the Cambodian language to both Cambodian Americans and non-Cambodian Americans.

Kaj: Right now, [father] he's doing a Hmong school. So, every Saturday he has Hmong school in [two locations in Central Valley]. He runs a Hmong Saturday school. So, my nieces and nephews speak; they can read and write Hmong.

Doungchanh: When I was younger..., my dad taught Lao school on Sundays. So, we're growing up in ... and that was fun to be just a part of that. Zaih: We don't have a written language, but then the Mien shaman, all of the religious texts, are written in Chinese. But not everyone knows how to read. I think only the men who are shaman were taught how to read that language. But now there is a Romanized Mien language. I would say that very limited number of Mien people actually know how to read and write in Mien. The language is just mostly spoken.

Some students do not find value in maintaining their home language and are not interested in learning or speaking the language. Bounsy's Lao language class was closed after not having enough students enrolled. Saeng did not see the value of learning his own 
language when he was not going to use it, and when he needed to take AP classes, which he felt were more valuable.

Bounsy: My mom had me in Lao language classes in elementary school, but those classes didn't last very long. I think because not a lot of people went and so, the school stopped putting it on.

Saeng: We didn't want to go to like Lao school either because we're like, why are we even go to Lao school and try to learn Lao when ... you're not taking AP classes, trying to like learn English or that we'll never use.

As a Cambodian language teacher, I also experienced the lack of interest from the Cambodian community in learning the Cambodian language. After offering a children's class for six years, I had to close it in fall 2017 due to the lack of interest. The adult class remains open. However, it has a low attendance of several Cambodian and nonCambodian students.

Students from the same ethnicity often prefer to speak English to each other. Speaking English within their community can deteriorate their heritage language fluency and create difficulties when speaking to their parents. Below Doungchanh and Liuz describe how they lost fluency in their heritage language.

Doungchanh: My boyfriend and I speak English to each other; my brothers and I speak English to each other. My friends and I who are even Lao speak English to each other. So, when I speak to my parents, it's a bit of a struggle and it's just because I'm not around it.

Liuz: I'm more fluent in English than I am in Mien. It's kind of sad to say, but that is how it is in my situation and me being Mien. I know a lot of the Mien people and I see them in the same boat. 
Since the heritage language is often not recognized at school or used outside of home and ethnic communities, the chance of speaking the language fluently deteriorates. In addition, speaking English at home or in their neighborhood further reduces their native language fluency. Yet some participants still saw value in their language and when they become adults or in college.

Doungchanh: I don't have children, but I do want children. And I want them to feel that connection with their heritage and you have to lead by example the same way my parents are. So, definitely I feel like if I ever have children like that I would have to do the same, so, yeah. I need to practice what I preach.

Vireak: I would say, it's really important to maintain that and to remember the language. Don't forget that. Just be able to speak it. That's something that I still wish I had. I've travelled to many places now. It's not until then that I realized how big the world was and how wonderful it is, and how helpful it is to know another language.

To summarize, cultural expectations among the four ethnic groups are generally similar. The cultural value of being a good child to the family was seen across the four ethnic groups. Likewise, maintaining a life balance was seen as important for all the four ethnic groups, probably due to the reality of living in two different cultures. The values of hard work, personal honor, and honesty were also shared among the four ethnic groups. Furthermore, parents' educational expectations were shared across the four ethnic groups. At the same time, gender differences and expectations have shown some shifts in ways that serve to enable females to achieve higher educational attainment. Moreover, religion and language were not particularly salient in this study. 


\section{Like-Minded Friends}

Similar to Guiffrida's (2003) and Tang, Kim, and Haviland's (2013) studies, friends and classmates emerged as salient factors in achieving academic success for Cambodian, Hmong, Lao, and Mien college graduates. Like-minded friends motivated, encouraged, supported, and pushed their Southeast Asian friends to do well in school and to go on to college. Many of these friends were high achievers, self-driven, and focused on academic performance. Liked-minded friends clustered into the following categories: (a) role models, (b) high achievers, (c) friends with educational access, (d) friends from outreach programs, (e) ethnic friends, and (f) friends in all aspects of life.

\section{Role Models}

Friends who went to college were role models for several participants. Ponleak and Vireak, for instance, applied to the colleges where their friends had applied. Without friends to show the way, Ponleak and Vireak might not have considered going to college.

Ponleak: Some of my friends went to college, and some of them went to the same school at [CSU campus], so that was a motivating factor. I probably might not have gone to college. I might have graduated high school, but I probably wouldn't have gone on to get a Bachelor's degree or anything like that if I didn't have any friends who went to college, like why should I go to college?

Vireak: I just applied to the colleges [where] my friends applied to. It was what everyone else was doing. I was just trying to model my behavior after all the smart people in school. They say they came from good families of money. 


\section{High Achievers}

Friends who are academically driven can encourage and motivate their friends toward the same goals of doing well in school. Liuz, Saeng, and Npaim purposely made friends with other high achievers in high school to help motivate themselves.

Liuz: I did what every other person did, played sports. A lot of my friends over here are friends I knew from college. So, I surrounded myself with people who were in college. I guess pushing towards the same goals that I wanted to strive for.

Saeng: I surrounded myself with people who are ambitious and who want better for themselves and their friends. You know, so don't let other people hold you back even if it's their own family.

Npaim: I think it's just finding your clique and your group that you associate with and taking the good friends. ...you're pretty much picking out good friends out of the bunch rather than surrounding you with people that's steering you to a different path.

\section{Friends in College prep Programs}

Cherng, Calarco, and Kao's (2013) study found that the students with resourcerich best friends whose mothers are college-educated are more likely to graduate with a four-year degree, regardless of the students' family resources and for other factors.

These best friends can provide access to the cultural and material resources to support the students going and completing a four-year college (Cherng, Calarco, \& Kao, 2013). The excerpts below demonstrate interactions between study participants and their friends in college prep classes.

Zaih: My friends and I are basically on the same [AP] track. We study together. We basically help each other out. 
Saeng: Because I was in those types of classes like the Honors and Advanced [Placement] classes, I was surrounded by other students who were also intent on going to a UC school. And so, ... you can learn from each other like what courses to take or like ... having to take ACT or SAT, study materials.

Bopha: You get trapped into classes and student system and because I was thinking like AP classes in high school. I would put into a social circle with other students who were on the same level of educational attainment as myself. So, these are the friends that I made.

\section{Friends in Outreach Programs}

Like friends in a college prep program, friends in outreach programs encouraged their classmates to set higher goals for themselves and share their knowledge about the educational system and resources. In addition, these friends generally came from lowincome families and were first-generation students themselves. They thus had a deeper understanding of the challenges that their Southeast Asian friends were facing.

Bopha: The friend that I made at Upward Bound was a key to helping me set higher goals for myself as well. Like for example, ... the friend ... had told me, "you shouldn't just apply to the [public] schools, you should also go towards the private schools because they're the ones that have the money to give you, the scholarships, to go to your school or you should think about Ivy League Schools."

Npaim: Because being part of health tech, being part of AVID, [and] being part of EOP ...you see ... these students over and over, and you share this ... common value that you tend to be more focus in school, and we tend to be serious about school ... because being surrounded by that environment ... it's having that common knowledge; it just made us support each other.

\section{Ethnic Community Friends}

Friends from ethnic student organizations can provide social and emotional support (Guiffrida, 2003; Tang et al., 2013). These friends can also connect students with 
academic support, act as a support group, and help develop a sense of ethnic pride (Guiffrida, 2003). Friends from one's own heritage community can also make one feel at home when pursuing the uncharted territory of higher education, which can be lonely and intimidating. These may be friends from their neighborhoods and from ethnic student organizations. Both groups have the potential to understand the students' struggles and help their friends persist in a hegemonic institution.

Saeng: Through the friends that I made being at an organization ... we would have study groups ... It was the learning process early on figuring out how to balance, how to get through the academic stuff, but I also knew what helps me was ... having that community and the friends who are trying to go into it, too because honestly, like we all felt that way... We all related to each other in that experience of how hard it was for us to get through or how hard and rigorous academics were.

Sathea: Being in [high school], the good thing is there are other people that are like you that you can hang out with, and you don't have to worry about lunchtime that someone's going to jump you.

Kham: I feel like having the right friends who kind of help me with the good selfesteem and feedback like it doesn't matter if you were poor. People relate to like my friend [Nyugen]. He was super poor. He's also Asian. He totally had the same kind of upbringing I did.

\section{Friends in All Aspects of Life}

Having friends in all areas of life can offer students comfort and support. For example, a friend on a college campus can help a student feel familiar with college life when new to campus. Kaj was a new transfer student and did not know anyone on campus. 
Kaj: I lived with this girl ..., a PhD, from education... She was really super involved in like Hmong Club because I'm a transfer student. So, I didn't really know anybody ... what I did was I followed her around. She's like, do you want to go to the Hmong club meeting? Okay. Do you want to go set up the Hmong club potluck table? Okay. I was game. So, I just said okay to everything because I was bored, and she had friends.

Moreover, friends from all sides of the spectrum can help each other. High-

achieving friends can help their friends academically, and the ethnic friends can help their friends feel at home.

Chenda: Friends..., I had two different worlds... I had friends who weren't thinking about college... and who ... were thinking about college... So, these are friends that I had classes with... And so, academically you're surrounded by people who ... take their homework seriously... And another group of friends that helped me ... maintain ... a sense of home..., things we do at our family. So, those two types of friends are really important to my upbringing.

Also, encouraging friends, whether or not they are on the same track as their friends, can motivate them to realize their goals. Liuz credited his friends from his business organization for his academic success.

Liuz: A lot of ... people I probably never would've spoken to or hung out with if I weren't in a fraternity ... we're all business students; it's a business org. We have the same classes; we're using the same textbooks, the same professors. So, we're just a great resource. We were able to get together, to study for exams, [and] to share books.

Just having a friend to give a hand when one is at a vulnerable time can strengthen and reaffirm one's commitment to success. This finding was also supported by the 136 survey participants. Three of the four ethnic groups chose student organizations as places where they had the highest frequency of interactions with their friends. Lao participants 
had similar interactions with their like-minded friends at school, social events, and student organizations (see Figure 25).

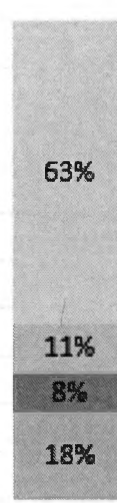

Cambodian

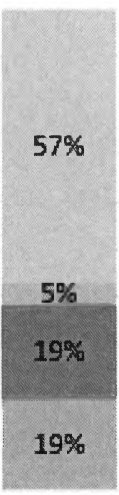

Hmong

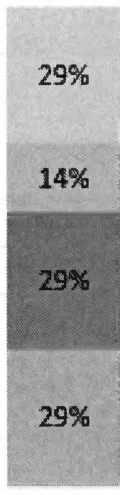

Lao

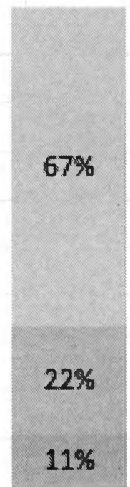

Mien

- School Administrators

- Social Event Members

- Heritage and Religious Event Members $=$ Student Organization Members

Figure 25. The highest frequency of interactions of survey participants.

In addition to friends and classmates, like-minded friends came up repeatedly.

These friendships were formed not only in student organizations but also in advanced placement classes, college prep classes, sports teams, outreach programs, neighborhoods, schools, college classrooms, on campus, and in college. Ninety-seven percent $(\mathrm{N}=132 / 136)$ of the survey participants participated at least one of these contexts and thus encountered friends. Figure 26 compares the school activities that like-minded friends participated in when they were in school. 


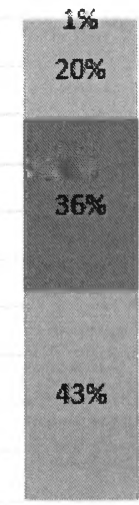

Cambodian

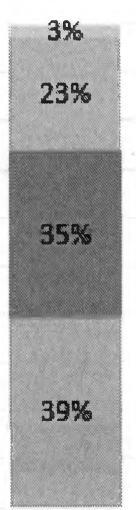

Hmong

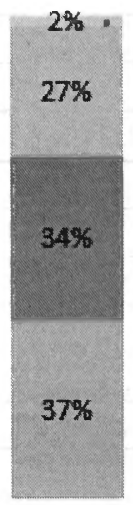

Lao

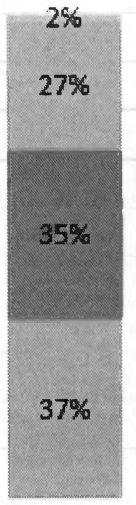

Mien

Extracurricular activities a High tracked classes

in Outreach programs Private tutoring services

Figure 26. School activities of survey participants.

College can be a lonely and intimidating place for many Southeast Asian students due to their hardships originating from being the children of refugees. Survey participants reported that $58 \%$ of them experienced a lack of parental involvement, $54 \%$ a lack of sense of belonging, $44 \%$ a lack of self-esteem, and $20 \%$ a lack of student engagement as their schooling constraints. Figure 27 compares these constraints across the four ethnic groups. These findings are similarly distributed across the four ethnic groups. 


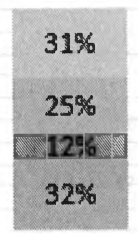

Cambodian

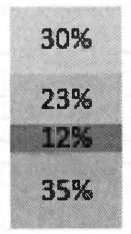

Hmong

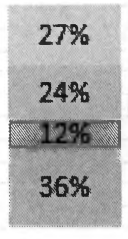

Lao

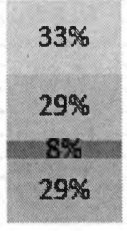

Mien

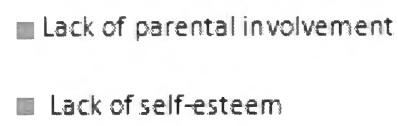

Figure 27. School constraints from survey participants.

When Southeast Asian students are confronted with hardships, they must find ways to compensate for their deficits in order to be competitive in school. One of these ways was like-minded friends. Friends can supplement the role of Southeast Asian parents by modeling, motivating, supporting, and encouraging classmates to succeed in college. Nonetheless, $82 \%$ of the survey participants reported their parents' value of education, encouragement, and support as their most valued support system for academic success, while $65 \%$ of them reported that peers sharing the same values were key supports for their academic achievement. Figure 28 shows reported supports for academic success across the four ethnic groups. Cambodian and Hmong students rated their peers sharing the same values of academic achievement higher than their parents' value on education while Lao and Mien students valued these in reverse order (Figure 28). 


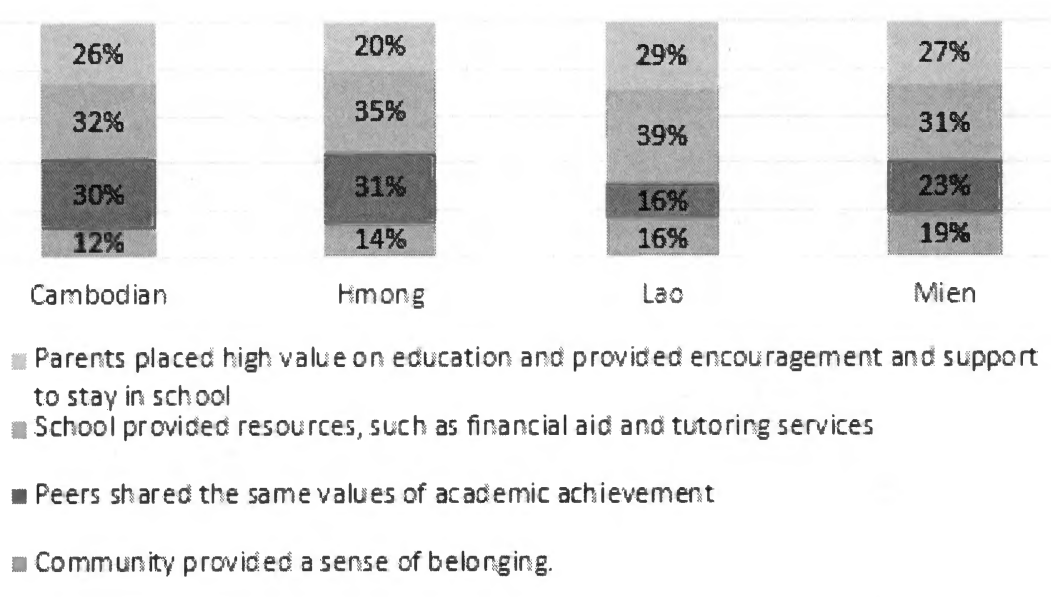

Figure 28. Supports for academic success for survey participants.

\section{Identity in Practice}

The theme of identity in practice is divided into the following four sub-themes:

(a) figured worlds, (b) positionality, (c) space of authoring, and (d) making worlds. These reflect the study's theoretical framework, which is based upon the work of Holland et al. (1998).

\section{Figured Worlds}

Figured worlds are places where individuals may encounter personal and social stories derived from historical accounts. These accounts can either oppress or liberate them via power distribution, rank, and prestige. Individuals learn to accept, reject, or negotiate these relationships. Many of the students in this study, for instance, learned about the broader geopolitical context of their family and community history for the first 
time in college, and they tried to make sense of how that history could fit together with

family stories, and consequently, their own stories.

Chenda: I learned at [UC campus] a lot about my parents' history, trajectory, but also the geopolitics that led to my family's diaspora. For the first time, I learned about what occurred in Cambodia, what transpired, how does my family stories fit into this, how did my own story fit into this.

Kaj: And I focused on the new history of the 20th century because that's like the cold war. That's where you get that French Indochina War and World War II and all that stuff. That ... spoke to me because I ... wanted to understand how I operated in the world, like how did my story fit in this big puzzle? ...growing up Hmong, it's such a Hmong story, but there's a bigger context; there's more international that shaped our lives.

Once they understood their figured worlds, they started to recognize their positionality within those worlds.

\section{Positionality}

Positionality refers to the social location that individuals occupy in different

figured worlds. When individuals are positioned, they may be limited in their capacity to accept, reject, or negotiate their identities that are available to them. In a related way, the participants recognized the differences in their demographics, culture, and socioeconomic status during college. They were in a space with White or non-Southeast Asian students with whom they could not always relate. Southeast Asian students were thus positioned in a space where they had to accept, reject, or negotiate the identities that were available to them. There were four identities that they tended to consider, including (a) 
American identity, (b) model minority identity, (c) refugee identity, and (d) multiple identities.

American identity. "Being an American" for participants in this study meant having an American name and disassociating from one's own ethnic heritage identity. Having an American name is a tool that can be used to fit in with mainstream society and to disconnect from one's ethnic identity. Bopha's father, due to his negative experience during the Cambodian civil war over, purposely gave Bopha an American name, "Nancy," so that she would not have any evident connection with Cambodia. In a related way, to fit in as an American, Keola's sisters gave him an American name, "Michael," which he used from elementary to high school. However, he went back to using his Lao name, Keola, when he started college.

Bopha: I had very Anglo-American western name, and I was like, "Why did you name me Nancy?" I don't have a Cambodian name... He was like, "Well, you know when we left Cambodia," he's like, "I didn't want any association with that country because of what happened, and any future generation of mine are not going to have any connection with Cambodia" because of what had happened to him and his family which I can understand at that point.

Keola: In elementary school..., my sister gave me an American name. So, everybody would pretty much call me, Michael. But ... when I got a chance to go to college, I realized I was like what do I have to be ashamed of my name for. Kids used to make fun of it so much when I was growing up.

Southeast Asian students were frequently targets of racial discrimination and harassment, and such practices were often ignored by teachers and school administrators (Kiang \& Kaplan, 1994; Kiang, Ngoc-Lan, \& Sheehan, 1995; Uy, 2011). Thus it was thought by 
some refugees that having an American name might limit one from being targeted for negative stereotypes.

In addition, some thought that disassociating oneself from one's own ethnic community would change one's self-representation as a poor refugee kid from a lowincome community. Bopha's father told her not to play with her Cambodian neighbors, because he perceived them as being uneducated and that they would be a bad influence on her. Malayvanh's aunts and uncles told her not to spend time with her extended family or the Lao community because they went to a low-income school and would be a negative influence.

Bopha: Growing up in Section 8 Housing [government housing assistance program] in... the ghettos of [Local City] and having also ... a weird thing, ...my dad was pretty adamant that we ... separated ourselves from the rest of the Cambodian Community in [Local City]. I found that rather strange especially as a child where we had Cambodian neighbors in our neighborhood, but he was like, "Oh, no. You're not going to play with them because they're like totally uneducated, and they're just going to give that influence on you."

Malayvanh: Growing up ... a lot of my aunts and uncles would actually tell us to not interact with ... the Lao community, our extended family, our cousins, and things like that because they would tell us your cousins ... go to [low-income school]. They didn't want them to negatively influence us... I used to be really close to my cousins growing up but then my aunts and uncles told me and my siblings to stop hanging around [them].

At times, being different from one's own cultural identity meant being identified as White or assimilated. When Kaj, for instance, wanted to be different from other Hmong girls, she not only assimilated culturally but also dyed her hair blonde and wore blue contacts. Hli was called "whitewashed" by other Hmong girls for being vocal, 
volunteering, and being involved in school activities, and for having diverse groups of friends.

Kaj: It's that kind of hyper assimilation at that stage in your life, too... So, you're like okay; I don't want to do what all these other Hmong girls were doing. I want to do something different. Being different almost meant like having to be White. Okay, I'm going to a very White route and seriously, I did dye my hair blonde and put in a blue contact.

Liuz: [Parents] they still carry on some of the Mien traditions but as time goes on ..., they become more Americanized, and I'm pretty American. Like every other American high school student, I wasn't really thinking about academics. I'm thinking about hanging out with my friends and doing this, this, and that. I felt like I really found myself because I joined the business organization.

In this study, being different could mean attempting to physically and mentally assimilate to "becoming White"; however, it could also mean being actively involved in school activities, volunteering and running for a student government, and having friends from other ethnicities, including White friends.

Fitting in as an American also seemed to mean having what other people had.

Doungchanh worked while in school so that she could buy the things that other classmates had. Similarly, Bopha did not want to stand out as a poor refugee child from a low-income neighborhood. Fitting in was her goal, and this she thought would require her to develop an American identity.

Doungchanh: You want to fit in high school. You want the new shoes or ... in your adolescence, material things matter. So, I ... as well as my brothers, we were like, oh, I want this and my dad says, well, I'm going to pay for the basic and if you want anything beyond that, then you buy it. 
Bopha: My... freshman year, I was really to find my fitting in every sense of the world ... socially, who I can be friended with? Who's going to understand me? How do I behave among these people? I really felt like a foreigner, and I felt like I had to ... play a role that wasn't necessary the same role that I played back in high school. What important was just fitting in, making sure that I didn't stand out as...the poor refugee kid from [Local City] even.

Model minority identity. The term "model minority" connotes a stereotype that depicts Asian Americans, including Southeast Asian Americans, as a group that has achieved educational success despite facing marginality and discrimination (Covarrubias \& Liou, 2014; Wallitt, 2008). This stereotype was experienced by multiple Cambodian and Lao participants in the study.

Bopha: As an Asian-American female, I would immediately label the model minority. I would have to say that obviously my record and my behavior probably just added to that stereotype because I'm probably one of the top students, and I was well behaved.

Saeng: My parents always ... ingrained in our upbringing like to go to school and to do well at school and to get good grades. And so, it was easy for me to fit the model minority kind of image because I was a really quiet kid ... and so when you don't cause trouble in the classroom, teachers don't ... worry about you.

Many of the study participants did, in fact, compile superb academic records. For instance, three of the five Cambodian interview participants (Bopha, Chenda, and Sathea) attended Ivy League schools for at least one of their degrees. All five Cambodian interview participants hold a master's degree or higher. Chenda completed her doctorate during the time of this study. Three of the six Lao interview participants (Bounsy, Keola, and Saeng) hold a master's degree. In addition, Bounsy applied and was accepted into a $\mathrm{PhD}$ program during the study. Three of the five Hmong participants (Hli, Kaj, and Xia) 
hold a master's degree. In addition, Paj was in the process of applying to a medical school during this study. Although none of the three Mien interview participants holds a master's degree or higher, this could be due to the smallest sample size among the four ethnic groups.

Bopha and Saeng were seen as model minority students in high school, but they felt isolated once they got into college.

Bopha: Once we got into college..., I sought out other Cambodian-Americans, and I think probably that was because I felt so isolated in a community where I did not fit because here at least in high school, I was among a very diverse group of student body where everybody from [Local City] was kind of representing whereas once I got into [Ivy League University], I felt I was way out of my league.

Saeng: When I went to undergrad..., you come to the realization ... fast ... how different you are from the people there..., seeing culture as well as like your socio-economic standing. It's very isolating to experience ... when you're ... living in the dorm surrounded by certain types of people, and you can see the privileged.

Both Bopha and Saeng sought out other students from their own ethnic groups to cope with their isolation. Bopha reached out to other Cambodian-American students, and Saeng joined the Lao club with her sister on their college campus.

Five (26\%) of 19 interview participants did not feel they belonged on their college campuses, and this sense of isolation was supported by approximately one third of the survey responses (see Figure 27).

Malayvanh: It was very tough being surrounded by ... that ... Asian population at [UC campus] that is larger than the White population. So... I was surrounded by 
the most Asians I've ever been. I felt I can't connect with them because the Southeast Asian population was very low.

Lowc: It was challenging to be in a school where you're being told you're over represented because there's so many Asian Americans, but when I got here, I couldn't see myself in them because they didn't go through the same challenges... It was very hard to explain that to people at [UC campus] and to be able to have to constantly fight and ... defend being Southeast Asian and what that meant, and how that was different and from just being Asian American or being an immigrant.

At the national aggregate level, the achievement data of Asian Americans consistently has been similar to or higher than that of White Americans, which reinforces the model minority myth and minimizes the racial complexities of Southeast Asian Americans (Covarrubias \& Liou, 2014; Teranishi, 2002). Due to this perception, Southeast Asian Americans tend to be excluded from racial discourses on educational issues.

Xia: When I first got to [UC campus], I didn't have a laptop right away ... and then everybody around me, my roommates... had laptops. [Also] going from a high school with ... ethnic minority ... students to [UC campus] ... with a lot of Caucasians; even though Asian-Americans are considered one of the higher minority groups that are represented at [UC campus], I didn't feel that way. So..., that was the first time, I felt I didn't ... belong.

Only $21 \%(4 / 19)$ of the interview participants could be seen as high performing, "model minority" students in high school, and one third of the participants felt isolated once they got to college. In addition, many of these students experienced various challenges relating to their refugee status. 
Refugee identity. As noted earlier in the section on Refugee Experience (see pp. 118-139), Southeast Asian students often came from low-income neighborhoods plagued by violence and lack of opportunity. Because of the language barrier, their families could not find jobs or worked in low-paying jobs and had to rely on public assistance.

Multiple identities. Being Southeast Asian American students, these students had to navigate between their home culture and the American culture. However, the multiple identities in this study went beyond the two cultures. Four (Chenda, Hli, Kham, and Keola) of the 19 interview participants had multiple identities. Chenda navigated a balanced life between her two cultures. Hli expected to bridge between her field of study and her Hmong community. Kham was gay, and Keola considered himself more American culturally.

Chenda lived in a low-income neighborhood but went to a predominantly White high school. She had academic friends from school and neighborhood friends who were important to her. During lunch, Chenda would spend time with her Cambodian friends. She also would share her Cambodian snacks with her academic friends, which allowed her to connect with both her White classmates and her Cambodian friends.

Chenda: I was with predominantly White students, ... and then at lunch time and so forth, I'd hang out with my Khmer friends and we brought the salt and pepper and ate sour fruit. ... it's almost like you had to be both, but I felt like I was able to connect. So, I share my sour fruit and salt and pepper with my friends during class, and they get interested. So, I remember it as being tenacious, but because I had to interact with different people, and you just learned the different cultures. 
Hli was called "whitewashed" for being active and for having diverse groups of friends. She also majored in theatre arts, which was a unique major and put her together with diverse friends.

Hli: When my parents moved us ... to ... where the Hmong population was really small and I got involved in drama and theater arts, ... my social circle expanded again. ... I started hanging out with ... more diverse circle of friends. Once I was put in a situation where ... you're not going to have ... all those Hmong kids hanging around, you got to find someone to be friends with and that really changed things up for me. There was always this expectation that I would bridge ... to the Hmong community in my field.

Kham was gay and did well academically, which helped him through to college.

He surrounded himself with academic friends who were willing to try new things to help with his academic journey. However, his brother, who was also gay but was not academically accomplished, ended up dropping out of middle school.

Kham: I was gay, and I was very smart. So, I knew ...I need to go to college and make money. I had a lot of friends who are just like don't be afraid to try different types of things; despite how people make fun of you. I had ... six years of friends that are supportive. That's kind of ... extra step that you grew up that... helps ...my middle brother was also kind of gay but not very smart and confused. He basically dropped out of middle school. I think it was also because he dealt with a lot of pressuring and bullying.

Keola hated being poor and on welfare. He wanted to be an American so that he could fit in. He changed his Lao name, Keola, to an American name, Michael, which he used throughout high school. Once he learned about the historical links between the U.S. and Laos that had caused him to become a refugee, he did not want to be an "American" any more. He started to use his Lao name in college. After volunteering for the Peace 
Corps, traveling abroad, and seeing his family doing well in the U.S., he could not deny

being part of the American culture. Keola now sees himself as Lao and Chinese

ethnically, but American culturally.

Keola: So, I went through that struggle of finding ... my own identity, being a refugee, being a minority. As much as I tried to deny ... wanting to be American in the beginning and then after denying it and didn't care about being American [but] having the opportunity to live in the United States and have been educated and having this life, ... I can't say that I'm not a big part of the culture. It's a part of me: how I dress, the music I listen to, everything. I can say I'm ethnically Lao and Chinese but culturally not really. I'm culturally more American.

Multiple identities in this study went beyond experiencing between the two cultures. Chenda connected the two cultures by connecting her academic friends with her neighborhood friends. Hli was expected to bridge her theatre arts major to her Hmong community. Kham was gay and surrounded himself with academic friends to help with his academic journey. Keola's identity was dynamic. He wanted to be an American initially, then denied it, and then accepted it.

\section{Space of Authoring}

Space of authoring is the capacity of Southeast Asian students to make sense of their identities or positions through internal dialogue. Some of these students were faced with family restrictions that prevented them from fully participating in school activities or going to the school that they wanted to attend. In addition, many students more fully recognized their disadvantages when they got to college. When these students were required to accept, reject, or negotiate their positions, they had to make choices and 
respond. The following two main conceptual tools are used to explain the choices and responses they made: (a) improvisations, and (b) self-directed symbolizations.

Improvisations. Improvisations are a form of human agency and a means for improvement because even the most powerful institutions, educators, or parents cannot prevent individuals from improvising. These are the moments of resourcefulness that connect existing cultural resources opportunistically to address present conditions and problems (Holland et al., 1998). Some Southeast Asian students in this study had to combat with family restrictions and disadvantages on their college campus, and they did so through various instances of improvisation.

Family restrictions. Parents are instrumental in their children's success; however, they can also be the obstacles when they do not understand the U.S. education system and bar their children from certain school activities or certain schools. Their children sometimes have no choice but to go against their parents' wishes in order to achieve success. Vireak, Paj, Zaih, Xia, and Kaj all had to resist their parents or their parents' expectations to succeed.

Vireak's parents always wanted him to go home after school and were upset when he stayed after school for extracurricular activities. Vireak went against his parents' wishes and participated in extracurricular activities, because he felt they were important for his success. Because he was well-rounded, he got accepted into the school to which 
he applied and received full scholarships for both his undergraduate and graduate degrees.

Vireak: My parents really wanted me to come home and just be with the family. But in order to be successful, I felt like I had to stay after school, participate in these after school activities like sports, so I could be a well-rounded student ... I also had to work for money... I really wouldn't come home till like 9:00 PM. That really upset my parents ... In college, I moved out to live in the dorm. They would always want me to come home, like every weekend or every day, but ... I would rarely come home. I never really listened to my parents.

Vireak graduated with two bachelor's degrees and a master's degree. He now works at a software company and works around the world. His interview for this study was done from his hotel room in Thailand, where he was working for two months.

Like Vireak, Paj's parents did not want her to participate in any extracurricular activities, but only to focus in school. She joined a debate team in her freshmen year, but her father made her quit in her sophomore year. In her junior year, she resisted her father and participated in the debate team and led her team to a national competition. Since then, her parents were more open to extracurricular activities for her younger siblings.

Paj: I started on with the debate team ... in my ninth grade year. I had done so well, and I won so many tournaments. [However] throughout high school, we [Paj and her siblings] shouldn't do extracurricular [activities] because my parents were like, "You have to just go to school. That's it." ... At the end of ninth grade, my dad, "You got to quit debate." ... I ended up telling my coach that I needed to quit debate and he was like, "Why? You're so good at it." ... I couldn't explain to them besides the fact that my parents wanted me to focus on school.

[And...] then again, 11 th grade, I decided ... I'm going to do this because it's so important, and my parents don't completely understand it ... So, after that experience in 11 th grade, I ended up going to national, and ... after my parents 
saw that, they were then more open to extracurriculars for my younger siblings. I sort of changed the way they saw school, but it was definitely hard.

Like Vireak and Paj, Zaih's mother did not want her to participate in extracurricular activities. However, Zaih kept participating in the activities because they helped develop her leadership skills.

Zaih: I guess the most tension I got was from my mom where she would be annoyed about my participation in my extracurricular activities in high school. Because I was involved in other Asian organizations in high school and she would be really irritated then. I guess it's always focused on my school and got better grades. But I think my experience from those organizations was really good because it helped us developed our leadership skills ... It's just one of those things. Like I'm going to keep on doing it, and then she kind of didn't support me, but then she gets over it.

Xia's father wanted her to stay close to home during college so that he could look

after her. He did not want her to go far away to a well-known [UC campus] when she got accepted to the school. However, she argued with her father to let her go to the [UC campus]. He finally agreed, but they still had disagreements until he recognized that Xia was a responsible adult while she was away from home.

Xia: We actually got into a lot of disagreements ... because he [father] wanted me to stay close to home... I think it goes back to ... just make sure everyone's okay and take care of everybody mentality that is very much is a Hmong father type of approach ... And so, he did not want me to go away to [UC campus] at all, but I was really stubborn, and I just told him that I needed to do it, and so, eventually he agreed to it, but we disagreed a lot ... Once he saw that I was able to be a responsible adult ... he realized that I could be responsible too and that I was doing well academically.

Unlike Vireak and Xia, while in college, Kaj went home to support her family and play the daughter's role until her grades suffered. When she realized that having a college 
degree would allow her to help her family better, she gave herself more freedom to live on campus.

Kaj: It was extremely hard ... about going to [UC campus], [is] when I made a conscious decision because I had so much turmoil of taking care of my parents. Going back home, giving my financial aid money not because they asked for it ... but I just felt like I got all this money, I should give it to them to help them pay rent, or there's going to be a feast this weekend, I should go and help and do my daughter role.

And I kept going [back home] to the point where my grades are suffering. So, I made a decision that you have to essentially save yourself. I have to make it through [UC campus], so that I can actually better provide for my parents after getting a degree.

Although supportive families were key for participants in this study, family restrictions could also prevent refugee children from achieving their full potential. Vireak, Paj, Zaih, Xia, and Kaj were fortunate enough to have the will to improvise resistance against their parents to ultimately achieve success.

Disadvantages on a college campus. With an understanding of their history and their disadvantages on a college campus, some of the participants became involved in various programs to address social justice concerns, to further understand their identity in a broader context, and to educate the next generation.

Saeng: I also started participating in the student organization, ... which focused ... on the refugee experience, the war, in Southeast Asia and ... how that translates into our lives and ... our family lives, ... trying to gain a better understanding of that and educating the younger generation of that as well.

Bopha: My freshman year ... was ... to find my fitting in every sense of the world like socially, who I can be friended with? Who's going to understand me? How do I behave among these people? I had to ... play a role that wasn't necessary the 
same role that I played back in high school. I just didn't think that they would understand ..., "Oh, well, there's that poor kid" because I hadn't found a group of other students who came from a similar background.

Many Southeast Asian students learned about the disadvantages and challenges of their community during college. They understood the privilege of being on a college campus and used their positions to address social justice issue. They employed multiple forms of improvisation to help them respond to the challenges during college.

Self-directed symbolizations. Self-directed symbolizations are another form of agency. Holland et al. (1998) argued that people use whatever is at hand to opportunistically change their position in the cultural arena they experience to form their own sets of characters. To enhance understanding of self-directed symbolizations, this study supplements those notions with the human agency concept of Bandura (2001). Bandura's concept consists of four core features: intentionality (making choices), forethought (action plans), self-reactiveness (motivating and regulating execution), and self-reflectiveness (personal agency).

Intentionality (making choices). This is a form of intention that is a proactive commitment to act on future performances. It is the force that motivates an action to take place for a given purpose (Bandura, 2001). Chenda and Liuz had strong intentions of wanting to go to college, graduate from college, and get a job, while Hli wanted to do something that she was passionate about.

Chenda: I want to go to college, and no matter what I did, it was to achieve that. 
Liuz: Wanting to get that degree and me wanting to succeed, ... it tremendously impacted my academic success because I feel like without that passion or that drive, for me, getting a degree wasn't easy ... it was just the journey, but it was just long and tedious ... if your heart wasn't there, it's hard for you to get there.

Hli: Always doing something that I was passionate about and I enjoy. And so, then my classes that I was taking ... would be the things that I enjoy doing ... it made it seemed like school was a lot easier for me.

Forethought (action plans). After the participants made their choices, they expected to see intended consequences of their actions (Bandura, 2001). They chose courses of action to produce desired outcomes and to avoid unfavorable ones (Bandura, 2001). With forethought, they inspired themselves and directed their actions in anticipation of future events. A "forethoughtful" perspective gives direction, coherence, and meaning to one's life, according to Bandura (2001). Vireak followed the four-year path that was laid out for him. Npaim focused on her homework and put the effort into doing it. After Ponleak got rejected into a master program at a [CSU], he took several more advanced classes and applied again.

Vireak: I just wanted to be successful... I had to be successful, go to college, and then not be poor. ... I was just given this ... four-year program. You go through this to graduate. It was kind of like, "Here are the instructions to graduate," and I just follow them, and I get through.

Npaim: So, I was focusing on homework; I was putting the effort in them. So, I was doing well. ... that's all it takes, and it's just ... focused on studying and reading. ... then I started to excel and then ... getting awards. So, it made me even more motivated to study harder.

Ponleak: The first time I didn't get accepted into any graduate schools, ... I decided to take a few more advanced courses that I felt might help me in my 
application process the next time around. ... then the second time around I applied again, ... I got accepted into a master's program at [CSU].

These students had good intentions, but if they did not act on them, their intentions would not be realized. Once they acted, they achieved their intentions. Working hard was the common theme among the 19 participants.

Self-Reactiveness (Motivating and Regulating Execution). Once the participants made choices and formed action plans, they followed appropriate courses of action and monitored their execution (Bandura, 2001). Chenda had to be different, Npaim wanted to prove to the students from affluent schools wrong, and Paj just wanted to learn when opportunities were presented to her.

Chenda: When you're aware of what you don't have, and you're trying to succeed in a world that you don't understand, you seek to bridge that ... when you're invited to dinner with ... a big shot person [your professor], they're not going to have Khmer [Cambodian] dinner ... how am I supposed to behave? What do I dress? I don't know those norms ...I think it's being aware as even early on that I have to be different.

Npaim: I want to prove them wrong; even though, I go to the ghetto school ...there's a few teachers here that believe in us that are willing to support us and push us to do well.

Paj: I ... wanted just to learn. ... when you get those opportunities, you feel ... you are equal [and] that you can contribute something to your class ... all those experiences ... gave me the confidence to have a voice. So ... that was ... some inspiration, and ... I'm going to be impactful and be committed to learn continuously.

Self-reflectiveness (personal agency). "Agentic" people are those who exercise control over the nature and quality of their lives. They are also self-examiners of their 
own functioning, with the capability to reflect upon themselves and their thoughts.

Agentic people assess their motivation, values, and the meaning of their life pursuits.

They respond to conflicts with motivational encouragement (Bandura, 2001).

Npaim: I wanted to get into a UC campus. ... because they [AVID] were saying ... to be a strong candidate, ... you need to do this. ... to be competitive. ...that's why I did so many activities because ... I need to do this to boost my application.

Liuz: I remember my dad used to say, "I can't tell you what to do. I need just to let you make your mistakes, and that's how you're going to learn from because that's how you are." He was completely right. I knew I wanted to push toward my degree... I just kept working at it every day.

The Southeast Asian students in this study improvised resistance against their parents to participate in extracurricular activities and to go to the school that would give them the highest potential. They also used their positions as students, and the knowledge gained during college, to address social justice issues. Moreover, they were also selfdirected and exercised human agency to achieve academic success. They had the strong intention of wanting to go to college and succeeding. They also laid out and followed action plans to succeed. In addition, they persistently pursued their purpose of succeeding . in higher education, which kept them motivated during college. Finally, they reflected on their experiences and took appropriate actions to succeed.

\section{World Making}

World making refers to a newly imagined world, which through social interaction creates the possibility of a new way, artifacts, discourses, acts, and potentially more liberated worlds. World making connects personal and social stories and identities back 
to figured worlds. The outcomes of improvisations and self-directed symbolizations created new worlds for those students. Some of the Southeast Asian students translated their experiences into new opportunities. Because of the challenges that they had faced, being in the same institutions with those who never knew what it was to be a refugee was a privilege, and they used that as a motivation to persist in college.

Sathea: And I started realizing, for example, out of the 50 families that I grew up with ... no one went to college... This is ... a ... really special opportunity for me, and I better take advantage of it. So, ... I just ... pushed myself even harder. Because there's no Superman that's going to save me.

Keola: When I got to college, ... it was a whole new, different world, and it gave a boost of motivation and inspiration. Because I got that second chance, I did so well. ...not many people get a second chance in life.

Saeng: I knew that ... there aren't many looking like me to represent this campus. So, if it's going to be someone, it probably has to be me because there's no one else.

In summary, the findings of this study appear to match Holland et al.'s (1998) research on identity and agency in cultural worlds. The findings align well with the four contexts of practiced identities: figured worlds, positionality, space of authoring, and world-making. In addition, the two concepts of the space of authoring were also applicable to enhance the understanding of the identity in practice in this study. The first concept, improvisations, was used to improvise resistance against family restrictions and against students' disadvantages on a college campus. The second concept, self-directed symbolizations, was supplemented with Bandura's (2001) four core features of human 
agency to illustrate how Southeast Asian students directed themselves to achieve academic success.

In college, many of these Southeast Asian students learned for the first time about their history and how that history translated into their family's lives and their lives. At the same time, they recognized the differences in their demographics, culture, and socioeconomic status during college. Many felt that they were in a space with White or nonSoutheast Asian students with whom they could not relate. Despite their differences and feelings of isolation, the students had to make choices and respond to the positions that they were in. With an understanding of their history and their disadvantages, some students got involved in programs to address social justice concerns. Others translated their experiences into new opportunities. Because of the challenges that they had faced, they realized that being in college was a privilege, and they used that as their motivation to persist.

Many Southeast Asian college students had the strong intention to go to college, graduate, and get a job. Once they set their goals with strong intentions, they generated courses of action to achieve them. Working hard and putting forth effort was a common theme among the 19 participants. Following a path to graduate was also important. Moreover, doing whatever was required to get their goals accomplished was also found in this study. Once they had their plans of action, they took appropriate courses of action to monitor and achieve their execution. Some students took the approach of negotiating 
their identities among friends, home, and teachers to bridge gaps and reach the goals that they were trying to achieve. 


\section{Chapter Five: Conclusions and Recommendations}

\section{Overview}

In this chapter, the study's findings are summarized, followed by a discussion of their implications for educational leadership, educational equity, improvements to Southeast Asian community centers, community-based Ethnic Studies programs, and recognition of culturally relevant programs. The chapter concludes with limitations and recommendations for action and for future research.

\section{Interpretation of Findings}

Throughout this study, the researcher sought out patterns of academic success of Southeast Asian Americans in higher education and investigated how those patterns impacted their lives. Five major themes emerged in the findings (schooling experiences, refugee experiences, cultural expectations, like-minded friends, and identity in practice) as patterns of academic success of Southeast Asian Americans in higher education, which are categorized for the purposes of this chapter into three broad thematic categories: (a) schooling experiences, (b) social experiences, and (c) identity in practice.

\section{Schooling Experiences}

Schooling experiences included: (a) high school experiences, (b) transition challenges, and (c) college experiences. 


\section{High School Experiences}

College prep courses. Key aspects of many participants' schooling in high school had to do with the types of courses they took. If they were tracked into college prep courses, as was the case for many participants, they were meant to be prepared for college level courses. Eighty-four percent of the interview participants and $76 \%$ of the survey participants took college prep courses. These students were exposed to more options and had more challenging classes than the students in regular classes. They were also expected to go to a four-year college after high school. This was the case for 16 interview participants.

Outreach programs. Many of the students in college prep courses also benefitted from extra resources from outreach programs, including Upward Bound, AVID, summer school, and EOP. These programs were generally created to support marginalized students to prepare for college. Forty-two percent of the interview participants and $50 \%$ of the survey participants participated in at least one outreach program. Most participants credited these programs for the extra help to get through high school and into college.

Extracurricular activities. Those students in college prep courses and outreach programs were informed of the importance of extracurricular activities for the college application process, and they thus became involved in extracurricular activities. Eightynine percent of the interview participants and $86 \%$ of the survey participants took part in such activities. 
Teachers and counselors. Teachers and counselors played a critical part in guiding participants in this study to achieve college access. Many of the participants would probably not have been as successful if teachers and counselors had not taken the initiative to guide them. Eighty-four percent of interview participants had positive perceptions of specific teachers and counselors who impacted their academic careers. Thirty-seven percent of survey participants identified teachers as having an influence on their success. The 16 participants who took college prep courses reported positive interactions with teachers or counselors, while the three students who did not take college prep courses did not report any substantive connections with their teachers.

In addition, teachers and counselor perceptions of students can affect college access. In this study, teacher and counselor perceptions of student potential were reported as generally higher than the students' perceptions of their own potential. In contrast, those three participants not tracked into college prep courses reported feeling invisible to their teachers and counselors.

Based on this study, students who already had resources from their college prep classes received additional resources from teachers and counselors. They had positive interactions with teachers and were perceived positively by their teachers and counselors. They learned the importance of extracurricular activities from their teachers, outreach programs, counselors, and college fairs. Counselors were willing to share information with them and help them prepare for college. 
In contrast, the study also found that the students not tracked into college prep courses did not share the same level of college preparation support and access. They had little connection with their teachers or counselors and were not given access to special support programs. Two of the three students with this experience went instead to community college after high school.

\section{Transition Challenges}

Once they were on campus, participants generally felt unprepared for college work whether or not they had college prep and AP classes in high school. Only two of the 16 interview participants who took college prep courses in high school felt prepared. Participants felt unprepared due to one or more of the following challenges: content gaps, structural gaps, special treatment gaps, lack of academic support, the quarter system, feelings of isolation, lack of cultural awareness by professors, and emotional challenges. Curriculum gaps between high school and college level courses, especially science and math, were reported by 17 of the 19 interview participants. Because of this challenge, one participant reported dropping out of a four-year college to go to a community college, later transferring to a private four-year college. Another participant changed her major from neuroscience to a different major that did not require science and math. Some participants reached out to classmates who shared similar struggles to cope with the challenge. 


\section{College Experiences}

College was difficult, a struggle, and a lonely place for many of the Southeast Asian students in this study. Most were away from their families for the first time. Many found support from ethnic student associations and a few participated in professional organizations. They also found supportive community coalitions or networks among the four ethnic groups. Some took the opportunity of being on a college campus to address social justice issues, bringing students from their communities to campus to encourage them to go to college. In addition, mentors played a critical role for many participants, serving as role models, guides, and reality checkers.

Many of the participants learned for the first time in college about the history and the politics of their refugee families. This often prompted them to become involved in their communities. Some participants had to work while in college to cover all their expenses. As a consequence, many struggled to balance their student lives. To persist, they had to reprioritize their purpose for coming to college and to encourage one another, emphasizing getting the degree as their highest priority. Without the degree, they realized that they would not be able to help themselves, their families, or their communities.

\section{Social Experiences}

The findings categories of refugee experiences, cultural expectations, and likeminded friends have been collapsed into the broader category of social experiences in this concluding chapter. 


\section{Refugee Experiences}

Understanding their family's refugee histories and recognizing their parents' struggles inspired the participants to succeed. They did not wish to "be a statistic" and felt that they had to succeed regardless of challenges. Although most participants' parents could not help their children academically, they helped them with whatever they could so that their children could take advantage of the educational opportunities in this country. Participants reported that Southeast Asian parents value education and support their children unconditionally in school-related activities. They were a strong source of motivation for their children.

\section{Cultural Expectations}

Cultural expectations among the four ethnic groups appeared to be more similar than they were different. The cultural value of being a good child to the family was seen across the four ethnic groups. Likewise, maintaining a life balance was seen as necessary for all four ethnic groups. Moreover, the values of hard work, personal honor, and honesty were shared across the four groups, as were parents' high educational expectations. At the same time, traditional gender expectations were shifted substantially to enable girls and women to achieve higher education. Religion and language were not found to be particularly salient in this study. 


\section{Like-Minded Friends}

Since high school and college could be lonely and intimidating places for many Southeast Asian students, they often found support via like-minded friends who motivated, encouraged, and supported them to achieve academic success. Like-minded friends sometimes supplanted parental roles by modeling, motivating, supporting, and encouraging each other to succeed in college. Some participants consciously picked and chose their friends, identifying high-achieving students from college prep courses and outreach programs as friends who could support their college success. Some also had friends from the same ethnic community to help cope with their struggles.

\section{Identity in Practice}

On their journeys through higher education, participants in the study had to navigate between the figured worlds of school, refugee family, community, and friends. In these figured worlds, four identities were commonly identified: American identity, model minority identity, refugee identity, and multiple identities.

The American identity was reported to be more prevalent in high school than it was in college. Luiz was the only student who kept his American identity throughout his academic journey, and he was the only second-generation student in this study. The model minority identity was generally reported as common in high school. The refugee identity and multiple identities were encountered throughout their academic journey. 
With these identities or positions and the knowledge they gained from school, the participants had to make choices and respond.

The participants encountered multiple challenges during their academic journeys, including family restrictions, neighborhood effects, gender role differences, selecting like-minded friends, and college transition challenges. Some participants saw going to college as a challenge because there were so few Southeast Asians on campus. Some improvised resistance to their challenges to achieve their goals and to persist in college. Others relied upon their refugee experience as a motivation to persist in college. The results of their improvisations and self-symbolizations became new worlds, including the experience of college graduation.

\section{Limitations of the Study}

One limitation of this study is the size of the sample. Findings are based on the experiences of 19 interview participants, supported by 136 survey participants across four ethnic groups. The findings are thus not intended to be generalized across all Southeast Asian college graduates.

Another limitation of this study is the possibility of an implied condition of gender equity among the male and female participants, which creates an inaccurate picture of Southeast Asian cultures. All of the participants were self-selected to be in this study and the majority of them were high-achieving students who had mentors to help them decode mainstream institutional settings and supportive ties in the home and 
community. However, these students represented only a small percentage of the four communities, and the women in the study in no way represented typical experiences of women in their individual communities. Although some participants did not experience the gender bias, others had to resist their parents' gendered views and expectations so that they could participate in extra-curricular activities or go to the school of their choice. Many of the female participants also postponed marriage —-sometimes against their families' wishes or expectations - in order to pursue higher education. Several female participants consciously pursued success in higher education in order to pave the way for the next generation of women and to prove themselves that they could succeed in higher education. One participant redefined her gender role to include financial independence and higher education. Even though gender roles are in the process of changing, gender inequity still persists among Southeast Asian cultures.

A final limitation of this study is that only Southeast Asian students who went to high school and college in the U.S. were interviewed. It is possible that there are differing experiences affecting Southeast Asians who went to high school elsewhere but also went on to complete college successfully. Nonetheless, this study adds to the literature by highlighting successful practices of marginalized Southeast Asian students in U.S. schools, which can be useful for educators, policy-makers, and other stakeholders to learn from their experiences. 


\section{Implications}

\section{Educational Leadership}

With the findings from this study, educational leaders are offered tools that can be used to support Southeast Asian students to integrate academic experiences with other supportive experiences. Currently, policymakers, educators, and community members have little or no knowledge to Southeast Asian students' levels of need or accomplishments because data on this group are generally grouped together with other Asian Americans, producing a "model minority" stereotype that depicts all Asian Americans as a group that has uniformly achieved lofty educational success.

Such aggregated data on Asians can prevent educational leaders from seeing the struggles of Southeast Asians, potentially preventing them from addressing the needs of these groups. Without appropriate support to address their unique academic needs, many Southeast Asian students continue to disproportionally fall behind other students, both academically and socially. Instead of receiving help, Southeast Asian students and parents are sometimes viewed through a deficit lens, portrayed as underachievers. Southeast Asian students are thus generally excluded from policy discourses on education because their issues may not reach a level of policy visibility, even though they have a demonstrable need for resources. This invisibility acts to keep Southeast Asian Americans at significantly lower levels of educational attainment. 
Therefore, policymakers, educators, and community members are called upon to act to alter existing perceptions and begin to provide appropriate supports for Southeast Asian students at both high school and college levels. The following changes are recommended to close the achievement gap for Southeast Asian students in P-12 and higher education.

States, school districts, and the federal government should be required to gather and report disaggregated data on subgroups (such as Southeast Asians) within the Asian American population at P-12 and college levels. Second, educational leaders should provide bilingual educational programs for Southeast Asian ELL students until they reach the English proficient level. Educational administrators should also consider augmenting high-stakes tests with multiple measures of student achievement that engage student learning and measure student growth over time. In addition, they should include Southeast Asian history and culture in curriculum to heighten student interest and reinforce cultural identity. Finally, educational leaders should recruit Southeast Asian educators and community members to preserve heritage languages.

In higher education, educational leaders are encouraged to continue to work with P-12 leaders to bridge the content gap between high school and college and to promote increased access for Southeast Asian students. Once these students are on campus, funding should also be provided for support programs that offer academic advising and social support. Southeast Asian studies programs should as well be considered, together 
with greater financial incentives and explicit outreach programs to Southeast Asian students at both high school and college levels.

Ultimately, the results of this study should serve to heighten the consciousness of educational leaders to address the needs of a group of underrepresented minority students. By documenting success instead of failure, the study generates a set of best practices to support the academic success for Southeast Asian students.

\section{Educational Equity}

The study examined the experiences of academic success of Southeast Asian students in higher education. The findings of the study have the potential to enable educators to gain insight into the obstacles of Southeast Asian students and factors that contribute to their academic success in higher education. With these findings educators should be able to more effectively manage resources to increase the quality of educational outcomes for this and other marginalized groups. Inequity is addressed when educational institutions allocate tangible resources equitably, challenge deficit perspectives and behaviors of educators, establish strong support and high expectations, and help low-income students and students of color commit to themselves and their learning. Otherwise, inequality will remain a social issue not only for Southeast Asian Americans but also for many other marginalized popluations in California and the United States. 
Due to disproportionately high poverty rates, Southeast Asian students live in predominantly low-income communities that lack the human capital and economic resources needed to promote academic access. In addition, Southeast Asian students are being forced to learn arts, language, culture, and religion of cultures different from their own, while programs that emphasize their own cultures are frequently nonexistent. Few, if any, culturally relevant programs for Southeast Asian students are offered in high schools or colleges. This lack can prompt young people to disconnect from education.

Many Southeast Asians also attend low-income neighborhood schools that receive inequitable funding due to problematic public fiscal policies. Schools in low-income communities have the poorest populations of students and greatest student needs, yet they receive fewer resources and opportunities than suburban schools. This impacts Southeast Asian students' access to high quality educational resources and services. When these students are academically underprepared from elementary through high school, many of them tend to drop out of high school and fail to enter college. For those relatively low numbers of Southeast Asian students who do become qualified to attend college, many are enrolled in remedial courses during their first year and are thus more likely to drop out of college without completing a degree.

\section{Improvements in Southeast Asian Communities}

Academic achievement and the upward mobility of some Asian American communities can be attributed in part to a strong sense of community and a tendency to 
preserve ethnic values and maintain social cohesion. For example, Chinese and Korean communities often emphasize cultural values to underscore the importance of educational values and college access (Kim, 2012). They also use ethnic business networks and organizations to transmit information and resources.

In contrast, Southeast Asian community centers, including temples, churches, non-profit organizations, and other related organizations frequently lack the human and economic capital needed to promote the importance of college access. The participants in this study rated their communities relatively low in terms of general and academic support. This problematic finding contrasts with what is reported from Chinese and Korean communities, and it can be traced in part to the experience of war and refugee status.

Multiple researchers suggest that effective urban school reform begins through partnerships with communities that enable young people to maintain their identities while becoming academically successful (Duncan-Andrade \& Morrell, 2008). Such an approach suggests that schools need to create pedagogies and curricula that are relevant to Southeast Asian youth, while working to break the cycle of disinvestment of human capital in Southeast Asian communities. Southeast Asian youth need to be able to recognize their potential agency to improve their own communities. This can lead to a renewed sense of purpose in school and contribute to the social, economic, and political revitalization of their communities. 
Many researchers advocate that effective services for refugees must match their specific religious, linguistic, psychological, and social characteristics (Brown, 1982; Hirayama \& Hirayama, 1988; Montero \& Dieppa, 1982; Phmmasouvanh, 1981; Sanders, 1978; Schultz, 1982; Tran \& Wright, 1986; Weil, 1981; Wong, 1981; as cited in Canda \& Phaobtong, 1992). One of the salient aspects of culturally sensitive support for refugees is cooperation with ethnic community support systems. Yet many Southeast Asian community centers do not have the human or economic capital to support youth outside of school. Youth must rely on resources external to their communities, such as teachers, counselors, or outreach programs to prepare them for college. In general a relatively small proportion of the Southeast Asian community has access to the kind of support that the 16 participants in this study received. Most Southeast Asian adults over 25 of age have never gone to any college, in part because they did not receive support services. Southeast Asian community centers, then, have the potential to help such students, but only if they have adequate resources and human capital to do so.

Stanton-Salazar (1997) states that the ability of minority children and youth to resist the alienating effects of mainstream institutional life is directly linked to supportive ties of family and community. Youth family background can be categorized into three major components: financial capital, human capital, and social capital (Coleman, 1988). Financial capital is the family's income or wealth that provides physical resources, such as a space to study at home, study materials, and financial resources to ease the family 
problems. Human capital is measured by the parents' education, skills, and capabilities, all of which help cultivate a learning environment for the child.

Social capital can be attributed to social organization, which includes networks, norms, and trust that bring about coordination and cooperation for mutual benefit (Putnam, 1993). Social capital can increase the benefits of investment in physical capital and human capital, and to a focus on community development. Social capital can refer to not only relations in the family, but also the parents' relations with the institutions of the community, especially a community based on religious organizations (Coleman, 1988; Putnam, 1993), such as Southeast Asian community centers. Social capital can have three forms: obligations and expectations based on trustworthiness of the social environment, information-flow of the social structure, and norms accompanied by sanctions (Coleman, 1998). For example, educational outcomes for those students who have relationships with the adult community outside of school were found to be better than those who did not have such adult relationships outside of school. In essence, both social capital in the family and social capital in the community can impact the creation of human capital in the next generation. Therefore, social capital further supports the need of Southeast Asian community centers to provide their students access and to help them succeed in college.

Thus, educators, policy-makers, and other stakeholders should recognize the considerable potential of Southeast Asian community centers, including temples, 
churches, non-profit organizations, and other related organizations, and fund them to provide services that build the educational future of young community members.

\section{Community-Based Ethnic Studies Programs}

In this study, Southeast Asian students frequently learned about their families' geopolitical histories by taking Ethnic Studies classes, or from ethnic student associations. Understanding the experience of war in their countries of origin and knowing how their families sacrificed to be in the U.S. often inspired their college success. This knowledge also enabled them to realize how privileged they were to be in college, which in turn motivated them to get more involved in their communities. They began to recognize social justice issues in their communities, and as a result, they became involved in community organizing to expose high school students to campus and college life. The students in this study sincerely valued ethnic studies, and four of them went on to minor or major in the discipline.

Ethnic Studies as a discipline emphasizes race and racism as strong social and cultural forces in American society. It values the knowledge produced in communities of color that is often ignored by mainstream curricula at the secondary and postsecondary levels. The Ethnic Studies field is also generally responsive to grassroots communities and calls on educators to engage in local community struggles and organizations (De los Ríos, López, \& Morrell, 2015). Ethnic Studies high school courses, for instance, have been shown to produce students with robust academic skills, as well as an ethical 
responsibility to self and community. Although Ethnic Studies has been offered in some US high schools since 1968, it remains limited in most school districts. None of the participants in this study, for instance, took ethnic studies prior to college. Thus, this study suggests that Ethnic Studies course be more broadly offered at the high school level, in order to give greater purpose to Southeast Asian high school students and encourage them to continue their higher education.

\section{Recognition of Culturally Relevant Programs}

Culturally relevant programs for Southeast Asian students could include foreign language, visual arts, performance arts, and social studies, including cultural anthropology, religious studies, world religion, sociology, psychology, and political studies. In the current school system, Southeast Asian students have no option but to learn about cultures other than their own, such as European foreign languages, arts, and religions, while their schooling appears to implicitly reject and devalues their own cultural manifestations. Few if any culturally relevant programs for Southeast Asian students are currently offered in high schools, and they remain rare in colleges.

Offering culturally relevant programs for Southeast Asians could help engage students in academic achievement. It could also increase community involvement, promote healthy social development, and enable parental involvement in academic progress. Such programming could build a sense of ownership, enhancing the critical relationship between belonging and academic success. Since the Southeast Asian 
population is small and scattered across the U.S., it would be most economical to target the development of culturally relevant programs at Southeast Asian community centers where the population is concentrated.

\section{Recommendations for Action}

The goal of this study was to investigate patterns of academic success of Southeast Asian Americans in higher education. Recommendations for action include: (a) providing Southeast Asian students with more college prep courses in high school, (b) bridging the curriculum gap between high schools and colleges, (c) providing full financial assistance to cover both tuition and housing fees, (d) supporting student organizations on campus, (e) providing mentorship, (f) supporting Southeast Asian community centers, and (g) granting P-12 and college credit for community-based ethnic studies programs.

\section{Provide College Prep Courses for All Students}

College prep courses offered in the local high schools are designed to prepare a student for college-level courses. Classes ranging from AP English to college-level math classes can help prepare students for college. The 16 participants in this study who completed college prep courses in high school were accepted into the four-year colleges of their choice. Unfortunately, many schools maintain tracking systems that prevent all students from gaining access to college prep curriculum. For instance, the three participants in this study did not have access to college prep materials. Thus, two of the 
three received no assistance on how to prepare for a four-year college and ended up going to a community college after high school. The third student got into a four-year college almost by accident via a special admission EOP program.

Because students who were in college prep classes had more access to educational resources, were helped to prepare for a four-year college, and were accepted into the four-year college of their choice, it is recommended that all students, including Southeast Asian students, should be offered the opportunity to take college prep courses. Once enrolled in these classes, they can be informed of college requirements and receive support to prepare for entry into a four-year college. This study thus offers further evidence of the problems of tracking systems and their negative effects on students who are tracked into non-college tracks.

\section{Bridge the Curriculum Gap between High Schools and Colleges}

Transitioning to a four-year college was difficult for 14 of the 16 students in this study who took college prep classes in high school. The college transition process is also difficult for many other students from a broad range of backgrounds. Research on AP classes in low-income urban high schools found that the students still did not feel appropriately prepared for college, despite their college prep classes. Thus, many categories of students, particularly those from low income communities, are challenged to bridge the gap between their high school and college courses. In addition, some students who enroll in college prep courses in high school are still required to take 
remedial classes in college. This is a perennial problem in the CSU system, for instance. The feeling of unpreparedness can cause some students to drop out of college and return home.

Though the issue of high school-to-college transition is not a new one, and it affects multiple populations, it appears particularly problematic for Southeast Asian and other marginalized students. Educators from P-12 and higher education are therefore recommended to continue to work together to bridge this problematic gap.

\section{Provide Sufficient Financial Assistance}

Refugee students often come from low-income families. Most are first-generation students and need sufficient financial assistance during college because their families cannot support them. Existing financial aid packages are often not enough to cover tuition and housing. As a result, many students in this study had to work full-time during college. Such pressures can cause students to drop out, as was the case for Sathea. Financial hardship was a big issue for Southeast Asian students in this study. Therefore, it is recommended that policymakers explore avenues to provide sufficient financial support to cover both tuition and housing fees for all low-income students, including refugees.

\section{Support Student Organizations on Campus}

College is difficult, a struggle, and a lonely place for many Southeast Asian students. Since these students no longer have their families directly available as a support 
system, they can feel isolated on campus. In this study, ethnic student organizations and career-oriented professional student organizations offered supportive communities of peers to support persistence in college. In addition, Southeast Asian students joined student associations, including coalitions of different ethnic groups, which reinforced their goals and commitment to push their communities forward.

Student organizations can provide not only a sense of belonging and a supportive commuity, but they can also serve as a platform to advocate for social justice issues in communities. Therefore, it is recommended that university leaders offer expanded support for a range of student organizations on campus.

\section{Provide Mentorship}

A mentor cares for and fosters the mentee's growth and development and serves as a role model. The mentor can support and protect the mentee, serving as a guide and reality checker. The mentee in turn applies insights gained from the mentor's wisdom. Many of the study participants benefited from mentors, some as early as the third grade. Many of their mentors were interested teachers, but they could also be friends, community members, or others. All 16 participants who were in college prep courses in this study were guided by mentors at some point during their educational journeys. Therefore, it is recommended that policymakers, administrators, teachers, and other professionals work to expand mentorship programs, particularly for first generation and 
marginalized students. There is compelling evidence in this study of the considerable effectiveness of mentoring.

\section{Support Educational Opportunity Programs}

Multiple study participants benefited from EOP programs at different stages of their academic careers, some while in high school, some while in community colleges, and some while in four-year colleges. Thus, EOP programs positively impacted the academic trajectories of many of the students who were low-income, first generation, academically underprepared, and underserved, to enable them to obtain a four-year college degree. It is therefore recommended that EOP programs be supported and expanded to continue to serve low-income, first-generation students.

\section{Support Southeast Asian Community Centers}

There is a case to be made for transforming and reshaping Southeast Asian community centers, including temples, churches, non-profits, and other related organizations, into a coordinated support system, featuring centers for non-formal education, social centers, advocacy groups, and liaison centers between the mainstream dominant culture and ethnic communities. To do so requires economic resources and human capital. Therefore, it is recommended that policy-makers, educators, community leaders, and other stakeholders join to support Southeast Asian community centers to help strengthen these communities. Expanded services could include bilingual 
counselors, community-based Ethnic Studies programs, tutorial services, heritage language classes, and cultural arts activities.

\section{Grant P-12 and College Credit for Community-Based Ethnic Studies Programs}

As shown in this study, ethnic studies programs can enable Southeast Asian and other students to become aware of and connected to their communities and families. They then can use their new knowledge as a strong motivation to pursue college success. Accordingly, such programming should be made broadly available through high schools, community centers, and other sources. However, unless academic credit is granted for this important learning, it is unlikely that college-bound students will have the time or motivation to participate. Thus, university outreach efforts to provide collaborative, credit-bearing ethnic studies programs in high schools and community centers should be developed and promoted.

In summary, the path of academic success of Southeast Asian students in this study began with having access to college prep classes, which informed the students of college requirements and prepared them for a four-year college entry. The students learned of the importance of extracurricular activities and found out how to participate in outreach programs to help them with the college application process. Their counselors also helped them prepare for college, because they perceived the students who were enrolled in college prep as high achievers. Once they got into college, most of participants experienced transition challenges due to the content gap between high school 
and college courses and the feelings of isolation on campus. To address this gap, they reached out to other students who shared similar backgrounds to cope with their challenges and to encourage each other to persist in college. Many of the participants learned about their family histories for the first time in college via ethnic studies classes. With a new understanding of their families' histories, many became involved in activism and community outreach. However, the academic success of these students represents only a small percentage of the total population of Southeast Asian American students. Their success was the exception rather than the rule.

\section{Recommendations for Further Study}

Because this study involved interviews with Southeast Asian college graduates who went to high school and college in the U.S., it would also be valuable to investigate the perspectives of those who achieved college success through other paths. Further studies could, for instance, include Southeast Asian college graduates who went through high school outside the U.S. but went to a four-year college in the U.S. Investigations from the perspectives of teachers, mentors, friends, and families of Southeast Asian students could also provide insight into student patterns of academic success. Since most of the participants in this study had AP classes, mentors, and resources to help them succeed, an experience which only represents a very small percentage of the overall Southeast Asian population, additional investigations could include a great proportion of Southeast Asian college graduates who did not have access to important academic 
resources-but still but went on to succeed in college. Further investigations, in addition, could include the perspectives of P-12 and university counselors, faculty, and leaders on the question of Southeast Asians, and other marginalized groups' college success patterns.

\section{Reflections on the Research Process}

This research was originally intended for Cambodian, Hmong, and Laotian college graduates. As a Cambodian refugee, I was more familiar with the Cambodian population than I was with the other three groups. I knew the struggles of the Cambodian community with few successes. I had some knowledge of Cambodian culture and traditions through word of mouth and through attending cultural events. Yet, during the research process, I learned new things about Cambodian culture that I had not known before.

Once the survey questionnaire was made available via Facebook, two Mien Americans requested to become part of the research, and they were added to the study as a fourth ethnic group. Prior to this research, I was not well acquainted with the Mien population. As for the Lao and Hmong populations, I had only previously associated with them during periodic cultural events in San Francisco. Due to the low visibility of research on Southeast Asian Americans, I took this opportunity to include all four groups in this study. 
As a Cambodian refugee student who went through high school and college in the U.S., I was surprised about certain components of the findings. I did not realize, for instance, that refugee experiences could be used as an internal drive to succeed. I was also proud to see so many Southeast Asian students committed to helping the next generation. What gratified me most was how the four ethnic groups in this study reported working together to help each other to succeed in college. The Asia Pacific Coalition and the Southeast Asian Student Coalition played a major role in connecting these four groups.

I knew that friends could also play an important role in the academic success, but I was unaware of how one could hand pick friends to help them succeed, or navigate between the friends who were serious about school and those who were not.

The findings in the area of cultural expectations also had many new elements for me. I did not know many of the cultural expectations of the four ethnic groups. As a result, this theme took considerable effort to develop. Finally, in the area of schooling experiences, I was not well acquainted with the opportunities that outreach programs such as EOP offer to students from disadvantaged backgrounds to succeed in college. Overall, I was comfortable with the results.

\section{Conclusion}

There is a long-standing "model minority" myth in the U.S. that Asian students perform better in school than White students and thus do not need extra resources. 
However, Southeast Asians, particularly Cambodian, Hmong, Lao, and Mien students, have been performing far below the national average in a way that is similar to African American and Hispanic students. After over 35 years in the U.S. following the end of the war in Southeast Asia, college graduation attainment for this population remains far below the national average. The purpose of this study was to examine patterns of academic success of Southeast Asian graduates and generate recommendations for best practices in programming for this population.

The study reports that having access to educational opportunities plays a critical role in the academic success of Southeast Asian students. These opportunities include access to college prep classes, information about college requirements and how to prepare for college, and support to succeed in high school. Once in college, students require adequate guidance to ease their transition into college level courses, along with sufficient academic and financial support. These findings are not new and have long been known by researchers, educators, policy-makers, and community leaders. However, only a small percentage of Southeast Asian students and students have had this access, which accounts for the continuing low rate of college attainment for this population. The recommendations of the study are primarily for educators and policy-makers to act by taking relatively well-known, simple steps to expand access. While there has been some progress to date, it is still far less than what is needed. 
The academic achievement and the upward mobility of Asian Americans such as Chinese, Koreans, or Japanese contributes to a strong sense of community and reflects a tendency to preserve cultural values and maintain social cohesion. This is a key issue for the Southeast Asian community. Having a strong sense of community is key to building improved education for Southeast Asian communities. Research on effective urban school reform movements suggests the importance of developing partnerships with communities that will enable young people to maintain their identities as Southeast Asian youth and provide them an opportunity to be successful (Duncan-Andrade \& Morrell, 2008). Therefore this study calls upon schools to create pedagogy and curricula that are relevant to Southeast Asian youth while working to break the cycle of disinvestment of human capital in Southeast Asian communities. It encourages Southeast Asian Americans to link their identity to their academic achievement and to reinforce the importance of identity development and academic performance. This can be done by recognizing and valuing culturally relevant Southeast Asian programs and by offering community-based Ethnic Studies programs.

This study seeks to be responsive to grassroots communities and calls upon educators to connect with local community struggles and organizations by engaging members of historically underserved populations with compassion and problem-posing dialogue to address and eventually transform oppressive social and structural conditions within Southeast Asian communities and the larger society. 


\section{References}

Akiba, D. (2010). Cambodian Americans and education: Understanding the intersections between cultural tradition and U.S. schooling. The Educational Forum. 74(4), $328-333$.

Allen, J., Gregory, A., Mikami, A., Lun, J., Hamre, B., \& Pianta, R. (2013). Observations of effective teacher-student interactions in secondary school classrooms: Predicting student achievement with the Classroom Assessment Scoring System-Secondary. School Psychology Review, 42(1), 76-98.

Anyon, J. (1980). Social class and the hidden curriculum of work. Journal of Education, 162(1), 67-92.

Ark, W. C. (2014). Effects of meditation practice on altruism, empathy, guilt, and depression among Theravada Buddhists (Order No. 3664309). Available from ProQuest Dissertations \& Theses Global: The Sciences and Engineering Collection. (1729107651). Retrieved from https://search.proquest.com/docview/1729107651 accountid=13802

Asian Pacific American Legal Center \& Asian American Justice Center. (2011). A community of contrasts: Asian Americans in the United States. Los Angeles, CA: Asian American Center for Advancing Justice.

Astin, A. W. (1993). What matters in college? Four critical years revisited. San Francisco, CA: Jossey-Bass. 
Bankston III, C. L., \& Hidalgo, D. A. (2006). Respect in Southeast Asian American children and adolescents: Cultural and contextual influences. New Directions for Child \& Adolescent Development, 114, 25-38.

Bempechat, J., \& Omori, M. C. (1990). Meeting the educational needs of Southeast Asian Children. ERIC/CUE Digest No. 68. New York, NY: ERIC Clearinghouse on Urban Education, Teachers College, Columbia University.

Bandura, A. (2001). Social cognitive theory: An agentic perspective. Annual Review of Psychology, 52, 1 .

Blanchard, S., \& Muller, C. (2015). Gatekeepers of the American Dream: How teachers' perceptions shape the academic outcomes of immigrant and language-minority students. Social Science Research, 51, 262-275.

Brooks, J., \& Allen, K. (2016). The influence of fictive kin relationships and religiosity on the academic persistence of African American college students attending an HBCU. Journal of Family Issues, 37(6), 814-832.

Canda, E., \& Phaobtong, T. (1994). Buddhism as a support system for southeast Asian refugees. Social Work, 37(1), 61-67.

Canniff, J. G. (1999). Traveling the middle path: The cultural epistemology of success, a case study of three Cambodian families (Order No. 9933116). Available from ProQuest Dissertations \& Theses Global: The Humanities and Social Sciences 
Collection. (304502049). Retrieved from https://search.proquest.com/docview/304502049?accountid=13802

Carreón, G. P., Drake, C., \& Barton, A. C. (2005). The importance of presence: Immigrant parents' school engagement experiences. American Educational Research Journal, 42(3), 465-498.

Casebeer, A., \& Miller, M. (1991). Education in Thailand: A model for developing countries. Charleston, WV: Appalachian Educational Laboratory. (ERIC Document Reproduction Service No. ED 334 035).

Chambers, T., \& Huggins, K. (2014). The influence of school factors on racial opportunity cost for high-achieving students of color. Journal of School Leadership, 24(1), 189.

Chen, C., \& Stevenson, H. (1995). Motivation and mathematics achievement: A comparative study of Asian-American, Caucasian-American, and east Asian high school students. Child Development, 66(4), 1214-34.

Cherng, H., Calarco, J., \& Kao, G. (2013). Along for the ride: Best friends' resources and adolescents' college completion. American Educational Research Journal, 50(1), 76-106. Retrieved from http://www.jstor.org/stable/23319708

Chhuon, V. (2013). "I'm Khmer and I'm not a gangster!" The problematization of Cambodian male youth in US schools. International Journal of Qualitative Studies in Education, 27(2), 233-250. 
Chhuon, V., \& Hudley, C. (2008). Factors supporting Cambodian American students' successful adjustment into the university. Journal of College Student Development, 49(1), 15-30.

Chhuon, V., Hudley, C., Brenner, M. E., \& Macias, R. (2010). The multiple worlds of successful Cambodian American students. Urban Education, 45(1), 30-57.

Chung-Do, J., Filibeck, K., Goebert, D. A., Arakawa, G., Fraser, D., Laboy, J., \& Minakami, D. (2013). Understanding students' perceptions of a high school course designed to enhance school connectedness. Journal of School Health, 83(7), 478484

Cimmarusti, R. (1996). Exploring aspects of Filipino-American families. Journal of Marital and Family Therapy, 22(2), 205-217.

Clark, W. A. (1998). Articulation agreements between public high schools and postsecondary institutions: Development, implementation and results (Order No. 9901010). Available from ProQuest Dissertations \& Theses Global: The Humanities and Social Sciences Collection. (304444120). Retrieved from https://search.proquest.com/docview/304444120?accountid=13802

Coleman, J. S. (1988). Social capital in the creation of human capital. American Journal of Sociology, 94, S95-S120. 
Creswell, J.W., \& Plano Clark, V.L. (2011). Designing and conducting mixed methods research. Thousand Oaks, CA: SAGE Publications, Inc.

Covarrubias, A., \& Liou, D. D. (2014). Asian American education and income attainment in the era of post-racial America. Teachers College Record, 116(6), 1-38.

Darling-Hammond, L. (2010). The flat world and education. New York, NY: Teachers College Press.

De los Ríos, C., López, V., \& Morrell, J. (2015). Toward a critical pedagogy of race: Ethnic studies and literacies of power in high school classrooms. Race and Social Problems, 7(1), 84-96.

DeCuir-Gunby, J., Taliaferro, T., \& DeVance, J., \& Greenfield, D. (2010). Educators' perspectives on culturally relevant programs for academic success: The American excellence association. Education and Urban Society, 42(2), 182-204

Duncan-Andrade, J. M. R., \& Morrell, E. (2008). The art of critical pedagogy: Possibilities for moving from theory to practice in urban schools (Vol. 285). New York, NY: Peter Lang.

Dvoráková, Kamila, Kishida, Moé, Li, Jacinda, Elavsky, Steriani, Broderick, Patricia C., Agrusti, Mark R., \& Greenberg, Mark T. (2017). Promoting Healthy Transition to College through Mindfulness Training with First-Year College Students: Pilot Randomized Controlled Trial. Journal of American College Health, 65(4), 259267. 
English, B. L. (2015). Spirituality and religion among black men in college: A potential mechanism for achieving student success (Order No. 3709714). Available from ProQuest Dissertations \& Theses Global: The Humanities and Social Sciences Collection. (1700848261). Retrieved from https://search.proquest.com/docview/1700848261 ?accountid=13802

Fester, R., \& Perna, Laura W. (2010). Participation in Precollege Outreach Programs and the Transition from High School to College, ProQuest Dissertations and Theses.

Fraenkel, J.R., Wallen, N. \& Hyun, H. (2015). How to design and evaluate research in education (9th ed.). New York: McGraw-Hill.

Fontana, A., \& Frey, I. H. (2008). The interview: From neutral stance to political involvement. Collecting and Interpreting Qualitative Materials (3rd ed.), 8, 115 159.

Gándara, P. (2015). Rethinking Bilingual Instruction. Educational Leadership, 72(6), 6064.

Gordon, L. W. (1987). 7: Southeast Asian refugee migration to the united states. Center for Migration Studies special issues, 5(3), 153-173.

Gomez, G. G. (2005). The negotiation to college: Examining the school and home influences in the college -choice process for Mien American female and male students (Order No. 3190471). Available from ProQuest Dissertations \& Theses 
Global: The Humanities and Social Sciences Collection. (305000925). Retrieved from https://search.proquest.com/docview/305000925?accountid $=13802$

Goyette, K., \& Xie, Y. (1999). Educational Expectations of Asian American Youths: Determinants and Ethnic Differences. Sociology of Education, 72(1), 22-36.

Guiffrida, D.A. (2003). African American student organizations as agents of social integration. Journal of College Student Development, 44, 304-319.

Guiffrida, D. A. (2006). Toward a cultural advancement of Tinto's theory. Review Of Higher Education, 29(4), 451-472.

Hallett, R., \& Venegas, K. (2011). Is Increased Access Enough? Advanced Placement Courses, Quality, and Success in Low-Income Urban Schools. Journal for the Education of the Gifted, 34(3), 468-487.

Hatt, B. (2007). Street smarts vs. book smarts: The figured world of smartness in the lives of marginalized, urban youth. The Urban Review, 39(2), 145-166.

Her, P., \& Gloria, A. M. (2016). Kev txhawb siab: Hmong parents' educational encouragement of their undergraduate daughter/son. Journal of Family Diversity in Education, 2(2), 19- 34

Holland, D., Lachiocotte, W., Skinner, D. and Cain, C. (1998). Identity and agency in cultural worlds. Cambridge, MA: Harvard University Press.

Hull, Susan Hudson, \& Seeley, Cathy L. (2010). High School to Postsecondary Education: Challenges of Transition. Mathematics Teacher, 103(6), 442-445. 
Hurtado, S., Milem, J. F., Clayton-Pedersen, A. R., \& Allen, W. R. (1998). Enhancing campus climates for racial/ethnic diversity: Educational policy and practice. The Review of Higher Education, 21(3), 279-302.

The Institute for Higher Education Policy. (1998). Reaping the benefits: Defining the public and private value of going to college. The New Millenium Project on Higher Education Costs, Pricing, and Productivity (pp. 1-26).

Jacobi, Maryann. (1991). Mentoring and Undergraduate Academic Success: A Literature Review. Review of Educational Research, 61(4), 505-32.

Jonassen, D. H. \& Rohrer-Murphy, L. (1999). Activity theory as a framework for designing constructivist learning environments. Educational Technology Research and Development, 47(1), 61-79.

Kahill, M. (2002). The Role of Social Support Network in College Persistence among Freshman Students. Journal of College Student Retention, 4(1), 39-52.

Kao, G., \& Tienda, M. (1995). Optimism and achievement: The educational performance of immigrant youth. Social Science Quarterly, 76(1), 1.

Kiang, P., \& Kaplan, N. (1994). Where do we stand? Views of racial conflict by Vietnamese American high-school students in a black-and-white context. The Urban Review, 26(2), 95-119. 
Kiang, P. N., Lan, N. N., \& Sheehan, R. L. (1995). Don't Ignore It: Documenting Racial Harassment in a Fourth-Grade Vietnamese Bilingual Classroom. Equity and Excellence in Education, 28(1), 31-35.

Kibria, N. (1993). Family tightrope: The changing lives of Vietnamese Americans. Princeton, N.J.: Princeton University Press.

Kim, S. (2012). Postsecondary assistance: A research project helps immigrant students plan their education futures. Knowledge Quest, 40(3), 48-53.

Kirsch, I., Braun, H., Yamamoto, K., \& Sum, A. (2007). America's perfect storm: Three forces changing our nation's future. Princeton, NJ: Policy Information Center. Ladwig, P. (2011). The Genesis and Demarcation of the Religious Field: Monasteries, State Schools, and the Secular Sphere in Lao Buddhism (1893-1975). Sojourn: Journal of Social Issues in Southeast Asia, 26(2), 196-223.

Lee, O. (2003) Equity for linguistically and culturally diverse students in science education: A research agenda. Teachers College Record, 105(3), 465-489.

Lee, J., Barnes, A., Kenkel, Mary Beth, \& Monteith, Margo J. (2015). Predominately White Institutions: Transition Programs to Address Academic Underpreparedness and Experiences of Discrimination. Translational Issues in Psychological Science, 1(4), 401-410.

Lee, G., Tapp, Nicholas, \& Gale Group. (2010). Culture and customs of the Hmong (Gale virtual reference library). Santa Barbara, Calif.: Greenwood. 
Levine, Arthur, \& Hirsch, Deborah. (1991). Undergraduates in Transition: A New Wave of Activism on American College Campus. Higher Education, 22(2), 119-28.

Lew, J. (2006). Asian Americans in class: Charting the achievement gap among Korean American youth. New York: Teachers College Press.

Linnehan, F., Weer, C., \& Stonely, P. (2011). High School Guidance Counselor Recommendations: The Role of Student Race, Socioeconomic Status, and Academic Performance. Journal of Applied Social Psychology, 41(3), 536-558.

López, N. (2002). Race-gender experiences and schooling: second-generation Dominican, West Indian, and Haitian youth in New York city. Race ethnicity and education, 5(1), 67-89.

Lor, P. (2008). Key life experiences contributing to Hmong students' matriculation. Multicultural Education, 16(1), 39-47.

Lörz, Markus, Netz, Nicolai, \& Quast, Heiko. (2016). Why Do Students from Underprivileged Families Less Often Intend to Study Abroad? Higher Education: The International Journal of Higher Education Research, 72(2), 153-174.

Louie, Vivian. (2001). Parents' aspirations and investment: The role of social class in the educational experiences of 1.5- and second-generation Chinese Americans. Harvard Educational Review, 71(3), 438-474. 
Maramba, D. \& Palmer, R. (2014). The impact of cultural validation on the college experiences of southeast Asian American students. Journal of College Student Development, 55(6), 515-530.

Martin, K. Galentino, R. , \& Townsend, L. (2014). Community college student success. Community College Review, 42(3), 221-241.

Matzen Jr., R. N. (1996). Emancipatory Education without Enlightenment? Thais, Americans, and the "Pedagogy of the Oppressed."

McCoy, D., Luedke, C., \& Winkle-Wagner, R. (2017). Encouraged or Weeded Out: Perspectives of Students of Color in the STEM Disciplines on Faculty Interactions. Journal of College Student Development, 58(5), 657-673.

McKinsey \& Company. (2009). The economic impact of achievement gap in America's schools. San Francisco, CA: McKinsey \& Company, Social Sector Office.

Miles, M., Huberman, A., \& Saldaña, J. (2014). Qualitative data analysis: A methods sourcebook (Third ed.).

Millhollen, B. J. (1994). The alienation of the Iu Mien: A Hegelian perspective (Order No. 1362461). Retrieved from https://search.proquest.com/docview/304134479?accountid $=13802$

Mole, R. L. (1973). Thai values and behavior patterns. Rutland, VT: Charles E. Tuttle Company. 
Moore, G., \& Slate, J. (2008). Who's Taking the Advanced Placement Courses and How Are They Doing: A Statewide Two-Year Study. The High School Journal, 92(1), 56-67.

Mordkowitz, E. R., \& Ginsburg, H. P. (1986). Early Academic Socialization of Successful Asian-American College Students.

Moua, M. Y., \& Lamborn, S. D. (2010). Hmong American adolescents' perceptions of ethnic socialization practices. Journal of Adolescent Research, 25(3), 416-440.

Museus, S. D. (2012). Generating Ethnic Minority Student Success (GEMS): A qualitative analysis of high-performing institutions. Journal of Diversity in Higher Education, 4(3), 147-162.

Museus, S. D., \& Liverman, D. (2010). High-performing institutions and their implications for studying underrepresented minority students in STEM. New Directions for Institutional Research, 148, 17-27.

Ngo, B., \& Lee, S. J. (2007). Complicating the image of model minority success: A review of Southeast Asian American education. Review of Educational Research, $77(4), 415-453$.

Norasing, V., Mack, F. R., \& Collins, S. (1999). Laotian refugee parents' perceptions of a "best teacher." Grad Valley State University: School of Education. 
Ogbu, J., \& Simons, H. (1998). Voluntary and Involuntary Minorities: A CulturalEcological Theory of School Performance with Some Implications for Education. Anthropology \& Education Quarterly, 29(2), 155-188.

Palmer, R. \& Maramba, D. (2015). The impact of social capital on the access, adjustment, and success of southeast Asian American college students. Journal of College Student Development, 56(1), 45-60.

Patton, L., \& McClure, M. (2009). Strength in the Spirit: A Qualitative Examination of African American College Women and the Role of Spirituality during College. The Journal of Negro Education, 78(1), 42-54.

Peng, S. \& Solheim, C. (2015). Negotiating two cultures: Hmong American college women's experiences of being a daughter. Hmong Studies Journal, 16, 1-16.

Phommasa, M., Duran, Richard P., Brenner, Mary, \& Hudley, Cynthia. (2016). Bridging Their Own Worlds: How Southeast Asian American Students Persist in the University, ProQuest Dissertations and Theses

Placenti, P. M. (2012). "God has my back": The role of faith-based institutions in preparing African-American students for college success (Order No. 3551543).

Retrieved from https://search.proquest.com/docview/1288840382?accountid=13802

Portes, A., \& Rumbaut, R. (1996). Immigrant America: A portrait (2nd ed.). Berkeley: University of California Press. 
Proefriedt, W. (2010). Education Reform vs. American History. Phi Delta Kappan, 91(6), 84-87.

Putnam, R. D. (1993). The prosperous community: Social capital and community life. American Prospect, 35-42.

Reid, M. Jeanne, \& Moore, James L., III. (2008). College Readiness and Academic Preparation for Postsecondary Education: Oral Histories of First-Generation Urban College Students. Urban Education, 43(2), 240-261.

Ritter, G. W., Barnett, J. H., Denny, G. S., \& Albin, G. R. (2009). The Effectiveness of Volunteer Tutoring Programs for Elementary and Middle School Students: A Meta-Analysis. Review of Educational Research, 79(1), 3-38.

Roberto, R. (1997). Reaching Out, But In Which Direction? The Future Focus of Academic Outreach Programs. Black Issues in Higher Education, 13(28), 16.

Rogoff, B. (2003). Chapter 7: Thinking with the tools and institutions of culture. In The cultural nature of human development. New York: Oxford University Press.

Roth, W.M. \& Lee, Y.J. (2007). “Vygotsky’s neglected legacy”: Cultural-historical activity theory. Review of Educational Research, 77(2), 186-232.

Rothstein-Fisch, C., \& Trumbull, E. (2008). Managing Diverse Classrooms: How to Build on Students? Cultural Strengths. Ascd. 
Routon, P. \& Walker, J. (2015). Are you there god? it's me, a college student: Religious beliefs and higher education. The B.E. Journal of Economic Analysis \& Policy, $15(4), 2111$.

Rumbaut, R. G. (2014). English plus: Exploring the socioeconomic benefits of bilingualism in southern California. Browser Download This Paper.

Saldana, J. (2013). The coding manual for qualitative researchers. Los Angeles, CA: Sage.

Samreth, S., Bradley, Darnell J., Drago, William, Jones, Janice, \& Vang, Chia. (2014). Souls of the Southeast Asian American Students: Experiences and Double Consciousness, ProQuest Dissertations and Theses

Segedin, L. (2012). Listening to the student voice: Understanding the school-related factors that limit student success. McGill Journal of Education/Revue des sciences de l'éducation de McGill, 47(1), 93-107.

Seidman, I. (1998). Interviewing as qualitative research: A guide for researchers in education and the social sciences. New York, NY: Teacher College Press.

Sengkhammee, Jenjee T.; Her, Pa; Gloria, Alberta M.; Lin, Mariko M.; Thao, Betty Jo; Cabinte, Desiree; and Aroonsavath, Linda (2017). "Txoj Kev Ntshiab: Hmong American undergraduates' perceptions of intellectual phoniness and psychosociocultural persistence decisions," Journal of Southeast Asian American Education and Advancement: Vol. 12.1. 
Sharpe, R. (1999, April 16). Beating the Ivy League Odds. Wall Street Journal (1923 Current File), p. W1.

Sin, B. C. (1991). Socio-cultural, psychological and linguistic effects on Cambodian students ' progress through formal schooling in the united states (Order No. 9205843). Available from ProQuest Dissertations \& Theses Global: The Humanities and Social Sciences Collection. (303949718). Retrieved from https://search-proquestcom.jpllnet.sfsu.edu/docview/303949718?accountid=13802

Somers, C. L., \& Piliawsky, M. (2004). Drop-out prevention among urban, African American adolescents: Program evaluation and practical implications. Preventing School Failure, 48(3), 17-22

Somers, C. L., Owens, D., \& Piliawsky, M. (2009). A study of high school dropout prevention and at-risk ninth graders' role models and motivations for school completion. Education, 130(2), 348-356.

Southeast Asian Resources Action Center. (2013). Overview of Southeast Asian educational challenges: Why Southeast Asian American students falling behind. Sacramento, CA: Increase Access to High Education. Retrieved from http://www.searac.org/sites/default/files/SEARAC Fact Sheets OVERVIEW FI NAL.pdf 
Stanton-Salazar, R. D. (1997). A social capital framework for understanding the socialization of racial minority children and youths. Harvard Educational Review, $67(1), 1-40$

Stebleton, M. J., \& Soria, K. M. (2012). Breaking down barriers: Academic obstacles of first-generation students at research universities. Learning Assistance Review, $17(2), 7-20$.

Strayhorn, T. (2011). Bridging the pipeline: Increasing underrepresented students' preparation for college through a summer bridge program. The American Behavioral Scientist, 55(2), 142.

Supple, A. J., McCoy, S. Z., \& Wang, Y. (2010). Parental influences on Hmong university students' success. Hmong Studies Journal, 11, 1-37.

Suarez-Orozco, M. (1987). "Becoming Somebody": Central American immigrants in U.S. inner-city schools. Anthropology and Education Quarterly, 18(4), 287-299.

Suárez-Orozco, C., \& Qin, D. (2006). Gendered perspectives in psychology: Immigrant origin youth. International Migration Review, 40(1), 165-198.

Suárez-Orozco, C., \& Suárez-Orozco, M. (2001). Children of immigration. Cambridge, MA: Harvard University Press.

Tang, K., \& Kao, D. (2012). Ethnicity, gender, and the education of Cambodian American students in an urban high school. Journal of Southeast Asian American Education \& Advancement, 7(3), 1-24. 
Tang, J., Kim, S., \& Haviland, D. (2013). Role of family, culture, and peers in the success of first-generation Cambodian American college students. Journal of Southeast Asian American Education and Advancement, 8(2), 1-21.

Tatman, A. W. (2004). Hmong history, culture, and acculturation: Implications for counseling the Hmong. Journal of Multicultural Counseling and Development, $32(4), 222-233$.

Teranishi, R. T. (2002). Asian Pacific Americans and critical race theory: An examination of school racial climate. Equity \& Excellence in Education, 35(2), 144-154.

Tkatchov, O., \& Pollnow, S. (2008). High expectations and differentiation equal academic success. Educational Resources Information Center. Retrieved from http://files.eric.ed.gov/fulltext/ED502141.pdf

Tran, C. N. (2014). The ethnic identity development of Southeast Asian American college students: Experiences across academic and social contexts (Order No. 3682987). Retrieved from https://search.proquest.com/docview/1658214304?accountid=13802

Truong, K. K. (2014). Understanding the academic trajectories of Southeast Asian American college students: A funds of knowledge and forms of capital approach (Order No. 3617445). Retrieved from https://search.proquest.com/docview/1527108048?accountid=13802 
Truong, K., Rios-Aguilar, Cecilia, Paik, Susan, \& Thomas, Scott. (2014). Understanding the academic trajectories of Southeast Asian American college students: A funds of knowledge and forms of capital approach. (Order No. 3617445). Available from Education Database; ProQuest Dissertations \& Theses Global: The Humanities and Social Sciences Collection. (1527108048). Retrieved from https://search-proquestcom.jpllnet.sfsu.edu/docview/1527108048?accountid=13802

Turner, D. W. (2010). Qualitative interview design: A practical guide for novice investigators. The Qualitative Report, 15(3), 754-760.

Turner, E., Dominguez, H., Maldonado, L, \& Empson, S. (2013). English learners' participation in mathematical discussion: Shifting positionings and dynamic identities. Journal for Research in Mathematics Education, 44(1), 199-234.

Urrieta, L. (2007). Figured worlds and education: An introduction to the special issue. The Urban Review, 39(2), 107-115.

Um, K. (2003). A dream denied: Educational experiences of Southeast Asian American youth: Issues and recommendations. Washington, DC: Southeast Asia Resource Action Center.

Uy, P. S. (2011). The educational experiences of Lao and Khmer high school students: The influence of families, friends, and teachers on academic achievement (Order No. 3459746). Available from ProQuest Dissertations \& Theses Global: The 
Humanities and Social Sciences Collection. (875953433). Retrieved from https://search-proquestcom.jpllnet.sfsu.edu/docview/875953433?accountid $=13802$

Vue, R. (2013). Contours of race and ethnicity: Institutional context and Hmong American students' negotiations of racial formation in higher education (Order No. 3549809). Retrieved from https://search.proquest.com/docview/1284766323?accountid=13802

Wallitt, R. (2008). Cambodian invisibility: Students lost between the "Achievement Gap" and the "Model Minority," Multicultural Perspectives, 10(1), 3-9.

Watt, K., Huerta, J. , \& Alkan, E. (2011). Identifying predictors of college success through an examination of AVID graduates' college preparatory achievements. Journal of Hispanic Higher Education, 10(2), 120-133.

What Works Clearinghouse. (2013). What Works Clearinghouse quick review: "Late interventions matter too: The case of college coaching in New Hampshire."

Williams, D. L. (1983). Thai ways and my ways. Washington, DC: Center from Applied Linguistics. (ERIC Document Reproduction Service No. ED 231 183).

Williams, P. (2017). Student agency for powerful learning. Knowledge Quest, 45(4), 815.

Xiong, Y.S. (2012). Hmong Americans' educational attainment: Recent changes and remaining challenges. Hmong Studies Journal, 13(2), 1-18. 
Xiong, Z., Eliason, P., Detzner, D., \& Cleveland, M. (2005). Southeast Asian immigrants' perceptions of good adolescents and good parents. The Journal of Psychology, 139(2), 159-175.

Xiong, S., \& Lam, S. (2013). Factors affecting the success of Hmong college students in America. British Journal of Guidance \& Counseling, 4I(2), 132-144.

Xiong, S., \& Lee, S. E. (2011). Hmong students in higher education and academic support programs. Hmong Studies Journal, 12, 1-20.

Xiong, T., \& Obiakor, F. (2013). Cultural connections and disconnections between nonHmong principals and Hmong parents. Multicultural Perspectives, 15(1), 39-45.

Yang, K. (2004). Southeast Asian American children: Not the "model minority". Future of Children, 14(2), 127-133.

Yang, T. (2008). Hmong parents' critical reflections on their children's heritage language maintenance. Journal of Southeast Asian American Education and Advancement, 3(1), 1-18.

Yang, Y. (2012). An introduction to Hmong culture. Hmong Studies Journal, 13(1), 1-6.

Yosso, T. J. (2005). Whose culture has capital? A critical race theory discussion of community cultural wealth. Race, Ethnicity and Education, 8(1), 69-91.

Youn, Y. S. (1993). Academic achievement of Asian-American students: Relating home environment and self-efficacy. (Order No. 9403017, Memphis State University). 
ProQuest Dissertations and Theses, 104-104 p. Retrieved from http://search.proquest.com/docview/304084891 ?accountid=13802. (304084891).

Zha, B. Eliason, P., Detzner, D., \& Cleveland, M. (2005). Southeast Asian immigrants' perceptions of good adolescents and good parents. The Journal of Psychology, 139(2), 159-175.

Zhou, M., \& Bankston III, C. (2001). Family pressure and the educational experience of the daughters of Vietnamese refugees. International Migration, 39(4), 133-151.

Zulli, R. A., \& Frierson, H. T. (2004). A focus on cultural variables in evaluating an upward bound program. New Directions for Evaluation, (102), 81-93. 


\section{Appendices}

\section{Appendix A}

\section{Recruiting Text}

Hello, my name is Marlai Ouch. In addition to being a Jefferson Award winner for serving the Cambodian community in San Francisco and an active member of the Southeast Asian Art and Culture organization, I am a doctoral student in Educational Leadership at San Francisco State University. I am conducting a research study on the academic experiences of Southeast Asian students in higher education, particularly Cambodian, Hmong, and Laotian Americans. I am inviting you to participate because you are a Southeast Asian college graduate whose family is connected to refugees. The findings from this study will become part of a doctoral dissertation.

Participation in this research includes: (1) filling out a survey for about 15 minutes; and (2) being interviewed for approximately 30-90 minutes. During the interview, you will be asked to describe your experiences as you made your way to and through higher education. You also may be asked to participate in a follow-up interview of no longer than 30 minutes. All information you share will be kept confidential. Any information included in the study findings will be presented anonymously so that no one will know the individual identity of participants.

Your participation in this study is purely voluntary; if you decide not to participate, there will not be any negative consequence whatsoever.

If you have any questions, please feel free to contact me at (415) 823-8824 or email me via marlai@mail.sfsu.edu. 


\section{Appendix B}

\section{Informed Consent}

\section{PURPOSE AND BACKGROUND}

My name is Marlai Ouch. In addition to being a Jefferson Award winner for serving the Cambodian community in San Francisco and an active member of the Southeast Asian Art and Culture, I am a doctoral student in Educational Leadership at San Francisco State University. I am conducting a research study on academic experiences of Southeast Asian students in higher education, particularly Cambodian, Hmong, Lao, and Mien Americans. I am inviting you to participate because you are at least 21 years old and a Southeast Asian college graduate whose family is connected to refugees. The findings from this study will become part of a doctoral dissertation.

\section{PROCEDURES}

If you agree to participate in this research, the following will occur:

- You will fill out the survey questionnaire online.

- You will be asked to provide contact information if you wish to also be interviewed.

- If you have provided your contact information, you will receive an email explaining the goal and purpose of the study again and will be allowed to ask any questions about the study. You will have as much time as you need to decide whether or not to participate in the study.

- Once you have decided to participate, you will be contacted to make an appointment for a phone interview that is convenient to you and that mutually works with the researcher's availability; unless an in-person interview is more convenient for you.

- You will be asked to read, sign, and return an informed consent form.

- You will be interviewed.

- Your interview will be audio recorded to ensure the researcher has captured your complete and accurate thoughts.

- You may be contacted within three months of the initial interview for a follow-up interview for clarifications lasting a maximum of 30 minutes.

- The total time commitment will be two hours and 15 minutes.

\section{RISKS}


There is a risk of loss of privacy. However, no names or identities will be used in any published reports of the research. Only the researcher will have access to the research data. There is a risk of discomfort or anxiety due to the nature of the questions asked; however, you can answer only those questions you choose to answer and can stop participation in the research at any time.

\section{CONFIDENTIALITY}

The participants will be assured that their information will be confidential. Their data will be stored in a password-protected file on the researcher's computer. This will be for short term but long term data storage will be in the faculty advisor's office. All documents with identifiable information will be encrypted and stored on a password-protected computer and will be kept indefinitely for research purposes consistent with the study. All printed documents not stored on the researcher's password protected computer will be locked in the desk in the researcher's home in San Francisco, California.

\section{DIRECT BENEFITS}

There will be no direct benefits to the participant.

\section{COSTS}

There will be no cost to you for participating in this research.

\section{COMPENSATION}

There will be no compensation for participating in this research.

\section{ALTERNATIVES}

The alternative is not to participate in the research.

\section{QUESTIONS}

You have spoken with Marlai Ouch about this study and have had your questions answered. If you have any further questions about the study, you may contact the researcher by email at marlai@mail.sfsu.edu or you may contact the researcher's advisor, Professor Hemphill at hemphill@sfsu.edu.

Questions about your rights as a study participant, or comments or complaints about the study, may also be addressed to the Human and Animal Protections at 415:338-1093 or protocol@,sfsu.edu.

\section{CONSENT}

You have been given a copy of this consent form to keep. 
PARTICIPATION IN THIS RESEARCH IS VOLUNTARY. You are free to decline to participate in this research, or to withdraw your participation at any point, without penalty. Your decision whether or not to participate in this research will have no influence on your present or future status at San Francisco State University.

Signature

Date:

Research Participant

Signature

Date:

Researcher 
Appendix C

\section{Questions for Survey Instrument}

Background

- Where were you born?

- Cambodia

- Laos

- Vietnam

- Thailand

- The United States

$\circ$ Other

- What is your ethnicity?

- Cambodian/Khmer (at least one parent who is Cambodian/Khmer)

- Hmong (at least one parent who is Hmong)

- Laotian (at least one parent who is Laotian)

- Other

- What is your gender?

- Female

- Male

- What is your age?

- 21 and under

- 22 to 34

- 35 to 44

- 45 to 54

- 55 to 64

- 65 and over

- Decline

- Your family came to the US as

- Refugees

- Immediate relative and family sponsored

- Employer sponsored

- The Green Card Lottery winners through the Diversity Immigrant Visa program

- Other 
- What struggles did your family go through? Select all that apply.

- Being refugees of political persecution after the Vietnam War ended in 1975

- Having little or no formal education, limited English proficiency, and little understanding of the U.S. educational system

- Suffering from trauma-related ailments

- Depending on public assistance, including cash aid or housing assistance

- Other

- Who was responsible for relieving the hardships of your family? Select all that apply.
- Father
- Mother
- Older sibling(s)
- You
- Teachers
- Other

- What is your parents' highest level of education? Select one that applies.

- Less than high school

- Graduated from high school

- Completed from a 2-year college

- Graduated from a 4-year college

$\circ$ Other

- Did you attend high school in the U.S.?

○ Yes

- If not, please specify the country

- Did you attend your four-year college in the U.S.?

- Yes

- If not, please specify the country

- What is your highest degree obtained? Select one that applies.

- Bachelor degree

- Master's degree, Professional degree, or Doctorate

- Other 


\section{Expectations and Goals}

- Throughout your schooling, what were your expectations for yourself? Select all that apply.

- Graduating from high school and getting a job

- Graduating from high school and going to college

- Graduating from high school and college and getting a job

- Getting a job to support the family

- Other

- Who influenced your expectations? Select all that apply.
- Parent(s)
- Counselor
- Teacher(s)
- Self
- Other

- What were the common assumptions or expectations among school, family, and peers about you? Select all that apply.

- I had high potential for academic success

- I was a high risk for dropping out of school

- I needed extra support

- Extra support would be wasted on me

- Other

- What type of reward(s) did you expect to receive for achieving your goals? Select all that apply.

- Being able to support my family

- Being able to support my family and community

- Making my parent(s) proud

- Being a role model for my siblings and my community

- Other

- What were your constraints during schooling? Select all that apply.

- Lack of parental involvement

- Lack of student engagement

- Lack of self-esteem

- Lack of the sense of belonging

o Other

Social Interactions 
- Please rank the options below based on the frequency of your interactions with the following groups. ( 1 being the highest and 4 being the lowest)

- With teachers/counselor/school administrators at school

- With friends and community members in a social event, including wedding, party, or community gathering

- With friends and community members in a language class, religious class, or religious ceremony

- With friends/classmates at school or student organizations

o Other

- What did you expect to gain from involvement in your community? Select all that apply.

- Receiving academic support from the school, such as tutoring and mentoring services

- Learning the values of my culture and traditions and using them as my strengths

- Developing my identity and self-understanding

- Receiving moral support and encouragement to achieve my goals

o Other

- What school activities did you participate in? Select all that apply.

- Extracurricular activities, including sports, music, clubs, etc.

- High tracked classes, including AP, Gifted Students, College Preparation, etc.

- Outreach programs to support low-income and first-generation students

- Private tutoring services

- Other

- What supports did you receive from school, family, and peers that positively affected your academic achievement? Select all that apply.

- Parents placed high value on education and provided encouragement and support to stay in school

- Peers shared the same values of academic achievement.

- Community provided a sense of belonging.

- Other

- What obstacles kept your community, family, and peers from meeting your needs? Select all that apply. 
- Parents lacked financial resources, English language proficiency, and knowledge on how to navigate the educational system.

- School ignored student needs.

- Community lacked financial resources and infrastructure to provide support.

- Peers did not value academic achievement and college-going

- Other

Summary

- Overall, what led to your success? Select all that apply.

- Staying in school and completing all assignments

- Seeking help when needed and utilizing all resources available, including tutoring and counseling services

- Reaching high and not accepting the status quo

- Challenging the admission requirements

o Other

- Are you also interested in interviewing as a part of this study?

- If yes, please provide your contact information

- No

\section{Appendix D}

\section{Questions for Interview Instrument}

General Background

- Where were you born?

- What's your ethnicity?

- What's your highest level of education?

- Where did you go to high school?

- Where did you go to college?

- Talk about your parents' educational background.

Family Struggles

- How did your family arrive in the U.S.?

- What struggles did your family go through?

- How did they overcome these struggles?

- How did these struggles impact your academic success? 
Goals and Expectations

- What were your goals growing up, and how did you achieve them?

- How did these goals impact your academic success?

- What were some beliefs or expectations about you among school, family, and peers?

- How did these beliefs or expectations (by others and yourself) influence your academic success?

- What limitations (if any) were placed on you by school, family, and peers?

- How did you overcome these limitations, and how did this impact your academic success?

Social Interactions

- What were your social interactions like at school, with family, and with community peers?

- What school activities (if any) did you participate in, and how did they impact your academic success?

- What community involvement did you have (if any), and how did it impact your academic achievement?

- Were there any tensions between the demands of school, family, and peers and your academic achievement?

- How did you handle these tensions?

Overall

- To summarize, what were the keys to your academic success in college?

- How would you recommend the next generation if they wanted to be where you are today? 